\title{
THE SHADOW OF NON-DECISION: THE OFFICE OF THE PROSECUTOR OF THE INTERNATIONAL CRIMINAL COURT AND COLOMBIA
}

\section{DissertaçÃo de MESTRAdo}

Thesis presented to the Programa de Pósgraduacão em Relacões Internacionais, of the Instituto de Relacões Internacionais, PUC-Rio in partial fulfillment of the requirements for the degree of Mestre em Relacões Internacionais.

Advisor: Profa. Anna Gudrun Christina Leander

Rio de Janeiro

March 2015 


\section{Pontifícia Universidade $\mathrm{C}_{\text {atólica }}$

Ana Paula Pellegrino

The Shadow of Non-Decision: The Office of the Prosecutor of the International Criminal Court and Colombia

Thesis presented to the Programa de Pósgraduacão em Relacões Internacionais, of the Instituto de Relacões Internacionais, PUC-Rio in partial fulfillment of the requirements for the degree of Mestre em Relacões Internacionais

Profa. Anna Gudrun Christina Leander Advisor Instituto de Relacões Internacionais - PUC-Rio

Profa. Monica Herz Instituto de Relacões Internacionais - PUC-Rio

Prof. Florian Fabian Hoffmann University of Erfurt - UNI-EF

Profa. Monica Herz

Coordinator of the Centro de Ciencias Sociais - PUC-Rio

Rio de Janeiro, March 20 th 2015. 
All rights reserved

\section{Ana Paula Pellegrino}

The author graduated in International Relations from PUC-Rio in 2012.

Bibliographic Data

Pellegrino, Ana Paula

The shadow of non-decision: the Office of the prosecutor of the international criminal court and Colombia / Ana Paula

Pellegrino ; advisor: Anna Gudrun Christina Leander. - 2015.

107 f. : il. ; $30 \mathrm{~cm}$

Dissertação (mestrado)-Pontifícia Universidade Católica do Rio de Janeiro, Instituto de Relações Internacionais, 2015.

Inclui bibliografia

1. Relações internacionais - Teses. 2. Direito internacional. 3. Direito penal internacional. 4. Tribunal penal internacional. 5. Complementaridade positiva. 6. Colômbia. I. Leander, Anna Gudrun Christina. II. Pontifícia Universidade Católica do Rio de

CDD: 327 


\section{Acknowledgements}

This thesis, just like the research it is based on, would not have been possible without the help of many people. Academic work, while ultimately a very individual and lonely enterprise, is still very much the product of the collective effort that surrounds each student. No academic is an island, so I must thank the ones that brought me here.

First, I'd like to thank the professors at the International Relations Institute and beyond. You dared to offer research opportunities to a curious airhead still in her teens and subsequently had the patience to guide her through the ups and downs of maturing intellectually. This process is far from complete, but I can already recognize the growing pains I experienced were soothed in large part due to your careful guidance. I would like to particularly thank Roberto Yamato, Monica Herz, Carolina Moulin, Paulo Esteves, Paulo Jorge, Marcio Scalercio and Kai Kenkel. João Franklin Nogueira deserves special thanks, as does Nicholas Onuf, for their time and mentorship. I may have had to wait a long time at the front desk, but I never found a closed door during my six years in the Institute.

Some say that hardship brings us together. That is certainly true of the graduate experience. I had the privilege of having wonderful colleagues by my side during these past years. I thank all of them for the discussions and summaries we shared, sometimes late into the night. Watching some of you defend your own thesis 
before mine made me believe it was possible to do it myself. Catherina Godeghesi, Luisa Cardoso, Ana Clara Telles and Gabriela Roméro were particularly diligent in their friendship. Tulio Avena, Celio Somma, Thiago Abrahão, Bruna Fonseca, Julia Frazão, Vitor Miranda, Ariane Francisco, Patricia Nogueira and Guilherme France have been dealing with my academic unrest for far longer than the past two years. It is a miracle that you stuck around, thanks for doing so.

Beyond the campus, I'd like to thank others that kept me going. It is no coincidence that these are all women and feminists. Thais Bakker, Sofia Soter, Lorena Piñero, Clara Browne, Taís Bravo, Dé Albu, Mariana Paraizo, Laura Pires, Bia Quadros, Dani Feno and all Capitolinas; Adriana Azevedo, Bianca Lavezo and Mayara Pavanelli; Valéria Baptista. There are just too many of you to thank.

I would also like to thank those that have gotten in the way of completing this project as first planned. Ilona Szabó, Robert Muggah, Cristiane Oliveira, Renata Giannini, Michele dos Ramos, Barbara Silva (and Lara!), Solange Felizardo, Alice Watson, Joelma Ferreira, Nathan Thompson and the rest of the gang you've been made these past six months at Igarapé some of the best in my life. Thank you for the long talks, shared meals, opportunities and overall life lessons. Aldo Zaiden has been around less, but you have both helped and disturbed as much as the former ones. While this thesis would have probably been better off without you, I am certainly better off with you all near by.

Anna Leander, my supervisor, deserves a whole paragraph to herself; mostly due to the hard time I've given her these past months. I've been late in most of my deadlines, but she was always gracious enough to not make a big deal out of it. Better yet, she always came back with wonderful comments, helpful guidance and even more relevant things to read and incorporate in my text. Thank you for taking me on board so late into the process. You have done a marvelous job trying to keep me on track and the mistakes and faults that persist in this work are solely my own, for we both know that you did more than was expected to sort 
things out - all while listening to the best music Brazil has to offer. I hope our conversations - on International Law and other themes - do not stop here.

I also thank CAPES for the scholarship that has funded my time as a graduate student and the people at Revista Eletronica de Direito Internacional of the Centro de Direito Internacional for letting me use an updated version of the paper they published in 2014. A special thanks needs to be extended to all staff at IRI for having treated me so well these past six years. Vera, Lia, Geísa, Claudia, Aurélie, Peterson - you are all miracle workers. I also thank the staff of the International Criminal Court, who were so open to me during my stay there and my fellow interns, who showed me that Den Haag was not as sleepy a town as it seems to be.

Finally, I owe an enormous thanks to my family. Mom, Dad and Caco - this is as much a product of your effort as it is of mine. The love and care you have invested in me is what keeps me going. I am sorry that still I have not managed to explain very well exactly the nature of the work someone who has a bachelor's degree in international relations - and then is crazy enough to become a masters candidate - does. It is something hard to pinpoint and I know you have had a hard time explaining this to the extended family and friends. I hope I can make you proud regardless. 


\section{Abstract}

Pellegrino, Ana Paula; Leander, Anna Gudrun Christina (Advisor). The Shadow of Non-Decision: The Office of the Prosecutor of the International Criminal Court and Colombia. Rio de Janeiro, 2015. 107p. MSc. Dissertation - Instituto de Relações Internacionais, Pontifícia Unviersidade Católica do Rio de Janeiro.

This thesis explores the shadow cast by the International Criminal Court over Colombia through the means of a persisting non-decision. It uses the work of Koskenniemi to characterize the Office of the Prosecutor's positive approach to complementarity as an attempt to employ a culture of formalism. It then analyzes how actors involved represent the Court's engagement with key figures the country during the long time it has been under preliminary examination. Taking critical theory and hauntology studies as a starting point, the author then proceeds to ask: How is the impact of the impact/shadow of the Prosecutor's nondecision (pursuant to the opening of an investigation) portrayed/felt in Colombia? How does it come to be? She argues, departing from an aesthetic analysis of documents, political cartoons and the movie Manos Sucias, for a different approach on the politics of international law. Finally, she offers a critique of International Relations as a practice.

\section{Keywords}

International Law; International Criminal Law; International Criminal Court; Positive Complementarity; Colombia. 


\section{Resumo}

Pellegrino, Ana Paula; Leander, Anna Gudrun Christina (Orientadora). À sombra da não-decisão: o gabinete da procuradoria do Tribunal Penal Internacional e a Colômbia. Rio de Janeiro, 2015. 107p. Dissertação de Mestrado - Instituto de Relações Internacionais, Pontifícia Universidade Católica do Rio de Janeiro.

A presente dissertação explora a sombra que o Tribunal Penal Internacional faz sobre a Colômbia, por meio de sua persistente não-decisão. Usa do trabalho de Koskenniemi para analisar a abordagem positiva do Gabinete da Procuradoria à complementariedade, identificando-a como uma manifestação da cultura do formalismo. Em seguida, analisa como atores representam o envolvimento do Tribunal com principais figuras nacionais no caso colombiano, durante o longo período de tempo desde a abertura de um exame preliminar. Partindo da teoria crítica e de estudos de assombração, a autora então pergunta: Como o/a impacto/sombra da não-decisão da Procuradoria (sobre a abertura de uma investigação) é representada/sentida na Colômbia? Argumenta, a partir de uma análise estética de documentos, charges políticas e do filme Manos Súcias, por uma abordagem alternativa na política do direito internacional. Por fim, oferece uma crítica das Relações Internacionais enquanto prática.

\section{Palavras-chave}

Direito Internacional; Direito Penal Internacional; Tribunal Penal Internacional; Complementariedade; Colômbia. 


\section{Sumário}

1. The Shadow of Non-Decision..........................................

2. Guidelines for investigating the non-decision .................................20

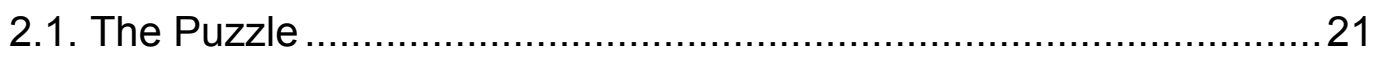

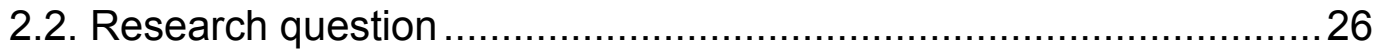

2.3. Relevance and Overall Objectives ..............................................28

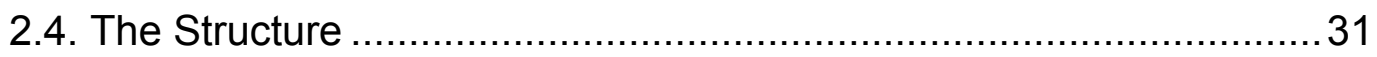

3. When (International) Law is not enough: understanding the long

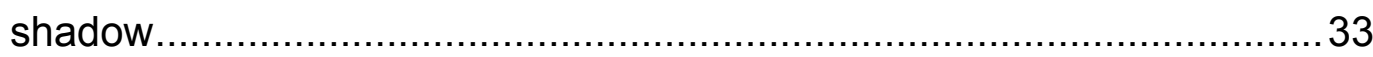

3.1. The International Criminal Court and Complementary Jurisdiction...33

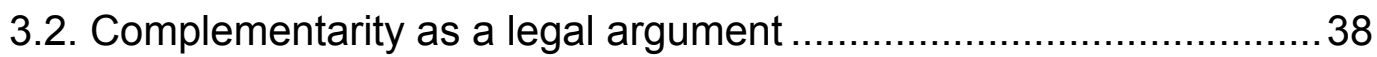

3.3. The Culture of Formalism and its Limits .......................................42

3.4. Can the Subaltern Speak International Law? .................................47

3.5. The case for Trans-disciplinarity as a method ................................49

3.6. Beyond the I(aw)ng shadow........................................................ 52

4. The International Criminal Court and Colombia..................................54

4.1. The International Criminal Court .....................................................54

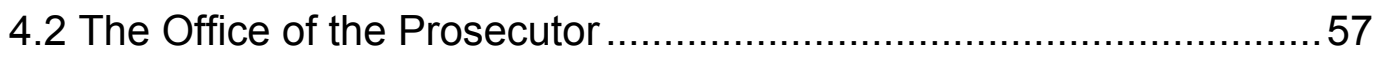

4.3 Preliminary Examination Process …............................................. 58

4.4 Situations under Preliminary Examination ......................................62

4.5 The relevance of Preliminary Examination .......................................65

5. Colombia and the International Criminal Court...................................70

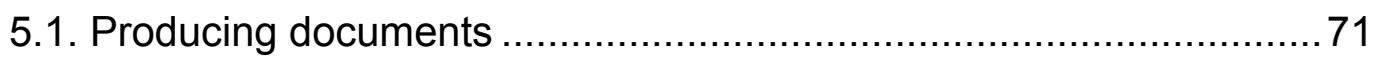

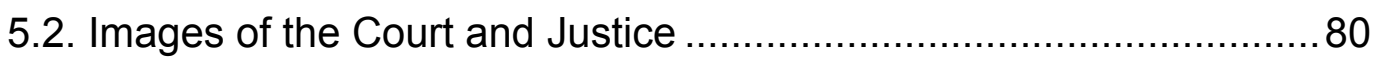

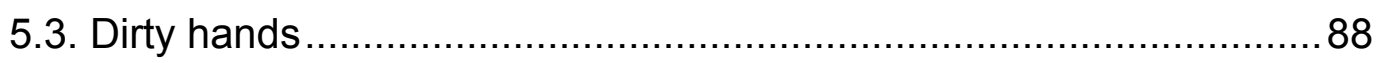

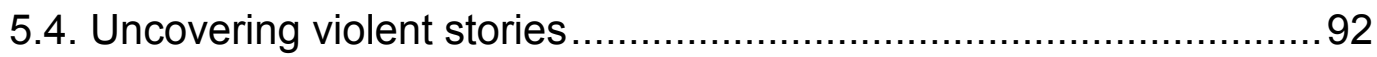

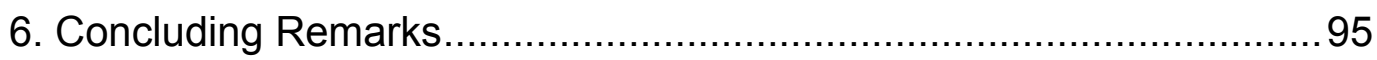

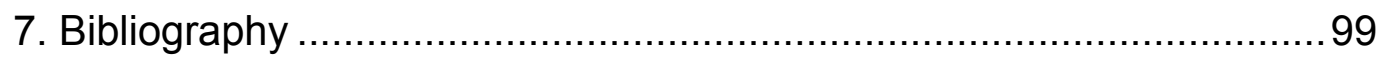




\section{Abbreviations}

ASP - Assembly of State Parties to the Rome Statute

AUC - Autodefensas Unidas de Colómbia

ELN - Ejército Nacional de Liberatión

FARC - Fuerzas Armadas Revolucionária de Colombia

JCCD - Jurisdiction, Complementarity and Cooperation Division

JPL - Justice and Peace Law

ICC - International Criminal Court

ICL - International Criminal Law

ICTY - International Criminal Tribunal for ex-Yugoslavia

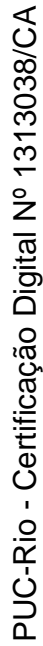

ICTR - International Criminal Tribunal for Rwanda

IEU - Information and Evidence Unit

IHL - International Humanitarian Law

IL - International Law

ILC - International Law Commission

IR - International Relations

LFP - Legal Framework for Peace

MJR - Military Justice Reform

NGO - Non-Governmental Organization

OTP - Office of the Prosecutor

PEP - Preliminary Examination Procedure

PTC - Pre-Trial Chamber

UN - United Nations

UNGA - United Nations Security Council

UNSC - United Nations General Assembly

US - United States of America 


\section{The Shadow of Non-Decision}

197. The Colombian conflict has generated high levels of violence and crimes against millions of victims. The information analyzed with regard to complementarity also indicates that the Colombian authorities have carried out and are still conducting a large number of proceedings relevant to the preliminary examination against different actors in the conflict for conduct that constitutes crimes within the jurisdiction of the Court. These efforts should be commended. Nonetheless, at this stage, the Prosecutor has determined that preliminary examination should continue in relation to the complementarity requirement (OTP, 2012a, p. 62).

152. During the coming year, the Office will continue to analyze the progress of these national proceedings - as well as those relating to the other areas of focus identified in the Interim Report - and will continue to analyze their relevance and genuineness in order to reach determinations on admissibility. The Office will also continue to analyze the implementation of the LFP [Legal Framework for Peace] and the MJR [Military Justice Reform] in order to assess their impact on the conduct of national proceedings relating to crimes under ICC jurisdiction. The Office will continue to consult closely with the Colombian authorities with a view to ensuring that genuine national proceedings are carried out against those most responsible for the most serious crimes (OTP, 2013, p. $37)$.

A specter is haunting Colombia. Or maybe it is a shadow. Those on the ground at least prefer to call it a shadow (see HRC, ISC and ISA, 2011). I find the words to be very close. In my native Portuguese, the word "haunt" has the same root as "shadow."

Inside shadows little can be discerned, linings become blurred and all that is left are impressions of apparitions - emergences (Gordon, 2008) or haunts. And just like something that escapes the gaze of definition, shadows manage to be at the same time a place where one is sheltered from the blistering sunrays of the tropics, where the breeze can actually make its presence felt and trigger the cooling mechanisms of the body. They are a place of refuge - the fugitive runs

\footnotetext{
${ }^{1}$ In Portuguese, 'shadow' is 'sombra' and 'to haunt' is 'assombrar,' which is similar to saying 'to shadow something.'
} 
away in the shadows, fleeing from captivity. ${ }^{2}$ For her, shadows mean safety, the way to freedom.

The shadow, like the specter that inhabits its depth, refuses to be completely defined. It is an absence that is present - a lack of light that renders transparency difficult. It is the very possibility of the impossible, for the lack of definition makes it possible for our imagination to soar about its contents. The shadow is creative and productive, as much as it is also scary and haunting. It is also timeless, like specters, for it holds a present promise of a future apparition one that points back to the fear of a recurrent past (Gordon, 2008).

In this thesis, I wish to explore a specific shadow: the one cast by the International Criminal Court (ICC) over Colombia.

Its presence is felt all over but more as an absence. Or, better yet, as the imminence of its presence, as if all around people were waiting for its apparition - some invoking it, others avoiding it; some waiting for its promised shelter and other dreading its darkness.

Studying ghosts and shadows - the presence of that which is ephemeral has been done before (see Cho, 2008; and Dudley, 2004 for empirical studies and Derrida, 2006; and Gordon, 2008 for theoretical expansions on the theme). "The mainstream of social science" writes Cho, "would dismiss the notion that something that is seemingly absent or nonexistent can be a powerful force in shaping empirical reality, let alone that this unseen presence can itself be the object of study," (2008, p.31) but thinking about them "is an imperative to come to terms with an unacknowledged history of violence" (p. 30). It is only fitting then to explore the shadow cast by an international regime that wishes to regulate the use of violence.

The shadow cast by the ICC, that has become a specter in Colombian political landscape, is the product of a lack of decision-making surrounding the

\footnotetext{
${ }^{2}$ The allusion to fleeing from captivity is not without purpose. The Colombian conflict is famous for involving the kidnapping of high-level political figures, who are held in the jungle by the Frente Armada Revolucionária Colombiana (FARC). The case of Ingrid Bettancourt, a former Colombian presidential candidate, is emblematic and her flight - as well as an account of her years in captivity - was later transformed into a book, Even Silence has an End.
} 
opening of an investigation ${ }^{3}$ into the situation ${ }^{4}$ at hand, which is of extreme violence. Colombia has lived a brutal war for the better part of the last century.

After lots of unrest surrounding its independence process, which took up most of the 19th century up until the separation of Panama in 1903, Colombia lived through a period of more open, albeit traditional, violence in its war with Peru in 1928. But internal violence also soared throughout the country, a direct product of the loose hold Bogotá - the country's capital - held over other regions and the vast abyss that lay between the elite and the rest of the population. Civil unrest in the countryside was quite common during this time.

Amidst more political outbreaks of violence, the period known simply as "La Violéncia" stands out. During the 1950's and 60's, Liberals and Conservatives battled for control - a bloody internal strife that ended only with the formation of the Frente Nacional. This was a political system designed to accommodate both sides involved in the dispute - but it lacked the mechanisms necessary to include those who did not fit in this divide, who automatically saw themselves left out and without access to political space in which to advance their interests and plights (LaRosa \& Meíja, 2012, p. 207). They decide to continue politics by other means, resorting to violence. Thus, the solution to one conflict La Violéncia - gave birth not to bipartite politics, but to a complex landscape of political and warring parties, such as the Exército de Libertatión Nacional (ELN) and the Fuerzas Armadas Revolucionárias de Colombia (FARC), initiating another cycle of violence ${ }^{5}$.

On top of this, one mush keep in mind that the Colombian civil war has never truly been only a national affair. In the past, it was entwined with the dynamics of the Cold War, due to the leftist leanings of the guerilleros. Yet, it did not end with the fall of the Soviet Empire, but rather transformed itself. It became the battlefront of the international War on Drugs, which morphed into a

\footnotetext{
${ }^{3}$ See glossary for a more detailed definition.

${ }^{4}$ See glossary for a more detailed definition.

${ }^{5}$ The history of violence in Colombia is much more complex than what is shown here. For broader overview, please see Chapter 5 of Larosa's and Meíja's "Colombia: a concise contemporary history" (2012). More detail into the intricacies of sides surrounding political desires of the FARC are available in Steven Dudley's book "Walking Ghosts" (2004), where he explores the rise and violent fall of the Unión Patriótica (UP), the political arm of the revolutionary FARC whose leaders were all crudely eliminated.
} 
battle of the War on Terror, which explains the tight-knit nature of United States (US)-Colombian relations.

There is, in fact, a "multiplicity of motives behind the violence" (Dudley, 2004, p. xii). The State, instead of monopolizing the legitimate use of violence, had had to put it to practice combating other violent non-state actors, be they the revolutionary army or the paramilitaries - who served as proxies for regional and national administrations. In the $21^{\text {st }}$ century, the State itself became a perpetrator of violence, aimed against its own population, disguised post-mortem as the enemy, in the case of the falsos positivos, ${ }^{6}$ to which we will return to later on in this thesis.

As Dudley writes of the country in his book's preface, "the story is painful to tell. I wish Colombia were more black and white. I wish there were clear-cut good guys and clear-cut bad guys. [...] Colombia is much more than that, which is why it's difficult to ignore. It's raw: humans at their best and worst" (2004, p. xii). Colombia is a testament to Gordon's theoretical claim that life is complicated (2008, p. 3).

In the meantime, the world around Colombia unraveled, oblivious to the explanatory powers of international relations models, all caught by surprise by the end of the $20^{\text {th }}$ century's turn of events. The United Nations' (UN) Decade of International Law (IL) started in the final months of the Cold War, its opening declared still in 1989 by the United Nations General Assembly (UNGA) just days after the fall of the Berlin Wall. The 1990's were taken by a chain of initiatives aimed at strengthening international rule of law, among other goals (UNGA, 1989).

Law came to be seen as an important part of international life, more so than it had during the preceding decades. The number of conferences - that frequently produced declarations and treaties, the latter of binding nature - that took place during these years was unprecedented. Legal solutions were also sought out by the international community, in the shape of the UN System, more specifically of the Security Council of the United Nations (UNSC), to address

\footnotetext{
${ }^{6}$ See gossary for a more detailed definition.
} 
problems of peace and stability internationally - in other words, to create a regime $^{7}$ to manage violence internationally.

Solutions devised by the UNSC were legal in two important ways. First of all, since it is a body governed by the UN Charter, whenever a member State or the Secretary General of the UN brought an issue to the attention of the UNSC, the proceedings and ensuing results were expressed in legal manner, set within preceding procedures and other rites of international life. UNSC resolutions are binding on all States, be they party or not to the UN Charter. Furthermore, during this decade, the UNSC also devised legal mechanisms to deal with problems of international peace and security. The war in ex-Yugoslavia and the genocide and ensuing conflict in Rwanda led to the establishment of international tribunals, declared by the UNSC specifically for their cases (see UNSC Resolution 827 and 955, respectively). This solution was also adopted later on, in the case of Sierra Leone (see resolution 1315) and others.

Table 1 - Post-Cold War International or Joint International-National Tribunals

Post-Cold War International or Joint International-National Tribunals

\begin{tabular}{|l|l|}
\hline ICTY & 1993 \\
\hline ICTR & 1994 \\
\hline Special Panels in East Timor & 2000 \\
\hline Kosovo International Judges and Prosecutors & 2000 \\
\hline Extraordinary Chambers in Cambodia & 2001 (Agreement with UN 2003) \\
\hline ICC & 2002 \\
\hline Special Court for Sierra Leone & 2002 \\
\hline Iraqi Special Tribunal & 2003 \\
\hline Special Chambers of Belgrade District Court & 2003 \\
\hline State Court of Bosnia Herzegovina & 2005 \\
\hline Special Tribunal for Lebanon & 2007 \\
\hline
\end{tabular}

${ }^{7}$ The word regime is used here rather liberally, though Krasner's classic definition fits well: "principles, norms, rules and decision-making procedures around which actors' expectations converge in a given area of international relations" (1982, p. 185). For more on the ICC and the construction of a regime of international regulation of violence, see Pellegrino (2014). 
In addition, there have been various domestic movements towards addressing (if not prosecuting) international crimes in countries such as Ethiopia, Chile, Spain, France, Britain, Liberia, Ghana and elsewhere.

Source: Goldstone, Richard J. Smith, Adam M. International judicial institutions: the architecture of international justice at home and abroad. London: Routeledge, 2009. p. 96.

It was in the midst of this movement that the Rome Conference took place, in the capital of Italy, in 1998, at the end of the decade. During the 32 days it lasted, from June 15 to July 17, countries came together to discuss the draft of the Rome Statute that would ultimately install the first permanent international criminal court. Prepared by the International Law Commission (ILC), a UN body, the draft document was the culmination of more than a century of intellectual and political debate on the virtues of establishing an international court of such nature.

A first attempt at establishing a court of such standing was made after World War 1, in order to address crimes committed during the conflict. But the Leipzig Tribunal never actually got to try the German Kaiser, who sought refuge in The Netherlands. The Dutch sovereign refused to turn him in, alleging sovereign immunity. The very same country now houses the ICC and many other international law bodies. Den Haag, its administrative capital, presents itself as the International City of Peace and Justice. ${ }^{8}$ It would take the end of another great war, albeit a cold one fought through proxies, for States to come to an agreement over the design of an international tribunal of permanent character - one that would not be contested by members of the international community as an instance where victor's justice had free reign nor would be hindered by arguments on sovereign immunity.

The Rome Statute came into force in 2002, when it was finally ratified by the minimum 60 States, a number stipulated at the Conference four years earlier. It established the ICC, whose jurisdiction is set to start on the date of the $60^{\text {th }}$ ratification. The Assembly of States Party the Rome Statute of the ICC (ASP) then came together in New York in September of that year, in a meeting where

${ }^{8}$ On the city's website, run by the municipality, one will find a box called "Peace and Justice" - not a common feature in these sites. The dedicated page's header reads "The Hague, International City of Peace and Justice". 
they adopted the Elements of Crimes, another document that further specified the material elements of the crimes under ICC jurisdiction.

Other legal documents continued to be drafted and adopted, either by the ASP or by the bodies of the ICC themselves, in an ongoing process that characterized the court's establishment as a functioning institution. These include Regulations of the Court, adopted in 2004 and that entered into force in 2007; Regulations of the Registry, which entered into force in 2006; Regulations of the Office of the Prosecutor (OTP), that entered into force in 2009 and others ${ }^{9}$. This shows that the Court is still in the process of being established, even well after it came into existence in 2002, through the continuing development, revision and amendment of the these documents that cover core proceedings and that flesh out daily life both in Den Haag quarters and field missions in countries with ongoing investigations. This is a testament to the court's mission as a transparent institution that abides to the rule of law and observes strict legal proceedings in order to guarantee its international legitimacy.

Despite their number and length, and this "will to transparency," a careful overview of these papers reveals that the everyday procedures of the Court itself are not exposed verbatim in these documents nor are they made public at all. Rather, they are accessible only to those on the inside of the ICC, who experience the routine of the deliverance of international criminal justice, or at least an attempt at its production. This explains why a large part of the research presented in this thesis was possible only due to the opportunity I had of taking up an internship position at the OTP.

The ICC had just completed a full decade of formal existence when I was accepted as part of its internship program. I arrived in Den Haag on the last days of June, 2012. My internship started on the $1^{\text {st }}$ of July and ended on the $2^{\text {nd }}$ of

\footnotetext{
${ }^{9}$ Interns - and I imagine that other professionals too - receive upon arrival a collection of all these documents, entitled Core Legal Texts of the ICC. They have them in both working languages of the court, French and English, and in a plethora of forms, be it in binders, in bound books or wired collections. There is a shelf full of old copies of these in the ICC library, a servez-vous of sorts. Interns are frequently seen carrying their own binders around, consulting articles for the labor-intensive documents they have to produce, one of the rare physical pieces most of them deal with during work, for the rest of the documents circulate digitally.
} 
October. During these three months, I was able to explore the workings of the ICC and of the OTP firsthand, coming closer to understanding its procedures.

During my time at the Information and Evidence Unit (IEU) of the Services Division of the OTP, I came into contact with the Preliminary Examination Procedure (PEP), which is what I wish to explore in this thesis. I first envisioned going to Den Haag to document this process and base my Bachelor's thesis on the material I gathered through participatory observation, a goal I ultimately managed to complete.

Yet, the richness of the experience lent itself to inquire into more than this. While working at the OTP, I came into contact with the uncertainty that lies behind PEP and the final decision on whether or not to open an investigation, despite all the regulations and provisions laid out in the Rome Statute that try to make the process as clear-cut as possible. As I helped pick out a color for all tags to be used in office-wide material on a then-possible investigation in Colombia, I remember feeling a surge of excitement typical of the recognition of leaving one's small mark in history: I would leave a trace on the first situation of the ICC outside Africa, in my own continent, South America.

That would have been something big, but it never happened. Life at the Court, not only in general, is complicated. I was there when the Prosecutor received a referral from Mali, which ended up becoming a situation, but felt nothing special as I saw the information being fed into the electronic filing system used throughout the whole court. The procedure had by then become mundane - an everyday exercise. The cover of the official document ended up becoming a fan that kept flies - which were prone to show up in our aircondition-free building in the height of the Dutch summer - at bay.

The story about Colombia stuck. I received a couple of Article 15 communications ${ }^{10}$ on it during my stay there and missed, by a couple of months, the presentation of a big report on the case of the falsos positivos, organized by civil society and presented to the Prosecutor (see FIDH, 2012). Other events around Colombia were also held at the ICC. Indeed, one of the most prominent and productive academics in the field of International Criminal Law, Kai Ambos,

${ }^{10}$ See glossary for a more detailed definition. 
has taken to studying ICC involvement in the situation and has extensively reflected on the case for the opening of an investigation (see Ambos, 2010).

The first Prosecutor of the ICC, the Argentinean Moreno Ocampo, opened a preliminary examination ${ }^{11}$ in Colombia in June of 2004 (OTP, 2012, p. 2) and informed the government of the country of this in March 2005 (OTP, 2013b, p. 29). The first reports on where the preliminary examination was going were only released much later, in 2012 (OTP, 2012a) and 2013 (OTP). More than ten years have passed since then and the OTP has not yet come to a conclusion on whether or not to open an investigation, which surprised me at the time, for all the seriousness of procedures, the minimal requirements clearly stated in every document produced by the ASP and ICC to govern its doings.

The OTP has taken to calling this non-opening-of-an-investigation a positive approach to complementary jurisdiction, ${ }^{12}$ which will be explained in further detail in the coming chapters. According to this interpretation, the Office's involvement does not necessarily cease when they find willingness and capacity to operate domestic proceedings, but can be extended through other types of strategies employed during the PEP that do not necessarily lead to the opening of an investigation.

This translates in the end into a lack of decision, a non-decision, regarding the opening of an investigation - a temporary decision not to open an investigation conditioned by continuous monitoring from afar and from close up, maintaining a present distance. The opening an investigation is always a possibility in this state of affairs. At this point, both strings of images of this first chapter come together. The proceedings of the ICC and the violence in Colombia meet. That they happen to do so in the shadow is no coincidence. It is in this suspended realm of the possible - where the past of the crimes to be investigated and the ongoing present of occurring violence and judicial procedures are meshed together with the promise of future justice, an end to impunity - that this research lays.

\footnotetext{
${ }^{11}$ See glossary for a more detailed definition.

${ }^{12}$ Also called "positive complementarity." See glossary for a more detailed definition.
} 


\section{Guidelines for investigating the non-decision}

Regarding the opening of an investigation, ${ }^{13}$ a procedure that came to be known as preliminary examination, the Rome Statute that governs the ICC states that the Prosecutor shall evaluate information searching for a reasonable basis to proceed considering matters of jurisdiction, admissibility and gravity. ${ }^{14}$ If the OTP finds there is no reasonable basis to proceed and later wants to reconsider this decision under light of new information, this is also possible. Thus, as the structure of the law reads, one may reason that there are two possible outcomes of PEP: the decision to proceed to an investigation - and submit this to the evaluation of the Pre Trial Chamber (PTC) - and the decision not to proceed, which can, in any event, be reconsidered under new light.

Yet, as we have seen with Colombia in the previous chapter, this is not always the case. Despite the ease with which it can re-open any preliminary

${ }^{13}$ An investigation generates two outcomes in the ICC: the situation and the case. See glossary for a more detailed definition of all three.

${ }^{14}$ Article 53 - Initiation of an investigation

1.The Prosecutor shall, having evaluated the information made available to him or her, initiate an investigation unless he or she determines that there is no reasonable basis to proceed under this Statute. In deciding whether to initiate an investigation, the Prosecutor shall consider whether:

(a) The information available to the Prosecutor provides a reasonable basis to believe that a crime within the jurisdiction of the Court has been or is being committed;

(b) The case is or would be admissible under article 17; and

(c) Taking into account the gravity of the crime and the interests of victims, there are nonetheless substantial reasons to believe that an investigation would not serve the interests of justice.

(...)

2. If, upon investigation, the Prosecutor concludes that there is not a sufficient basis for a prosecution because:

(a) There is not a sufficient legal or factual basis to seek a warrant or summons under article 58;

(b) The case is inadmissible under article 17; or

(c) A prosecution is not in the interests of justice, taking into account all the circumstances, including the gravity of the crime, the interests of victims and the age or infirmity of the alleged perpetrator, and his or her role in the alleged crime;

(...)

4. The Prosecutor may, at any time, reconsider a decision whether to initiate an investigation or prosecution based on new facts or information (Rome Statute, 1998). 
examination that has already closed if new information emerges the OTP has kept Colombia under PEP for more than 10 years. Realizing this led me to ask what the effects of this lack of decision regarding the opening of an investigation were. After I explored the documents produced by other actors in the Colombian case, I came to share their habit of calling these effects the shadow of the Court - a phenomenon that extends beyond legal proceedings per se and actually impacts more than the ICC itself is comfortable with admitting. This shadow - a present absence - is what this thesis will try to outline, through the analysis of its traces in the Colombian case.

\subsection{The Puzzle}

The fact that the OTP refuses to reach a decision pursuant to the opening of an investigation can be read as a decision not to decide whether to investigate or not a certain preliminary examination at hand. I will call this a non-decision. This non-decision has been incorporated as a part of PEP. It was officially identified, after it had already been continuously practiced for some time, as constituting a "positive approach" to complementarity ${ }^{15}$ (OTP, 2013a), the main trait of the ICC's jurisdiction vis à vis national jurisdictions. This thesis focuses on this non-decision adopted by the ICC, which, as it will show, has a series of effects produced by the continuous monitoring linked to the preliminary examination and the active engagement of the OTP with national and international actors relevant to the domestic proceedings at hand. ICC personnel do not always intend for these effects to happen, nor do they occur only in legal settings, such as the courtroom or through the hands of lawyers. They, in this sense, betray a limit in a purely legal analysis.

The OTP argues that non-decisions are legally grounded (OTP, 2012a). It states in its documents - as cited in the preceding paragraphs - that the preliminary examination of Colombia is currently the under the complementarity analysis phase of PEP, under Article 17 of the Rome Statute. Yet, there appears to be a slippage in this stance. The Interim Report states that national proceedings

${ }^{15}$ See glossary for a more detailed definition. 
are under way, thus fulfilling the complementarity criterion of admissibility. This consequently makes the situation inadmissible at the ICC. But it also says that the very issue of complementarity has to remain under preliminary examination. This seems to be a contradiction, one that becomes even clearer when you take into account the voices that dispute the willingness and due process of these national proceedings (Ambos \& Huber, 2010). In fact, by using the exact same legal argumentation and elements of crimes employed by the OTP, appealing to Article 53 of the Rome Statute, others have argued in favor of opening an investigation on the situation in Colombia (FIDH, 2012).

That the same legal structure can lead to two opposite decisions betrays the fact that what grounds the OTP's non-decision is not necessarily legal considerations per se - as alleged by the Office when it alludes to complementarity issues ${ }^{16}$ - but is also fruit of external calculations. These calculations, one can argue, are political. In fact, all legal argumentation is at once fruit of a decision that is legal in its structure but inherently political in its conclusion (Koskenniemi, 2005). The fact that the international lawyer can always argue inside the legal structure both in favor of or against a certain position, using either the reality of distribution of power or the normativity of principles as a base for their argument, betrays that he/she needs to look outside and beyond international law, and into the realm of the social, of history and of political philosophy, to actually make "legal" decisions.

The OTP's non-decision keeps the ICC at bay in Colombia, preventing the opening of formal international proceedings that surround investigations and the prosecution of Colombian nationals at the Court. It also keeps away all the obligations under the Rome Statute of international cooperation and judicial assistance that the country would then owe the ICC and, more specifically, the OTP during both investigation and prosecution of cases as a State Party. ${ }^{17}$ This

\footnotetext{
${ }^{16}$ In an interview about the preliminary examination in Colombia, an OTP employee stated that the Office looks only into legal matters, for they are all lawyers. Neither, I argue are true. There are many non-lawyers at the OTP and, furthermore, the legal practice does not offer final answers.

${ }^{17}$ These obligations come spelled out in Part 9 of the Rome Statute, from Articles 86 to 102. Failure to abide to the Court's requests can either lead to a referral of the matter to the Assembly of States Parties or, in the case of a Security Council
} 
would, in theory, leave the OTP and the ICC at large, without much say in the Colombian case. Since no reasonable basis to proceed has been confirmed by a designated PTC, the Office has not crossed the necessary threshold for opening an investigation. No other obligation to cooperate with the OTP can be found in the Rome Statute. Yet, civil society actors on the ground have identified what they call a "shadow" of the Court in Colombia and the government and other Colombian authorities receive OTP personnel in their offices out of more than sheer cordiality.

The prospect of prosecutions before the ICC has played directly into the dynamics of the armed confrontation, including the recent demobilizations of right-wing paramilitary groups (Isa, 2008, p. 7) as well as into the Colombian political landscape. Various high-level initiatives are being undertaken by the government to avoid having the OTP bring Colombian military officials and their civilian counterparts before the ICC. Left-wing guerrilla groups appear to be equally engaged in damage-limitation measures. In tandem, heightened sensitivity around issues of justice and peace has developed across Colombian society, as different sectors re-evaluate their positions or build new forms of alliances, both in elite political circles and among the diverse victims of the armed conflict (HRC, ICS, ISA, 2011, p. 10).

As one can see, the fact that the OTP has kept the preliminary examination open in the country for more than ten years is perceived to be impacting matters on the ground, despite the lack of any official decision on the involvement of the ICC in the country. If neither the Colombian State, nor its sub-national groups, its nationals or other international actors that may be involved are under international legal obligation towards the OTP, how can this impact be understood?

During the past years the OTP has taken a series of measures regarding the preliminary examination in Colombia under the mark of positive complementarity. The Office has, among other activities, maintained regular consultations with the Government and conducted two visits to Bogotá. It has also continued to receive and analyze additional information submitted through

referal, to the organ itself (Article $87(7)$ ). This takes matters clearly beyond the legal realm, into that of international politics. 
Article 15 communications and held meetings with relevant national and international actors. During visits, it has taken part in conferences and public events organized by the Ministry of Justice and universities. It has sent letters regarding the implementation of a framework for national legal procedures, the Legal Framework for Peace (LFP), to Colombian authorities. The Office even highlighted its Prosecutorial Policies, acclaimed by others as a model for national jurisdictions, in a letter to the Constitutional Court of Colombia. Colombian President Juan Manuel Santos and Fatou Bensouda, the current Prosecutor, have also met in New York in September 2013 to discuss common worries and agendas (OTP, 2012a). These interactions and exchange of visits and documents relate mostly to domestic judicial proceedings and are in sync with what the OTP has published as its guidelines on positive complementarity (OTP, 2012a; 2013).

Yet, civil society actors see more than what can be accounted for simply by looking at positive complementarity when stating the existence of a shadow of the ICC. The impact "goes far beyond merely influencing domestic criminal law" (HRC, ISC, ISA, 2011, p. 10), which is what the provision of positive complementarity aims at. There is, of course, debate over what exactly this shadow has been accomplishing and an even wider one on whether the OTP should actually open an investigation. Crosscutting support for the opening of an investigation has been communicated to the Office, directly through conferences organized by the ICC or through article 15 communications (Ambos \& Huber, 2010; FIDH, 2012). But the Office has held its ground and decided to continue non-deciding, thus keeping with PEP in Colombia.

Just keeping Colombia under this non-decision status would be enough to cause the impression of a "shadow", as alluded to earlier. Yet the positive character of the approach the OTP gives to complementarity exacerbates these effects even further. Thus, one can delineate three stages of impact that come before the actual opening on an investigation into the situation in a given country: these are the impact of (1) opening of a preliminary examination; (2) deciding to apply positive complementarity; and (3) the impact of the ICC's shadow, which does not follow automatically neither from provisions in the Rome Statute nor from the positive character of complementarity under the OTP's interpretation, 
but is rather the result of interactions that happen after these decisions are made. It is precisely at this third stage that this research proposal finds its puzzle.

Different actors have used the term "shadow", to highlight the impact of the ICC beyond its courtrooms, albeit with different connotations. Ban Ki-moon, United Nations Secretary-General, and the first Prosecutor, Moreno Ocampo, used it to talk about a preventive impact the Court's own functioning would have (Goldberg, 2010; Bensouda, 2012). Prevention, as stated in the Statute's Preamble, is also one of the goals that the States at the Rome Conference had in mind when drafting the Statute that governs the ICC. In this capacity, the ICC acts as a presence always ever-so-slightly felt, a promise of the end to impunity, that keeps would-be-offenders from committing crimes under its jurisdiction. It would haunt these men and women in order to keep them from committing violent international crimes. There is a positive connotation to this embodiment of the ICC as the caster of shadows, since the outcome would be the deterrence of crimes under its jurisdiction.

Others, such as the African-Swedish Non-Governmental Organization (NGO) Afrosvenskarna, mainly when referring to the fact that the ICC has only prosecuted cases in African countries, use the term 'shadow' with a more negative connotation, to refer to a dark presence that takes away leaders from their continent (Afrosvenskarna, n.d.). ${ }^{18}$ In Colombia, the term 'shadow' has been used to refer to the almost ephemeral presence of the ICC, that continuously threatens to open a formal investigation but never does so, and the impact that this has had in Colombian politics, the dynamics of conflict on the grounds, its peace process and the process of transitional justice, beyond domestic judicial proceedings (HRC, ICS, ISA, 2011; Ambos \& Huber, 2010). There is a plurality of meanings related to the image of the shadow and invoked by different actors on the ground.

When the Prosecutor invokes the ICC's preventive potential and goes about drafting policy papers, as her office has done on the theme of Preliminary Examinations, one can acknowledge that the Court's presence in international

\footnotetext{
${ }^{18}$ The "African Question" as it came to be called is also the object of large debate in the bibliography and practice surrounding the ICC. Chief Charles Achaleke Taku's and Tejan Cole's opinions regarding the theme are a good introduction to the discussion and can be found here: http://iccforum.com/africa.
} 
relations goes beyond its judicial proceedings. The reference to prevention in the Rome Statute's preamble is telling, since it lies not in the realm of legality but in politics: it is a goal beyond that of the law, which can be seen, under a utilitarian lens, as a means to its end. The preamble of the Rome Statute goes on to state other goals, such as peace, security and well-being of the world, putting an end to impunity and even reaffirms prohibitions on the use of force contained in the United Nations Charter.

The ICC's impact in Colombia surpasses the prevention of use of violence in the form of crimes characterized by the Rome State. It also cannot be explained by the provisions for international cooperation between State parties and the Court. The ongoing non-decision of the OTP - that can be regarded more as a process than as an end-point - has impacted the heart of Colombian society in ways that are still unclear in relation to its coming about and its effects, despite the ICC's official position of non-involvement in the politics of the country. The fact that OTP personnel claim that they only pay attention to legal matters in PEP only adds to this. It shows how much can actually escape the scope of analysis when one becomes two focused on legality in these instances. This lack of transparency in an enterprise that wishes itself so is the puzzle that motivates this study.

\subsection{Research question}

Actors on the ground in Colombia, including international and national actors of relevance in legal and non-legal spheres, have discerned an impact beyond the realm of domestic criminal justice, felt in Colombia as a consequence of the OTP's non-decision. The ICC, despite not being directly present, is perceived as impacting dynamics on the ground and casting a shadow that is far from transparent. This apparent contradiction was explored in the previous section. This research wishes to address this puzzle by asking the following question: 
How is the impact of the impact/shadow of the OTP's non-decision (pursuant to the opening of an investigation) portrayed/felt in Colombia? How does it come to be?

The first question relates to an attempt of mapping out the traces on the ground that came to be perceived as shadows of the ICC. The second question relates to more theoretical explorations that will try to understand this phenomenon. Despite the order in which they are presented here, in the actual structure of the thesis, I will tackle these in reverse order. The theoretical chapter, that follows, will deal with the coming to be of the shadow, while the two subsequent chapters will focus on its representations.

These questions naturally lead to other ones, related to the different effects opening an investigation and keeping ongoing preliminary examinations has; the effect of externalizing the judicial process that comes from pushing for its internationalization; the possibility of understanding complementarity as an enabler rather than only as a constraint to the Rome Statute's jurisdiction etc. Other relevant questions will appear and will be stated during the process of research. While writing this, I kept in mind that the OTP has decided to, relating to the preliminary examination in Colombia:

i) Follow-up on the Legal Framework for Peace (LFP) and other legislative developments;

ii) Proceedings related to the promotion and expansion of paramilitary groups;

iii) Proceedings related to forced displacement;

iv) Proceedings related to sexual crimes; and

v) False positive cases

(OTP, 2013, p. 29).

These five areas work only as first guidelines into places where enquiry may prove to be fruitful. Research may be taken beyond these immediate provisions, as already hinted at in the literature that was consulted during the elaboration of the first proposal that guided preliminary attempts at constructing a state of the art on the theme. Worries concerning the demobilization of paramilitary groups, damage-limiting measures taken by left-wing guerrilla 
groups and the newfound widespread sensitivity in Colombian society with regard to the violence that has shaken its foundations for so long (HRC, ICS, ISA, 2011, p. 10) are perhaps further paths to follow, but they did not fit into the scope of the present analysis.

\subsection{Relevance and Overall Objectives}

This study relates to a series of larger questions surrounding how the ICC and, through it, IL as a whole, is perceived in international politics and viceversa. International Relations (IR) literature has addressed the issue in different terms, mainly through the work of Steven C. Roach, Jason Ralph, Caroline Fehl, Thomas W. Smith, Antonio Franceschet and others. Legal authors have also addressed some relevant issues, such as the allusions to the culture of formalism contained in Koskenniemi's two seminal books on IL and his greater work. More classical scholars that fill this gap between law and politics such as Carl Schmitt and Hans Morgenthau are also of use here. Their studies have proposed different ways of thinking about International Law and, through it, the workings of the ICC.

The very existence of an international criminal court, one that tries crimes against humanity, can be thoroughly explored under the works of both Carl Schmitt and Morgenthau. The Court can be seen as the pinnacle of the expression of what both identified as the end of the European Era, where violence was not understood as crime in international politics and thus was not outlawed, but regarded as a duel among equals (Koskenniemi, 2001). This transformation of the name of violence, from duel to crime, in the international realm - but not its occurrence - is the object of worry on both authors' part. Morgenthau, which still holds in himself a certain measure of Weberian tragic optimism, would highlight the fact that power politics are the motor of the world, not worries about criminal proceedings in internal conflict (Koskenniemi, 2011). This would lead to a classical realist interpretation of the ICC's impact and proceedings, more centered on the hard realpolitik behind international relations.

Roach's work, on the other hand, calls for a new global political order where the Court can exercise what the author calls a "global juridical power", 
more in vein with liberal proposals of international relations. Despite drawing on Schmitt's decisionism and other elements that also influence Koskenniemi's arguments (2005), they bring very different proposals. The latter comes from another field, that of International Law, and thus approaches the issue from another entry point.

While Roach's focus is on the ICC's normative basis and thus the possibilities and its relationship with humanitarian intervention, Koskenniemi's "culture of formalism" has a different, critical proposal that will be further expanded in the next chapter. He identifies the possibility of using the legal argument to advance emancipation in a way that appeals not to any substance, but to form (2005) and does so in attempt to achieve universality - despite knowing that it is unattainable - through reference to something a particular community lacks (2001). The language of rights, typical of international law, would be able to transform a particular lack into something universally recognizable, as the argument goes.

As a consequence, the culture of formalism would render itself safe from falling into the hands of imperialists. It is not of a positive nature. It does not rest on the universality of a principle, which is in fact particular to only one polity but universalizes an experience based on the concrete lack of a particular polity. Understood under the lens of this culture of formalism, the ICC's shadow becomes an instrument of critique - perhaps a critique to a culture of impunity that tries to regulate the use of violence beyond simplistic characterization of its outlawlessness.

Falling back into the classical divisions of International Relations along the lines of realism and idealism becomes irrelevant, from Koskenniemi's point of view. The author's characterization of the dual structure of legal argumentation can also be applied to the field of IR when examining how it has accounted for IL - appealing either to utopia or realpolitik. In regard to the interdisciplinary approaches that surround institutionalism and ended up in legalization theory, the author is not optimistic. He does not see many possibilities for going beyond mere imperial uses of international law, what it calls a culture of dynamism, in these attempts (Koskenniemi, 2001). To use law 
critically, not rationally nor cynically, one needs to espouse the view of the culture of formalism.

Thus, using this culture of formalism as a starting point to explore the question of how this kind of impact can come to be, other aspects of the shadow can be explored more thoroughly. One of them consists in a peculiarity of the ICC, in that it is a paperless court, where proceedings are completed electronically and all information and evidence is kept and managed in databases. Following a new-materialistic line, ${ }^{19}$ questions regarding the consequences of this materiality for the production of documents and legal (and other) outcomes and directions of the flow of information will be raised. Particularly relevant to these enquiries is the work that has been developed by Annelise Riles regarding the materiality of legal documents and its consequence for IL as a whole (2008). The impact of this virtual nature of documents at the ICC remains underexplored. This is another interstice of the play between concreteness and normativity that shows itself in the case at hand.

This research is also relevant because it wants to understand a position that the OTP has been adopting for over 10 years regarding the situation in Colombia. There is always a possibility that the Office may wish to adopt the same stance in other cases. Hence, analyzing its impact beyond the judicial realm is of great importance here. Implicit in this task is the idea of comparing the impact of the Court's "shadow" in this specific situation to the opening of investigation in others. Questions surrounding the elements that push towards a decision or non-decision are also bound to appear during further into the analysis. They are important to bring up and surround issues such as political regime, presence of actors with whom the OTP feels it can exchange, as well as the relevance of external allies. This thesis is, in this sense, also an assessment of the possibility of understanding the ICC as an exponent of the culture of formalism as an instrument of critique of international status quo and of its limitations. The fact that Colombia would be the first situation open outside of the African country is also worth mentioning, as it may have been a factor at play in this non-

\footnotetext{
${ }^{19}$ For more theoretical insights into new materialisms, see Coole, D., Frost, S. (Ed) New Materialisms: ontology, agency, and politics. Durham: Duke University Press, 2010.
} 
decision. The importance of geopolitical calculations is another line of enquiry that will be explored in upcoming chapters.

These questions and directions of enquiry mean that I have pointed out here are intended to make this thesis relevant not only for the specific case of the ICC in Colombia, but to go beyond these narrow boundaries of a case study. I wish to use this research as a basis for critiquing of the stance of the ICC in the preliminary examination at hand; the wider practice of the Court as a whole; and of the wider enterprise of IL, particularly in its relationship with IR as both academic fields and practices.

\subsection{The Structure}

In order to contemplate the discussions I have outlined above, we will now follow into 3 other chapters.

In the third chapter, I will develop how the ICC fits into the culture of formalism as proposed by Koskenniemi (2005). Then, analyzing the telos of IL and consequently of the ICC - I will try and establish the limits of this culture of formalism as the only basis for the political. Here I will elicit the work of Gayatri Spivak and Michael Shapiro (2013), as well as hauntology studies (Gordon, 2008), in order to help make my point. Methodological notes are included in the last section, as a development of the challenge on how to flesh out the shadow of the ICC and its relevance for IL and IR.

In the fourth chapter, I will focus on proceedings and documents produced by the OTP and ICC. The content was mainly derived from the notes I kept during my time as an intern at the Court and the impressions I was able to gather concerning ICC proceedings. In it, I will argue that the actual IL practices of the ICC are far from being set in stone, particularly during the first years of its functioning. The importance of the different proceedings also fluctuated in ways not previewed in the Rome Statute. This, I argue, contributes to this formation of a shadow surrounding the Court's involvement in Colombia.

The next chapter will then progress into analyzing the Colombian side of the equation and analyze what kind of material is being produced outside of the ICC on the country, justice and violence. This is done in order to grasp how the 
ICC and its goal - justice - is being represented by those on the ground, fleshing out the institution that wishes itself transparent. These materials include both more official documents, such as reports and books, and cultural manifestations of the impact generated by the ICC. Political cartoons, movies and other formats will take the forefront, while documents will be analyzed aesthetically. I argue in this chapter that while civil society has attempted to mimic official court documents, they have done so with different goals in mind - not to render the law transparent, but to make it visible. This is apparent in the very aesthetics of these documents. I continue exploring the shadow of the Court through the different images used to portray it and justice - it's ultimate goal - in Colombian political cartoons, understood as traces. I then analyze the movie Manos Sucias (2014), which offers a new platform for talking about violence and loss that Colombian society has suffered without needing to use legal language. I argue here that aesthetic expression and fiction can, in these circumstances, be a better vehicle for uncovering violence and experiences than legal documents, particularly in the Colombian case, where the shadow never became a real presence of the ICC or other, national courts.

Finally, a concluding chapter will wrap up the main lessons derived from this research. When trying to grasp the contours and contents of a shadow, one finds that most tools traditionally employed by the social sciences are generally lacking - a lack that is also felt by those who work in the field of haunting (Gordon, 2008). This concluding chapter will elaborate on these difficulties and propose a need to reinvent both the practice of international relations and international law in order to really achieve a more "open" political practice in both enterprises. 


\title{
3. When (International) Law is not enough: understanding the long shadow
}

\begin{abstract}
"Only jurisdictional competence will dictate the end point of the legal polemic, and even it is powerless to prevent the legal argument from continuing outside the institutional frame." Koskenniemi, 2011a, p. 17
\end{abstract}

In this chapter, I will argue that the practice of the ICC fits into the scheme Koskenniemi has called "culture of formalism." In order to do this, I will explore the concept of complementary jurisdiction and the practice of positive complementarity, as adopted by the OTP. I will then sketch the limits of this approach to International Law and use the work of Spivak and Shapiro ground a critique of the ICC's practice. Finally, I will call on hauntology to understand the image of the shadow that is invoked by actors on the ground in Colombia in order to appreciate how this representation is incompatible with the telos of IL, as advanced by Koskenniemi.

\subsection{The International Criminal Court and Complementary Jurisdiction}

Jurisdiction is the "power (...) under international law to regulate or otherwise impact upon people, property and circumstances (...)", 20 conventionally understood as a power held by States (Shaw, 2008, p. 12) but that can equally be accorded to international judicial bodies, created by said States,

\footnotetext{
${ }^{20}$ This quote originally refers only to sovereign States. The reference has been suppressed here because we are focusing on an international court, but the overall definition is still valid since international courts and tribunals have at their foundation the binding will of the States that wished to created them and design their jurisdictions. Thus, it follows from this that an international court's jurisdiction is still the reflection of "the basic principles of state sovereignty, equality of states and non-interference in domestic affairs.
} 
who also set their mandate. While they might not be able to legislate - create new law - international tribunals and courts can decide on existing law, referring to and creating further jurisprudence. Each international judicial body's jurisdiction and applicable law - the set of rules and norms it refer to in decisions and that bind those that are party to the body - normally comes spelled out in its founding Charter, Statute or Treaty. There are many kinds of jurisdictions - national and international - and they may differ according to the source they refer to, as well as regarding their scope.

The International Criminal Court's (ICC) jurisdiction, contrary to popular belief, is not universal but rather complementary. The logic behind complementarity is simple: the ICC's jurisdiction complements, rather than supersedes, the national one of State parties. This means that the Court cannot decide on any matter it wishes to anywhere at anytime, but has a say only over a very specific set of crimes, that occurred in specific time-frame and in specific territories or were committed by nationals of specific States and only if no national proceedings are being undertaken. It is a clear constraint, in this sense, on the activities of the Court - limiting its functions, but also enabling its workings.

This is set out in articles 4(2), 12, and 13 of the Rome Statute and was the subject of much debate during the Rome Conference in 1998, where States agreed on the final draft of the document first prepared by the International Law Commission (ILC) of the United Nations (UN). This has a series of implications.

One of the most direct implications is territorial and national. The ICC only has jurisdiction over individuals - that either are in the territory or are nationals of a State that has ratified the Rome Statute. Citizens of States that have not done so and who do not commit crimes in the territory of State Parties may only come under investigation by United Nations Security Council (UNSC) referral or if the non-party State itself enters in a special agreement with the ICC accepting its jurisdiction over a certain situation, as explained in article 4(2) of the Statute.

This is very distinct from universal jurisdictions, which are applicable everywhere regardless of ratification or consent by any State Party and depend basically on extradition agreements between the country of prosecution and that 
of the prosecuted's nationality or current presence if a person is being indicted. An example would be Spanish jurisdiction over the Pinochet case, which was exercised in spite of the fact that Chile did not have any kind of agreement with Spain over the matter. This feature of complementarity can be understood as a preventive measure taken by States at the Rome Conference to avoid having the ICC over-run State sovereignty in any way - only those that agreed to be a part of the Rome Statute or those that appeared as subject of an UNSC decision could come under investigation by the Office of the Prosecutor.

However, notwithstanding its complementary nature, that limits its scope of action, still based on the territoriality of sovereign entities, the whole Rome Statute is very much under the same teleology that characterizes International Law as an enterprise - a will to unite that which is now separated through a universalizing pull, taking humanity from separation to unity (Koskenniemi, 2011a, p. 4 and p. 22). In theory, the text wishes to be universally accepted throughout the world and invokes humanity regardless of the fact that not all humanity is currently under its scope.

The preamble to the Rome Statute reads: "Conscious that all peoples are united by common bonds, their cultures pieced together in a shared heritage, and concerned that this delicate mosaic may be shattered at any time". Despite this, many important States have not ratified the Rome Statute and thus do not come under the ICC's jurisdiction. This maims the Court's telos and the goals spelled out in the Rome Statute's preamble, but is very typical of the world we live in today, of political dispute. The contested nature of IL is an important feature to which we will return to further along this chapter, for it plays directly into dynamics that result in shadowing.

Another implication of the complementary nature of its jurisdiction is the fact that the ICC may only engage in investigations where no proceeding has already been completed or may be done so by any State on the issue. This may be the case due to either inability or unwillingness of competent officials, according to the Rome Statute, and is one of the criteria of admissibility for opening an 
investigation by the OTP. ${ }^{21}$ According to the Statute, the OTP first has to analyze judicial proceedings and any judicial systems in place that could possibly have jurisdiction over the matter to know if anything is being done nationally. Judge Sylvia Steiner explains this implication as an important feature that are in the best interests of all those involved in a potential judicial proceeding. Local proceedings, according to her, are preferable to international ones since the actual physical distance that exists between the ICC and the ground encumbers everything from investigation to witness identification and subsequent participation during trial hearings (Steiner, 2014).

This has been further developed by the OTP that came up with the concept of positive complementarity, as already explained in the preceding chapter. According to this approach, wherever the OTP sees there is an opportunity to do so, it engages in alternative initiatives such as exchanging letters on prosecutorial good practices and conducting surveying visits on the ground, instead of initiating an investigation.

So far this has happened five times, ${ }^{22}$ the most notorious of which is Colombia. From an outsider's point of view, it simply looks like the OTP has never decided on whether or not to open an investigation into the situation. But for those on the inside, a lot has been happening. The OTP continues to produce reports on the matter and to undertake certain initiatives and consultations. Colombian authorities are constantly involved with international officials, be it through communication via official documents or through visits in The Hague, in Colombia or even meetings in New York. Furthermore, civil society has been discussing the matter, which frequently comes up in newspapers, in the activism of Non-Governmental Organizations (NGO's) and other cultural manifestations, such as political cartoons that circulate in print and online media. The decision a central feature of international legal practice, the lynchpin that closes the legal

\footnotetext{
${ }^{21}$ The other one is the consideration of the "interests of justice", a rather obscure category listed by the OTP in its policy paper on the Preliminary Examination Procedure.

${ }^{22}$ These are the situations under the third phase of analysis of the Preliminary Examination Procedure, according to the OTP policy paper on the matter (2013a). The other countries currently being examined for complementarity matters are Afghanistan, Geórgia, Guinea and Nigeria.
} 
argument (Koskenniemi, 2005) -, or rather, this lack of decision, has its own legal and non-legal effects.

In order to explore this non-decision in this chapter, I will employ images that recur in the debate over the ICC and its involvement in Colombia and, more broadly, in the debate about International Law and Politics. First, the structure of complementarity as a legal argument will be explored, using the work of Koskenniemi. The consequences of this image of the encounter between bottomup and top-down that the complementary argument creates will be analyzed, particularly in regard to what is proposed in the movement Koskenniemi calls counterdisciplinarity in International Law, in opposition to interdisciplinary approaches that have popped up in both IR and IL literature.

Here, the figure of the "shadow" becomes important. This word is doubly invoked in two bodies of work that I will try to bring together, and, as I have explained in the first chapter of this thesis, affects notions of temporality and spatiality, among others.

First, the image of the shadow is used by civil society actors to talk about this lack of decision of the ICC in Colombia. Paradoxically, it is also used to describe its more direct involvement in another part of the world, the African Continent, with a more critical undertone. Beyond this, the image of the shadow also appears in the Gayatri Spivak's work "Can the Subaltern Speak", a prominent scholar in post-colonial and cultural studies, as well as those authors that work with hauntology, namely Gordon (2008) and Cho (2008), aforementioned, that will be used in the final session to talk about the silences of the ICC involvement in Colombia and the more broader ones in International Law.

Here I will propose that to assess International Law as a practice, one need not appeal to counterdisciplinarity, that remains too conservative a project (Orford, 2016). I will than elaborate and advance a trans-disciplinary approach, as proposed by Shapiro (2013) to method or style as a better method in order to capture both that which the practice of international law captures and that which it cannot express, but is rather "disciplined" or silenced, to use Spivak's term, by the legal approach. We must first, as practitioners of academia, acknowledge the 
limits and possibilities of our craft in order to be able to uncover violent realities and start unraveling shadows, ghosts and specters.

\subsection{Complementarity as a legal argument}

Coming from the analysis of International Law not only in theory but also in practice, one can identify a dual structure that rhetorically characterizes its objectivity and distinguishes the legal argument from other kinds of languages and practices. International lawyers tend to be recurrently faced with the a crossroads: to rely on the concreteness of the practice of international law or on its normativity in order to defend its existence and relevance in international life (Koskenniemi, 2005) in such a way that "taking a position in either will immediately [make one] seem vulnerable to apparently justifiable criticisms" (p. 4). It is a dilemma that presents itself to legal practice and that can be disentangled by the exposition of the unified structure of legal discourse (Koskenniemi, 2005, p. 3) due to this central indeterminacy, a consequence of the fact that it is "based on contradictory premises [that] seek to regulate a future in regard to which even single actors' preferences remain unsettled" (p. 590).

But, when surveyed closely, one notices that this apparently dual structure only refers to itself and that the decision between being a realist and being utopian is beyond the structure of law. "The whole of legal 'talk' is an extended effort to solve certain problems created by a particular way of understanding the relationship between description and prescription, facts and norms in international life" (Koskenniemi, 2005, p. 4). Koskenniemi proposes that international lawyers should keep in mind that this stems from the adoption in legal practice of a series of assumptions of a liberal theory of politics $(2005$, p. 5), something they should be aware of when deciding which position to lean towards. He identifies the existence of a structural bias in international law - that despite its indeterminacy, "relevant legal institutions [...] serve typical, deeply embedded preferences, that something we feel that is politically wrong in the world is produced or supported by that bias" $(2005$, p. 607). 
Having established this legal grammar, the author proposes that the way out of this tension is to adopt a culture of formalism, whereby lawyers can cultivate this openness of the international legal argument and create space for advancing a normative project that goes beyond "raw" realist power politics, revealing the legal code's critical potential (2005, p. 11), one that Koskenniemi identifies as lying in the origins of international legal practice in the late $19^{\text {th }}$ century (p. 611).

Indeterminacy should be "thought of as a central aspect of international law's acceptability" (2005, p. 591). He states that this happens when law "shows that legal argument cannot produce the kinds of objective resolutions it claims to produce $[\ldots]$ thus it open up a possibility for alternative descriptive - and simultaneously normative - characterizations of the world States live in" (2005, p. 12), when the international lawyer acts "from the perspective of the idea of law as the expression of the "social"' (p. 612), as an enabling device (p. 614).

In doing so, he advances that IL is not a discipline in the traditional sense and as such cannot be fully captured in its richness and possibilities by interdisciplinary attempts to "bridge the gap" between IR and IL. The culture of formalism is rather a style - one he has diagnosed as particular to international legal practice - than a method and thus can be employed in this greater normative project, to explore its own openness in a politically-minded manner.

Complementarity and, more broadly, the ICC's existence can be understood, under the structure of the legal argument, as an encounter between the normativity of legal sources and power realities and interest of States and, specifically, as a decision to be critical. "The choice to refer to 'law,' in the administration of international matters - instead of, for example, 'morality or 'rational choice'- is not politically innocent," writes Koskenniemi, "its ideals include those of accountability, equality, reciprocity and transparency, and it comes to us with an embedded vocabulary of (formal) rights" (2005, p. 616). Decisions regarding the application of the ICC's complementary jurisdiction can consequently be placed beyond the realm of that which is strictly legal, since the letter of law is indeterminate as to whether one should argue according to apology or to utopia (Koskenniemi, 2005), but as betraying a choice in using law. 
Complementarity can be understood as an instance where this double structure of the legal argument meets in the middle and the politically contested openness of International Law becomes clear to those that are both within and outside the legal practice. To start the preliminary examination of a situation where violence that may have amounted to a crime under the Rome Statute is to decide to engage in an enterprise that values the ideals of Koskenniemi's culture of formalism - turning the duel of international violence into a criminal occurrence that must be investigated and dealt with through legal proceedings. It is the lack of decision that followed this first moment of ICC involvement in Colombia that has revealed the limits of this approach.

While the OTP justifies its decisions regarding this criteria of admissibility on grounds that there is willingness and capacity to proceed nationally in Colombia (OTP, 2012 and 2013b), civil society begs to differ (Amos\&Huber, 2010; HRC, ICS and ISA, 2011; FIDH, 2012). But on both sides, those who defend national proceedings and those that push for international ones, the choice seems clear in favor of and in valuing legal proceedings. But what can legal proceedings achieve, if the very own decisions they produce are beyond law?

The preamble of the Rome Statute states a first list of goals of the international legal enterprise: to avoid shattering the mosaic of common bonds and shared heritage of humanity; to preserve the consciousness of humanity; to ensure punishment of the most serious crimes; and to put an end to impunity for the perpetrators, preventing said crimes. States decided on this preamble at the Rome Conference, where they also decided to highlight, as I already mentioned, that the ICC's practice is complementary to national criminal jurisdictions. The ICC is supposed to act only when national jurisdictions have failed to proceed with satisfying legal provisions. In this sense, it betrays international lawyer's preference for international institutions over domestic ones (Koskenniemi, 2011a, p. 22), enlisting a practical explanation about the desirability of closer, local proceedings (Steiner, 2014).

This tension once again highlights the indeterminacy of international law in its place between apology and utopia. States are the main subjects and authors of International Law at the macro level, since they are the ones that may sign 
treaties and become party to international institutions. Yet international lawyers and activists, with their own particular preferences, are the ones that most of the time work in the institutions that draft these documents, such as the International Law Commission of the UN, in the Rome Statute's case, or argue on behalf of the sides to a dispute in international judicial bodies, such as the ICC.

Surveying the ICC, one can see how it ideally fits this culture of formalism. It would use law as a language, an overall structure, to advance the project of combating impunity and preventing the crimes that are characterized in its charter and other pieces of applicable law. It would do so in the name of a universal sense of humanity, as stated in the preamble to the Statute, by abiding to accountability, equality, reciprocity and transparency, employing a vocabulary of rights (Koskenniemi, 2005, p. 616). Whenever justice was lacking in a particular community, the Rome Statute would be invoked in order to make this a matter of the whole of humanity, through the critical use of IL, going against the grain of violence, no longer allowed under international law as a main feature of politics.

Seen in this light, the decision to maintain Colombia under preliminary examination can be thought of as an exploration of the openness of international law in order to foster national proceedings. The Rome Statute, under complementarity, argues that it is best to keep judicial proceedings local where there is the willingness and capacity to do so. Yet, there is a great parcel of Colombian civil society and even government officials that call for the opening of an investigation, especially because it has been ten years since Congress passed a special law for the investigation and trial of crimes under ICC jurisdiction but not much has been done on this front.

This then opens up questions regarding what exactly may one politically advance by practicing international law. More specifically, one can ask what are the effects of the ICC's non-decision in the Colombian case, the ways in which it ends up shadowing politics on the ground and how can we understand its impacts. 


\subsection{The Culture of Formalism and its Limits}

To understand international law as a practice is not to view it only as an instrument made available to international actors through international lawyers. Quite on the contrary, the culture of formalism is in fact a reaction to this instrumentalization of IL (Koskenniemi, 2011b). IL, the argument goes, should rather understood as a craft (Koskenniemi, 2011a). In this approach, the “objectives of IL appear differently depending on one's standpoint. [It] (...) seeks to realize political values interests and preferences of (...) actors [and] (...) also appears as a standard of criticism and means of controlling those in powerful positions" (Koskenniemi, 2011b, p. 241).

Here we are once again reminded that the decision to support either the status quo of the structural bias of international institutions or go against it lies beyond the letter of international law and is a matter of practice/choice - to which the letter of the law is open to. Koskenniemi goes beyond this and affirms that international law is also a culture "biased in favor of participation over selectivity, transparency over secrecy, and responsibility for the choices it has been used to justify" (2011b, p. 241). Here, IL goes beyond the realm of the legal and starts turning into a political project - the manifestation of a preference for a certain type of communal conduct in the constitution of political communities.

Yet this culture of formalism, despite fitting the main motivation behind the ICC as an international institution, is very much open to critique from the standpoint of IR literature and Political Science, more broadly speaking. Here we are forced to leave Koskenniemi behind, as he does not help us, for the author wishes to view international law as a unique and competent culture that goes beyond that which is the status quo and has the power to critique and advance its own telos - from the particular to the universal. Yet, in this move, dubbed counterdisciplinarity, Koskenniemi ends up leaving behind a very important part of IR literature and other related political science literature that would be more relevant to the work he is trying to develop inside the field of IL. To try and address critique of any status quo order without seriously engaging with Marxism and Critical Theory is difficult to sustain. 
When Koskenniemi states that IL as a culture stands for participation, transparency and responsibility over other options, (2005, p. 616), he seems to step over the very inaccessibility of international law as a language and as a practice, the foreign sounding words and principles it invokes and the violence that it carries within its very enterprise, institutionally speaking. The order of the courtroom is very specific, where the victim has to come to terms with her own trauma and exposes herself in front of others, hoping for the best. Access to justice becomes a secondary issue here for it seems that in the culture of formalism, judicial proceedings would be the way to achieve universal access to this common good. ${ }^{23}$

In the case of ICC involvement in Colombia, little was explained early on to civil society and victims as to why an investigation was never opened by the OTP. It took more than 6 years for the first report to be released - and all information at the ICC is subject to secrecy. There is currently no procedure in place to make evidence and other material collected during preliminary examinations or formal investigations open to public, nor during nor after the end of proceedings. ${ }^{24}$

The very proceedings of the ICC are not transparent to most of those directly affected by the crimes the Rome Statute focuses on. The language of law, particularly of international law, is not familiar to them and their experience then needs to be mediated by those that have been initiated and are, to use one of Koskenniemi's words, competent in the matter (Orford, 2006), a feature of the practice of international law that will be explored in the next chapter.

This makes international law discrepantly reliant on the sovereign State System, among other things, if not for actual proceedings, at least for the

\footnotetext{
${ }^{23}$ Justice is still a big issue in contemporary international society. Amidst the current debate on post-2015 development goals, for example, Open Society Foundations - an ONG founded and funded by George Soros - is promoting a campaign to raise awareness on the issue, that was not mentioned in the previous generation of Millenium Goals.

${ }^{24}$ During my internship, one of the tasks I was asked to complete was to sketch a preliminary lifeline of evidence and all information collected by the OTP - what should be kept, for how long, what should be discarded, how long after proceedings should evidence be made public, how, etc. The ICC's young age helps explain why most of these procedures have still neither been fully developed nor been put into practice.
} 
education of those that will become international lawyers and represent these people in court, since in most countries education is still mostly directly or indirectly supported by the federal government, be it through public schools or through the provision of financial aid that will put students through law school. This happens despite what can be identified as a bias of IL in favor of a critique of sovereignty (Koskenniemi, 2011a), but which is never quite completely fullthrottle and stops in its tracks before it achieves a critique of the (fragile) heroic model structure on which the narrative of the State stands.

When Koskenniemi wishes for International Law to be progressive and for the language of rights to "be used to articulate claims by those who are sidelined from formal diplomacy and informal networks and feel that something about the routines of both is responsible for the deprivations they suffer" (2011b, p. 249) "in a language of something greater than merely their personal interests" (p. 260), by "redescribing individuals and groups as claimants of rights (...) providing them with an identity that they may assert against the homogenizing pull of society's dominant elements" (p. 260); giving "an international voice to communities by allowing them to read their particular grievances as claims of universal entitlement, (...) lift[ing] a private wrong to the level of a public law violation" (p. 261). By doing so, IL would contribute to new ways of "imagin[ing] - and thus to creat[ing] - the international world as a set of public institutions within which public authorities should use power in roughly predictable ways and with public accountability to the community at large" (Koskenniemi, 2011b, p. 261).

Yet this is not what has been going on in the ground in Colombia, despite the critical potential and much of the critical activity undertaken by the same international lawyers of the OTP elsewhere. Taking the positive approach to complementarity as an example, culture of formalism without critique - the sheer promotion of better prosecutorial practices and exchange of visits - and, more specifically, without critical theory, is to be blinded by the grand teleological promises of this practice, letting the shadows it casts escape. IL, even when employed as the culture of formalism, can still reproduce violence.

That Colombian civil society actors talk about a shadow of the ICC is a very tattletale lead. They have undertaken the language of International Law and 
claimed it as their own, but once again these are people that are connected into the network that has had access to a series of privileges that work in their favor in the current bias of the status quo.

They have had access of funding, to prior education, to the production of documents - both at national and international levels. The ICC is a court for trying those that are the most responsible for the crimes under its jurisdiction and as such cannot be the ultimate place for justice for every last victim - but needs to be complemented by other forms of legal procedure, mostly of national origin. This is, in a certain way, beginning to sketch out the limits of ICC's practice and of the culture of formalism. The ICC very much depends on States and their national judicial systems. The law is still very much enacted in a particular and not universal stance, but remains inaccessible in a way that justice should not ideally be. There are other types of languages that become stifled in this scenario.

Not all that relates to justice can than be tried in the courtroom, using international legal practice in the culture of formalism; nor is the practice of law the only available condition of possibility for developing the political in a given situation, setting the grounds for politics through the language of rights, when violence ceases to be a valid or plausible means to achieve political goals. This has been happening in the Colombian case, where law has become associated not with the arrival of justice, but to other specters, that I have gathered in chapter 5 . Other languages need to have room to manifest themselves as political and break the shadow of this legal enterprise. To look for them is delve in the shadows of the ICC.

In order to be able to grasp these other possibilities, it is wise to go beyond Koskenniemi's proposal for international law and to draw a critique of the counterdisciplinarity of his culture of formalism, as is presented in his vast oeuvre. The interdisciplinary approaches of theoreticians such as Robert Keohane and Anne-Marie Slaughter that he mentions and critiques in his work are not the only options available, nor is the legal language the only one that can advance a critique of the status quo and promote universal experiences - nor is it the best or ultimate medium for that.

One can also employ trans-disciplinary methods and take the aesthetic turn, in a direct reference to Shapiro's work (2013), when asking to if the 
subaltern can speak through international law. I will now argue, using Spivak's work, that the answer to this question is negative and that there are other, still undervalued ways, in which experiences can achieve the same ends as those raised by international law in Koskenniemi's work without loosing the voice of the subaltern in the midst of a culture of formalism.

Undervaluing these alternatives is a violent act, for cultural pieces are not constrained in the same way that disciplines - such as IR, IL and, more broadly, social sciences - currently find themselves to be. When dealing with shadows, emergences and ephemeral presences, one cannot be bound to these strict lines that overvalue hypervisibility (Gordon, 2008, p. 15). Embeded in IL's telos, as forwarded by Koskenniemi, the ICC and its practice is still in the paradigm of visibility, of rendering the particular universally visible and thus accessible. As Gordon states, "hypervisibility is a kind of obscenity of accuracy that abolishes the distinctions between "permission and prohibition, presence and absence"" (2008, p. 16). This desire for visibility and truth-establishing present in the practice of IL produces further violence, albeit in the shadows of a supposed hypervisible and internationally investigated field. This is what still needs to be fleshed out.

I do not wish to be unfair to Koskenniemi, since he does admit that "international law exists to advance the repertory of substantive values, preferences and practices that those in dominant positions seek to realize in the world" (2011b, p. 265) and thus can serve as a vehicle of violence, but he is quick to add that it

\footnotetext{
"Also gives voice to those who have been excluded from decision-making positions and are regularly treated as the objects of other people's policies (...) a platform on which claims about violence, injustice and social deprivation ma be made even against the dominant elements" (p. 266).
}

He agrees that "law is instrumental, but what it is instrument for cannot be fixed outside the political process of which it is an inextricable part" (2011b, p. 266). But this means that "international law's objective is always also international law itself", for IL in its "pure form (...) provides the shared surface - the only such surface - on which political adversaries recognize each other (...) and pursue their adversity in terms of something shared, instead of seeking to 
attain full exclusion (...)", guaranteeing in a way that IL exists as a "promise of justice" (2011b, p. 266).

The keyword here is exactly promise - for if there were in fact fullfledged justice in political affairs, no law would be needed and promises of justice would not make sense. So IL, even in the culture of formalism, will always fall short of fully attaining the goal it so whishes to accomplish as this shared surface, as a medium through which others gain voice, etc. Yet Koskenniemi still holds IL in high regard, portraying it as the only possibly practice to guarantee the shared surface, which functions as the condition of possibility for the political. I wish to argue that not only is IL not the sole platform for this, as Koskenniemi claims (2011, p.266), but that even when it is adopted in this sense, it produces political consequences well beyond the legal sphere, thus enacting the shadow that actors perceive on the ground in Colombia, which is so difficult to legally grasp. The shadow might as well be seen as a sign that the surface is not as shared as originally thought. When choosing the path of IL, then, we should be aware that it is a political choice - and that there are consequences to it, as well as other options.

\subsection{Can the Subaltern Speak International Law?}

To maneuver the legal argument and to engage with others employing a language of rights, having the ability to recognize structural biases and so forth requires a certain legal competence (Koskenniemi, 2005; Orford, 2006). This is a first revealing sign of the difficulty of accessing international law, notwithstanding the fact that it subscribes to a liberal view of the world that praises universality - as goes the argument for the culture of formalism. Thus, who can speak and practice international law? Very few. In this point lies a first trace of violence in legal practice.

The famous piece called "Can the Subaltern Speak" (1988), written by Gayatri Spivak would beg to differ from Koskenniemi's portrayal of International Law. As a woman and an Indian, the author has much ground to doubt that IL, even in its culture of formalism, provides the only ground for advancing the political. She develops a staunch critique in her work of the kind of thinking that 
is being produced by French poststructuralists of her time, more specifically Michel Foucault and Gilles Deleuze, when they talk about the Other.

She, a double-other, raises the critique that when they are talking about this social entity, the authors do so rather carelessly and let a slippage occur, confusing representation with re-presentation, two very similar albeit distinct words. The same has happened throughout the very international history of imperialism, of which she raises some examples from her home country, India. She is quick to note that, during this experience, law - and the western interpretation of Hindu law - was integral to colonialism. Furthermore, she invokes the same figure Colombian civil society has used to refer to the ICC, the shadow, yet in slightly different terms.

When talking about the experience of the sati and how this was came to be understood as a prohibited practice under British rule, an instance of what she called "white men saving brown women from brown men" (p. 83), she contrasts the idea that the work of Foucault and Deleuze and many others in their tradition render the intellectual transparent (p. 69-70) while "the woman is doubly in shadow" (p. 84). Here, she recognizes the "inaccessibility of, or untranslatability from, one mode of discourse in a dispute to another" (1988, p. 96), something unthinkable in Koskenniemi's project of the culture of formalism. Spivak accords that to ignore this is to incur in epistemic violence.

The author answers her own question: the subaltern cannot speak, not in the terms that intellectuals set out for them to do so - not in the language or style a certain form can capture and translate into a certain universality. Entwined into this idea of advancing a culture of formalism embedded in a teleology of unity is, for Spivak, a fundamental and foundational epistemic violence that renders the place of the one who re-presents the message as transparent, as if he could argue from the top-down of from the bottom-up without much loss to the story, like the international lawyer proposes himself to do. Yet, much is not grasped in this narrative and lies in the shadow.

International law, as a style and the ICC as a manifestation of this style, has its limits. Since the political goes beyond these limits and concerns the very epistemic violence in which they are embedded, one needs to recognize that international law cannot be the only condition of possibility for international 
politics to run on a shared surface, to use Koskenniemi's words. The international lawyer is not transparent - and this is beyond the effects of his decision; international law is not transparent, despite vying for transparency.

In trying to provide common ground on which politics can occur, the ICC's proceedings, even when understood as an embodiment of the culture of formalism, as a promise of justice, cast shadows and reproduce epistemic violence. In the quest to try and render situations transparent through investigation, the OTP has gotten stuck in the Colombian debacle, where, instead of light, of a way out, it has cast shadows. No transparent being casts shadows. Thus, in order to uncover the traces of this ambiguous spectral-presence, one needs to go beyond international law and judicial proceedings per se and look into other realms. I have chosen to look into the aesthetics of this practice of international law - putting law back into the complex web of life that exists beyond courtrooms - and appreciate how actors on the ground have decided to represent the ICC and the situation at hand in their country.

\subsection{The case for Trans-disciplinarity as a method}

To go beyond the framework that is set up by Koskenniemi and be able to explore the shadows - in all the meanings brought here into this text - cast by the ICC specifically in Colombia and by International Law in Politics, one can adopt a trans-disciplinary method, as proposed by Shapiro (2013). In his work, the IR scholar does not try to bridge any gaps, but to "think rather than reproduce accepted knowledge frames (...) to create the conditions of possibility for imagining alternative worlds", by deploying a method the " 'disturb[s]' accepted relationships between 'the sayable and the visible' and that effectively repartition[s] the 'distribution of the sensible,' " by thinking with artistic texts (p. $\mathrm{xv})$.

In this way, he has discovered alternative subjects, aesthetic subjects, "those who through artistic genres, articulate and mobilize thinking" (p.11), diving into the politics of fiction, another style different that that of the legal practice, where thinking and communication is done through different modes of 
representation that do not present themselves as transparent. There is, in the arts, a "critical temporal multiplicity that challenges both humanist and sacred models of unitary time" and "encourages one to think" (p. 26), in an engagement with analysis as philopoesis in matters of justice. Instead of seeing justice as an unattainable promise, in this methodology it becomes an aesthetic dispositif that allows the "mapping of an emerging world of forces that justice - as part of an ensemble of knowledge practices and complex inter-agency relations references" (Shapiro, 2013, p. 71).

In analyzing both ICC and documents addressed to it specifically, this can be useful. When one beings to see documents as artifacts of modern societies, we can more fully appreciate their existence as vessels of both communication and preservation of data, serving multiple functions to different social groups. While documents can render information accessible and transmissible, they can only do so to those that share in the special language adopted. You must understand what must be done with blank squares and circles, what must be filled in or checked in order to engage in the intended use of forms, for example (Brenneis, 2006). Thus, documents also enter into this game of transparency and shadowing.

Yet, not all people use documents only as props for passing on or preserving information in a uniform manner. They can also serve other functions, such as being cherished as relics and artifacts that form a biography, for example (Heimer, 2006). Here, the aesthetic aspect of these documents come front and center. The media in which documents are elaborated and transmitted can also have an impact - be they on paper or in electronic formats (Gitelman, 2014). It is exactly because they are deemed as everyday objects/artifacts that - in a deflationary manner (Gitelman, 2014, p. 7) - they can be locus of traces left by shadows and present-absences.

Using this method that brings together both philosophy and political science to analyze the legal practice (Shapiro, 2013), its transparencies and shadows, different themes crop up. Instead of presenting itself as a place of participation, transparency and responsibility, law can take on other facets while other practices may take on this character.

Law disciplines everyday life in many ways. It tries to render comprehensible that which is complicated (Gordon, 2008, p.3), but it is in itself 
also part of this complicated world. Understood as a theoretical statement in Gordon's body of work, the complicated nature of life has two important implications. "The first is that the power relations that characterize any historically embedded society are never as transparently clear as the names we give to them imply" (2008, p.3) Second, it renders personhood complex (p. 4), in a way that "reminds us that even those who live in the most dire circumstances possess a complex and oftentimes contradictory humanity and subjectivity that is never adequately glimpsed by viewing them as victims or, on the other hand, as superhuman agents" (p. 4).

Documents that are meant to be of universal access, produced by experts in language that is supposed to be standard become incomprehensible - and even immaterial - and civil society actors that actually mimic their format are not listened to, despite employing the same language to make claims that should, theoretically, be heard by those that are supposed to comprehend them. We may find that that which was supposed to unite and become an ensemble, through law and the justice dispositif it claims for itself, can potentially become separated by the practice.

Other styles and mediums, such as cartoons and cinema, that are traditionally marginalized in political science research and enquiry, can, as practices, unite and present far more fecund opportunities for seeking exactly the justice international law wishes to deliver. Leaving behind the specific form of the culture of formalism, the rigidity of the legal argument and adopting the more supple nuances of aesthetics, justice becomes a broader goal that can be achieved beyond the courtroom - and not only through the reproduction of violence, but rather by acknowledging it aesthetically.

The distance between fiction and reality - that stems from a crisis of representation (Gordon, 2008) - closes up at this point. One does not need to look only into the "real" world in order to search for ghosts and shadows. Actually, authors such as Gordon even go as far as to challenge the "reality" of academic work:

"questions of narrative structuring, constructedness, analytic standpoint, and historical provisionality of claims to knowledge direct sociology to the ways in which our stories can be understood as fictions of the real" (2008, p.11). The 
reader must not find it strange that $\mathrm{I}$ have decided to analyze both academic and official documents alongside works of art and fiction in the same thesis, they are both, in a sense, cultural manifestations:

At the core of the postmodern field or scene, then, is a crisis in representation, a fracture in the epistemological regime of modernity, a regime that rested on a faith in the reality effect of social science. Such a predicament has led to, among other consequences, an understanding that the practices of writing, analysis, and investigation, whether of social or cultural material, constitute less a scientifically positive project than a cultural practice that organizes particular rituals of storytelling told by situated investigators. (Gordon, 2008, p. 10)

The lack of the decision of the OTP and the ICC in the Colombian case changes its face completely when phrased in these terms. It is a matter not of lack of international judicial procedures that can be argued to be appropriate or not. The questions advanced by scholars working within traditions such as the legalization school fall behind. Other matters, such as the placing of shadows and the transparencies in the specific form of the justice dispositif of the official discourse verses that of concurring ones and their own aesthetics can be now be posed as questions. Transdisciplinarity here is employed as a method that wishes recognizes that "there is still some room to claim rather than discipline its meaning into existence $[\ldots]$ look[ing] for a language for identifying hauntings and for writing with the ghosts any haunting inevitably throws up" (Gordon, 2008, p. 7). I will, in the remainder of this thesis, make this work for ghosts and for shadows.

\subsection{Beyond the $\mathrm{l}($ aw)ng shadow}

There are two important consequences of this approach that actually take promise of justice beyond the project of the culture of formalism as Koskenniemi presented it in his work. With them I make this chapter's concluding remarks.

First of all, this takes law beyond the courtroom and makes it possible to notice the effects legal practice has outside the traditional halls and actors associated with it. This is a first step in actually completing the critique of the sovereign subject and other subjectivities it in turn produces. To acknowledge this is to see the international lawyer not as transparent, not international law as 
only a style, but as an actor that takes part in a highly disciplining practice. Counterdisciplinarity becomes a utopia.

The other move central to my analysis is to go beyond the legal sphere. This is important in the effort of reimagining political possibilities invoked by Shapiro in his preamble (2013), and in creating spaces where Spivak's sexed subaltern need not remain so, but may leave the shadow through the uncovering of epistemic violence that keeps her there. A way to do this is to employ aesthetic trans-disciplinary method in an attempt to break the disciplinary boundaries that have kept these myths and claims of exclusivity in place. In doing this, it is also inevitable to also try and rethink the very relationship between international politics and international law, quite an ambitious project.

In order to accomplish this, over the next chapters of this thesis, I will raise a series of questions in the two aforementioned movements. First, documents and practices inside the scope of international law will be the object of aesthetic analysis. Afterwards, in another chapter, other representations of the ICC in situations being investigated and of the wider conception of justice as a dispositif will be brought into the discussion. The involvement of the ICC in Colombia will be used as a basis from which to proceed and as one of the unifying themes of the whole work. The images of transparency and the topdown bottom-up trajectories, as well as that of the shadow, will be invoked, replaced and displaced along these chapters.

By the end of this thesis, I hope to have expanded on why international law is casts these long shadows, even when it sets as its goals to be transparent when regulating violence so universally rejected as are the crimes characterized in the Rome Statute. That this has happened is not the sign of failure of the project, but rather of our conservatism and our own failure to look beyond this practice into the wider realm of the political and ask ourselves what are the real possibilities for achieving justice for humanity - not for only a handful of liberals. 


\section{The International Criminal Court and Colombia ${ }^{25}$}

This chapter will focus on the structure and procedures of the International Criminal Court, mainly on PEP. This chapter is the chapter where I will expand a critique on the understanding of positive complementarity as an application of the "culture of formalism." I have also already argued in favor of the existence a political, or at least beyond-legal impact of positive complementarity elsewhere, identified as "alternative strategies of engagement" (see Pellegrino, 2014, p.2).

\subsection{The International Criminal Court}

The ICC started working on the $1^{\text {st }}$ of July of 2002 , the day the Rome Statute entered into force after its ratification by 60 State Parties. More than 12 years later, they now amount to 122 countries $^{26}$. The ICC is court of last resort and it investigates crimes against humanity, genocide and war crimes committed after the abovementioned date. Jurisdiction over the crime of aggression, present in the Rome Statute, is still pending.

Jurisdiction is not only subject-matter and temporally constricted but also territorially or personally. The crimes to be investigated must have occurred on the territory of a State party or by a national of such States and situations can be referred by the own State party or initiated proprio motu by the OTP. Furthermore, situations may be referred to the ICC by the United Nations Security Council (UNSC) or by a non-party State that issues a declaration accepting the jurisdiction of the Court. In these last cases, the strict territorial limitation does not apply.

The ICC is the first permanent international tribunal of its kind and operates on the principle of complementarity. It does not substitute national jurisdiction, but complements it, as explored in the previous chapter, when cases

${ }^{25}$ A previous version of parts this chapter has been previously published in Revista Eletrônica de Direito Internacional, v. 13, 2014 and is reproduced here with the authorization of the Centro de Direito Internacional.

${ }^{26}$ As of May, 2013. (ICC, 2014c). 
are not thoroughly addressed nationally, either by lack of capacity or will. It also holds special representation for victims during trial procedure, an innovative approach, beyond the traditional prosecution and defense. It differs in these aspects from other international and joint national-international tribunals.

The Court is composed of 4 organs: the Registry, the Presidency, the Judicial Divisions (Chambers) and the $\mathrm{OTP}^{27}$. The first two are mostly administrative and representational. Our focus here will fall upon the OTP, considered for the purposes of this thesis to be the main face of the ICC in international relations. This is because it is with the OTP that States and the UNSC interact directly through the procedure of opening and referring situations, possibly cooperating throughout the whole process of investigation. This occurs mainly during PEP, and during the investigation phase, though there are only official guidelines and entitled obligations for the second one. Cooperation is also secured for extradition of individuals charged by the ICC.

ICC Chambers, while of utmost important for the Court's functioning, as one of the main actors inside the courtroom, deals mostly with individuals charged in the cases open with the OTP. The bulk of interaction with outside parties, even during investigation phase, is done by the OTP. Both organs for public defense and victim representation mostly interact with individuals - with exception to the prosecution of government personnel, when the defense ends up dealing with outside parties, but still in a more limited fashion than the OTP.

It is important to note that currently both Chambers and the OTP occupy the same tower, in the Arc building, in the outskirts of Den Haag. The Presidency occupies a separate tower, along with the Assembly of State Parties offices. The Registry and Defense offices are in another building, the Haagse Vest, that is on another block, near another building, the Saturnostraat, that houses security and information technology personnel, as well as some special rooms where training in court systems are routinely held. Public-access rooms such as the courtrooms and press-rooms are located in a separated wing of the Arc. The detention center, where individuals under custody during proceedings are kept, is farther north, in the beachside town of Scheveningen, neighbor to Den Haag.

${ }^{27}$ For more information, view ICC, 2014c. 
The OTP occupies floors 5 through 11 of the first tower, while Chambers has the first floors. In respect to due process, the plans for a new building, currently under construction, preview the complete separation of all organs of the court. Currently, privacy and security - central to due process - are achieved through a system of badges and locked doors. While this takes care of control over the circulation of people, it does not solve the problem of circulation of material, since all evidence and information received and collected by the OTP is digitalized and circulated in virtual form.

Despite using two separate systems of cataloguing data - one for communications and all documents collected before the opening of an actual investigation into a situation, HP TRIM; and one for evidence, Ringtail - there were no great security measures being taken regarding the restriction of data. No scanning of outgoing and incoming flash drives and hard drives were conducted and staff was even encouraged to use these equipments freely during my time at the court. ${ }^{28}$

The security of all information collected by the OTP, according to the Rules of Procedure and Evidence of the Office, the responsibility of the Information and Evidence Unit (IEU). According to others who had interned in other tribunals, like the ICTY, this state of affairs was uncommon, for most of them only allowed use of pre-appointed equipment inside the office, which was promptly formatted when returned.

In contrast to other international tribunals and instances where crimes against humanity were already tried, the ICC has, through the OTP, the power to initiate its own investigations, under the jurisdiction of the Rome Statute. This is a major advancement in international criminal justice, one that opens up a bigger space of maneuver for the court as an independent actor in the international arena. Thus, the ICC is able to work as a deterrent agent, one of its main attributions, in the effort to combat impunity ${ }^{29}$. If it were constricted to State or UNSC referral, this deterrent effect would not be readily accessible, or at least greatly impaired by the will of politicians. This information is relevant in order to

${ }^{28}$ Upon arrival, all interns received a flash-drive, courtesy of the ICC.
As coined in the Rome Statute. 
understand why the ICC has such a political pull over the Colombian case, to the point where it can be considered a "shadow."

More specifically, the OTP's Preliminary Examination Process (PEP) is of interest here mainly because it is during this time that the Office, and through it the ICC, shows initiative in dealing with other international actors, mainly States, but also non-State actors, particularly in what relates to the issues of complementarity and admissibility. This part of formal Court proceedings will be investigated in the next section.

\subsection{The Office of the Prosecutor}

The OTP, as prosecution, deals with diverse phases of proceedings at the ICC. Since it is responsible for presenting a case for the opening of investigations to the Pre-Trial Chamber, the OTP is involved in work prior to the proper trial phase of the proceedings. It is during this phase that it has to determine, like most prosecution offices, if there is a reasonable basis to proceed and present its case to the designated chamber, prior to the formal opening of a situation.

\section{Chart 1: Structure of the Office of the Prosecutor}

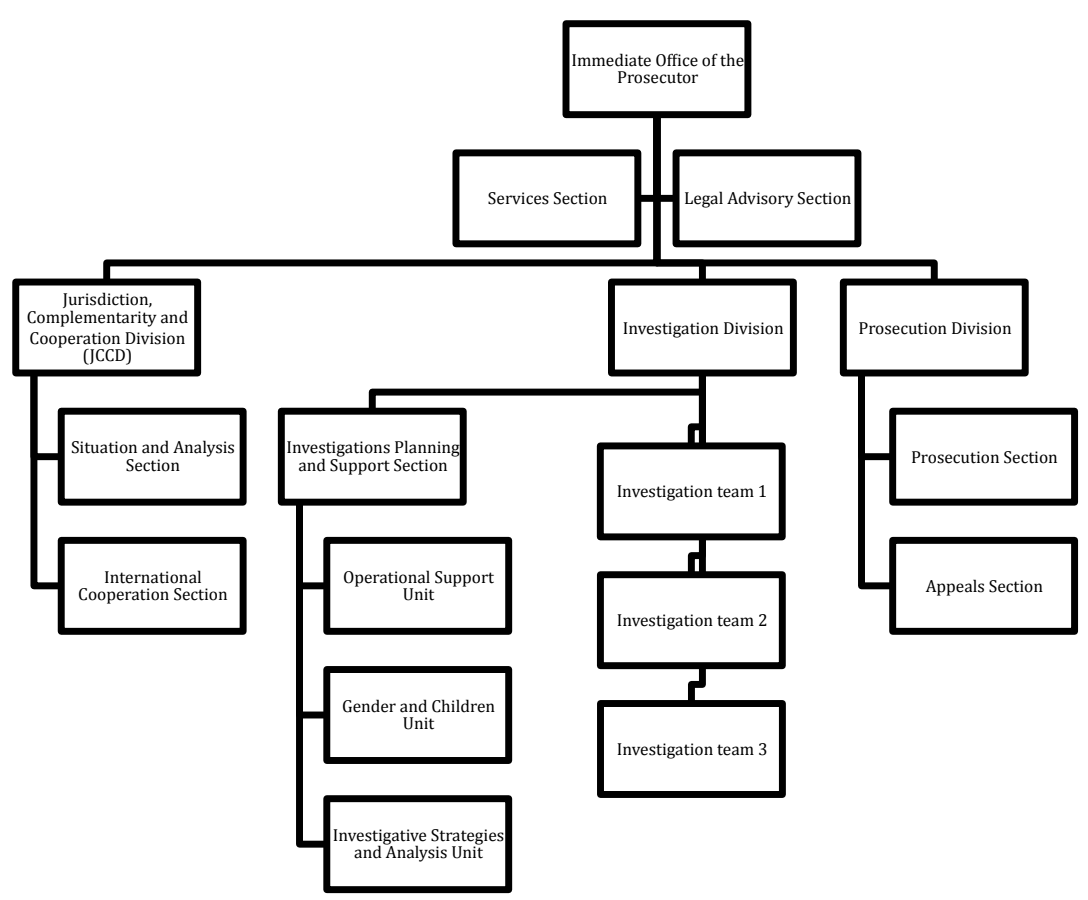

Source: ICC, 2014d. 
Due to the international and complementary basis of the ICC's jurisdiction, this particular phase of OTP proceedings, the PEP, is undertaken through cooperation with State parties. This work is conducted by the Jurisdiction, Complementarity and Cooperation Division (JCCD) ${ }^{30}$ of the OTP, in cooperation with the IEU, part of the Services Section of the OTP, which receives all referrals and communications ${ }^{31}$ sent to the Prosecutor. The IEU has received a total of 10,352 article 15 communications, according to the latest numbers officially released (OTP, 2013, p.1). During the three months I stayed at the ICC, I worked mainly inside IEU offices and had monthly meetings - as well as occasional special ones - with JCCD staff.

\subsection{Preliminary Examination Process}

According to the most recent OTP report on the matter, once a communication or referral is received by the IEU, it undergoes a series of phases (OTP, 2013). Since now there are already a number situations open, a first assessment is made on whether the information pertains to a new or already existing investigation. If it is the latter, it is forwarded accordingly. It not, it is considered under the PEP, under the legal framework of Article 53(1) (a)-(c) of the Statute. The examination of a situation may be initiated by information sent under Article 15, referrals from State Parties or the UNSC or a declaration of a State not party to the Statute, accepting jurisdiction of the ICC under Article 12(3).

The full process of receiving and classifying the actual material and virtual information received by the ICC was, during my time spent there and at least the five years prior, completely done by the two IEU interns, under the

\footnotetext{
${ }^{30}$ The OTP's structure is made up of the Immediate Office of the Prosecutor, the Legal Advisory Section, the Services Section and three divisions: JCCD, Investigation Division and Prosecution Division. JCCD, of more importance here, is composed of the Situation and Analysis Section and the International Cooperation Section.

${ }^{31}$ Any and all information sent to the Prosecutor under Article 15 of the Rome Statute is called a communication.
} 
supervision of a staff-member. Interns were responsible for daily checking the inbox of the Article 15 communications emails, as well as going down the seven flights of stairs and picking up mail from the mail room. They usually spent from 3 to 6 months in the Office and were routinely changed.

Since this first triage of the material received required very little legal knowledge, interns were not required to have law degrees. This was also true for interns that worked in JCCD and some positions in the Immediate Office of the Prosecutor. It is telling that these three instances that deal directly with actors outside those that inhabit the ICC courtroom, i.e. the accused and judges, need not to be trained - competent - in legal practice. Despite this, notes taken during my time at the Court betray that there was a certain superiority attached to working directly with legal proceedings.

The main purpose of this preliminary scanning of all information received was to identify if an actual claim existed. Pleas for help, requests of asylum or other types of communications were not registered into the court system and would not proceed to JCCD analysis. Albeit this, they were dutifully stored for further checking by superiors and for archival purposes. Those communications that contained claims and were registered into the system all received responses regarding ICC's jurisdiction. These were automatically generated and were sent out ideally in a month's time, both through electronic and paper mail. They contained a response as to whether the claim was deemed a fit under the Rome Statute and, if not, why this was not the case. This last point was added to the dismissal letters only after some time, as a suggestion of a fellow intern, who thought claimants should be informed of why they were being rejected, not only of the fact per se. She intended this to have a didactic effect, helping those unfamiliar to court proceedings learn more about the ICC and turn to better suited instances to have their needs met. But no letters of dismissal or any sort of explanatory communication was ever sent to those who submitted communications where no claim was found. These were dismissed without any follow-up.

The claimant could respond up to two times - on the third dismissal, like in baseball, they were out. From this point on, their communications were first noted in the corresponding slot in the filing system and then either deleted, if in 
eletronic form, or thrown out in the blue bin - an actual blue trash can whose content was all shredded from time to time.

Those communications that were found to be relevant under the Rome Statute were brought together and then came under preliminary examination. PEP consists of 4 phases of filtering that escalate according to the assertion of a minimum threshold of a reasonable basis to proceed, necessary for the presentation of the situation to the Pre-Trial Chamber, according to the Rome Statute. Despite this division into phases, the OTP states that it adopts a holistic approach to the PEP (OTP, 2013, p.5).

Reasonable basis to proceed consists of assessment of jurisdiction (temporal ${ }^{32}$, territorial or personal and material ${ }^{33}$ ); admissibility (complementarity ${ }^{34}$ and gravity ${ }^{35}$ ); and the interests of justice. In searching for further information to determine if an investigation can be open, the OTP may seek additional information from States, organs of the United Nations, intergovernmental and non-governmental organizations and other sources deemed appropriate, observing no timeline for its final decision.

Once it has undergone all 4 phases, the OTP can decide to i) close the situation due to a decision not to proceed; ii) continue to collect information in order to establish sufficient factual and legal basis to render a determination; iii) complete the preliminary examination and proceed to the investigation. According to the Court's website, but not to OTP PEP reports, the OTP may also decide to continue to assess relevant national proceedings (ICC, 2014e).

The 4 phases are explained in further detail in the last column of table 2.

\footnotetext{
${ }^{32}$ Date of entry into force of the Statute, namely 1 July 2002 onwards, date of entry into force for an acceding State, date specified in a Security Council referral, or in a declaration lodged pursuant to article 12(3)

${ }^{33}$ Defined by Article 5 of the Rome Statute (genocide, crimes against humanity, war crimes and aggression)

${ }^{34}$ Examination of the existence of relevant national proceedings in relation to potential cases being considered. Where these domestic proceedings exist, the OTP will assess their genuineness.

${ }^{35}$ Assessment of scale, nature, manner of commission of crimes and their impact.
} 
Table 2: Situations Under Preliminary Examination per Phase

\begin{tabular}{|c|c|c|}
\hline \multicolumn{3}{|c|}{ Preliminary Examination Phases } \\
\hline Phase & Current Examinations & Description \\
\hline Phase 1 & $\begin{array}{l}\text { Iraq }^{36} \\
\text { Ukraine }\end{array}$ & $\begin{array}{l}\text { Initial assessment of all article } 15 \\
\text { communications, identifying those } \\
\text { crimes that fall under jurisdiction of } \\
\text { the Court. }\end{array}$ \\
\hline Phase 2 & $\begin{array}{l}\text { Honduras } \\
\text { Comoros } \\
\text { Central African Republic }\end{array}$ & $\begin{array}{l}\text { Whether preconditions for } \\
\text { jurisdiction are satisfied, if the crime } \\
\text { is within subject-matter jurisdiction } \\
\text { of the Court. }\end{array}$ \\
\hline Phase 3 & $\begin{array}{l}\text { Afghanistan } \\
\text { Colombia } \\
\text { Georgia } \\
\text { Guinea } \\
\text { Nigeria }\end{array}$ & $\begin{array}{l}\text { Analysis of admissibility based on } \\
\text { complementarity and gravity }\end{array}$ \\
\hline Phase 4 & None & $\begin{array}{l}\text { Examination of the interests of } \\
\text { justice and the formulation of the } \\
\text { final recommendation on the } \\
\text { reasonability of initiating an } \\
\text { investigation. }\end{array}$ \\
\hline $\begin{array}{l}\text { PE: Closed, } \\
\text { decision not to } \\
\text { proceed }\end{array}$ & $\begin{array}{l}\text { Palestine } \\
\text { Republic of Korea } \\
\text { Venezuela }\end{array}$ & \\
\hline \multicolumn{3}{|c|}{ Source: ICC, PRELIMINARY EXAMINATIONS } \\
\hline
\end{tabular}

${ }^{36}$ This examination was closed in 2006, but reopened later this year (OTP, 2014a). Since it was opened after the latest report on PEP, issued in 2013, it is being placed under Phase 1, but this is the author's assessment. The same applies on the classification of Ukraine. 


\subsection{Situations under Preliminary Examination}

There are currently ten preliminary examinations, as can be seen in the chart above, divided into the different phases of PEP filtering. All eight situations presently under investigation in the Court also went through this process before they were completed and the OTP decided to open them. Other 3 situations have closed, due to a decision not to proceed. Iraq was closed in 2006, but re-opened earlier this year and is thus counted as being under PEP.

In the specific situation of Colombia, the case has been under PEP since June 2004 and the OTP has received 146 related Article 15 communications (OTP, 2013, p. 29). Colombia and its nationals have been under Rome Statute jurisdiction since 1 November 2001, but jurisdiction over war crimes has been effective only since 1 November 2009, due to a national declaration pursuant to Article 124 of the Statute. The Prosecutor has requested both further information on alleged crimes and status of national proceedings to the Government of Colombia and has published an Interim Report on the Situation in November 2012.

In this report, five areas of continuing focus were identified: i) follow-up on the Legal Framework for Peace (LFP) and other legislative developments; ii) proceedings related to the promotion and expansion of paramilitary groups; iii) proceedings related to forced displacement; iv) proceedings related to sexual crimes; and v) false positive cases $^{37}$ (OTP, 2013, p. 29). Since the publication of this Interim Report, further information has been received concerning national proceedings (OTP, 2013, p. 31) and the OTP is monitoring the implementation of the LFP, in sync with a positive approach to complementarity (p.32); seeking clarification on the ongoing Military Justice Reform (p. 32-34); and identifying gaps or shortfalls of judicial activity (p. 34-35).

\footnotetext{
${ }^{37}$ Allegations that state actors, mainly members of Colombian army, have "deliberately killed thousands of civilians to bolster success rates in the context of the internal armed conflict and to obtain monetary profit from the State's funds.
} 
The OTP has sent missions to Bogotá, where it met with senior officials from the three branches of government, national civil society, international nongovernmental agencies and international organizations, as well as participated in public events and international conferences on international criminal law and international humanitarian (OTP, 2013, 35-36). Furthermore, the Office has shared its views with Colombian authorities in relation to compatibility between LFP and the Rome Statute, after various parties cited the OTP's strategy as a prosecutorial model for national jurisdictions and Fatou Bensouda has met with Colombian President Juan Manuel Santos to discuss the establishment of peace in the highest standards of justice in the country (OTP, 2013, p.36). The Office has decided to continue to analyze proceedings and consult closely with Colombian authorities in order to ensure that genuine domestic proceedings take place (OTP, 2013, p.37).

The OTP has completed 8 PEPs, opening the following investigations: Central African Republic (2002-2003), Côte d'Ivoire, Darfur (Sudan), Democratic Republic of Congo (DRC), Kenya, Libya, Mali and Uganda. Proceedings on individual cases are most advanced in the DRC situation, the first one to be open at the ICC (ICC, 2004). Other than Mali, there is only public material describing PEP for the cases of Libya and Côte d'Ivoire (OTP, 2011). But, similar to the Malian case, others can also be characterized as situations where no challenges to admissibility on complementarity grounds were found, mainly due to incapacity rather than unwillingness to open genuine domestic procedures. Only those situations open through UNSC referral, Darfur and Libya, prove to be an exception to this characteristic, where the referral of the situation on the ground and the authority of the international body referring the situation prove to override challenges to admissibility, due to findings of unwillingness to undertake domestic procedures.

Since it first started considering situations under PEP, the OTP has closed 3 situations, under different claims of inadequacy: Venezuela (Ocampo, 2006b), Palestine (OTP, 2012b) and the Republic of Korea (OTP, 2014b). Specific responses to each case, with detailed account on the argument behind the rejection was written and distributed to all those who sent in communications 
deemed relevant during PEP (Ocampo 2006a; Ocampo, 2006b). Only Palestine features in Preliminary Examination Reports (OTP, 2012a; OTP, 2013).

After undergoing PEP, the OTP finally submits a plea to the Preliminary Trial Chamber assembled for the case, which will appreciate the argument of the Prosecutor and decide whether there is reasonable basis to open an investigation. If the OTP receives a positive answer, it then proceeds to actual investigation, for which a vast number of set procedures apply. Stegmiller (2011, p. 56) proposes a 4-stage division of the whole process of ICC proceedings after the approval of the PTC: investigation, judgment, appeal and revision and sentence execution.

All communications and evidence received and collected by the ICC are digitized upon arrival and entered into the aforementioned electronic cataloguing systems according to the status of the case or situation to which they belong. This means there is a constant flux of information inside the court, although its materiality is not extensively felt due to its paperless character.

Despite this high flux of virtual information, there are people dealing with material items at the entry point of the system. Both interns at IEU and investigators at the Investigation Division are those who are at the forefront of collecting material. Investigators ultimately bring evidence into the IEU office, so that it can be processed and made available throughout the whole OTP, registered to the appropriate situation and case, if one exists. I have already overviewed the how communications under Article 15 and other pieces of information received when a preliminary examination is being conducted are handled.

\section{Chart 2: ICC Process}




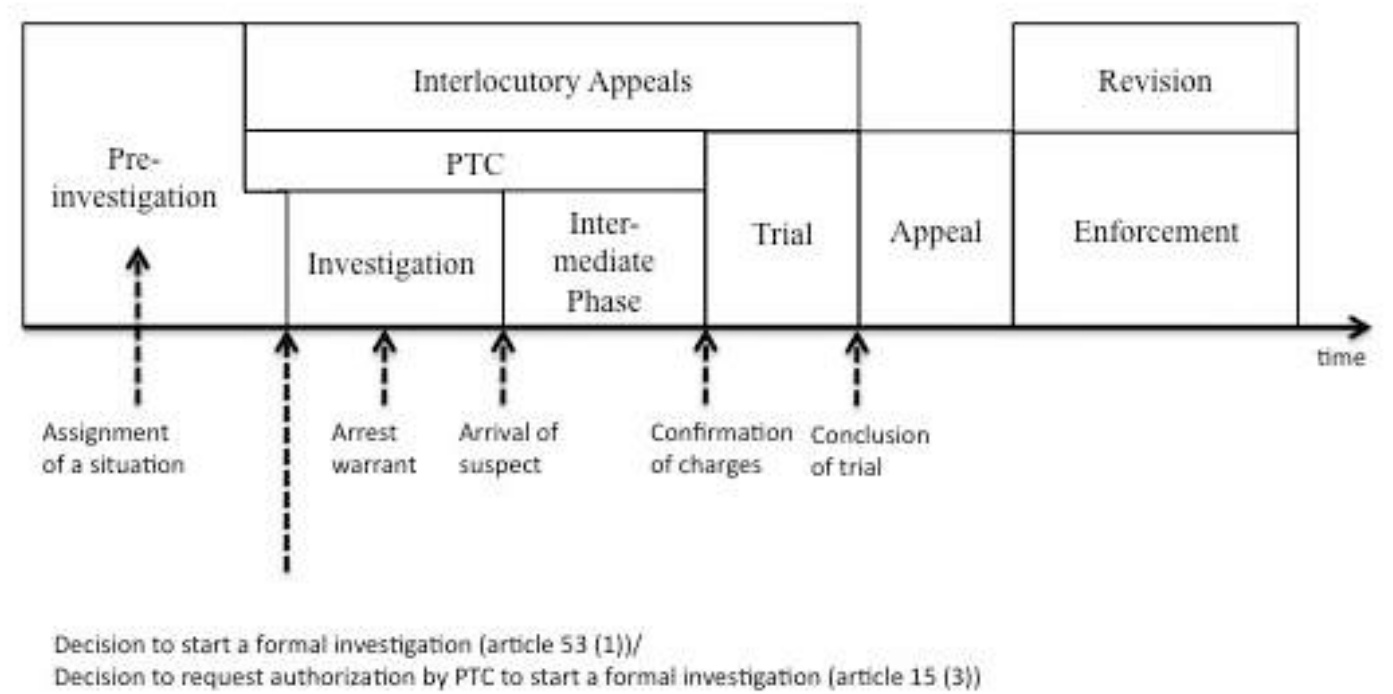

Source: STEGMILLER, Ignaz. The pre-investigation stage of the ICC: criteria for situation selection. Berlin: Duncker \& Humnblot GmbH, 2011. p. 66

\subsection{The relevance of Preliminary Examination}

PEP has risen in importance at the ICC in recent years. This can be clearly seen in the online homepage of the Court, which now features a map where all situations under PEP are highlighted, along with current investigations (see Image 4).

As can be seen in images 1 and 2 in the next page, there was no map in the Court's homepage during my time at the Court. The ICC was facing - and still is being challenged by - many accusations of being a court where black African leaders of powerless countries are being tried. This highly damages the reputation of the ICC, that, in line with Koskenniemi's proposal for a culture of formalism in IL, wishes itself a universal enterprise. The accusation sits uncomfortably with this perceived self image.

Image 1: Homepage of the ICC, circa June 2012. 


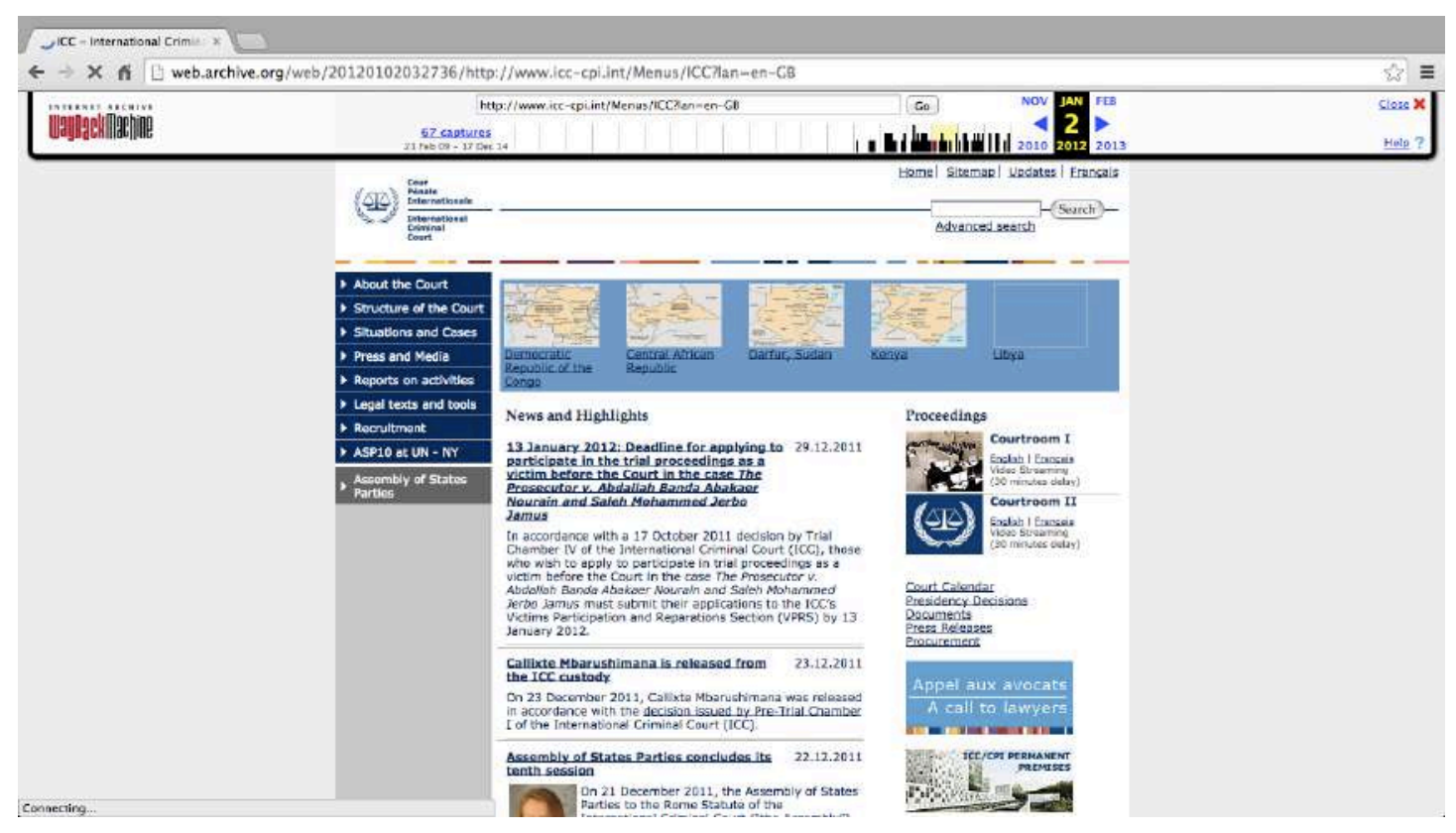

Source: archive.org.

\section{Image 2: Communications, Referrals and Preliminary Examinations page in} old ICC website.

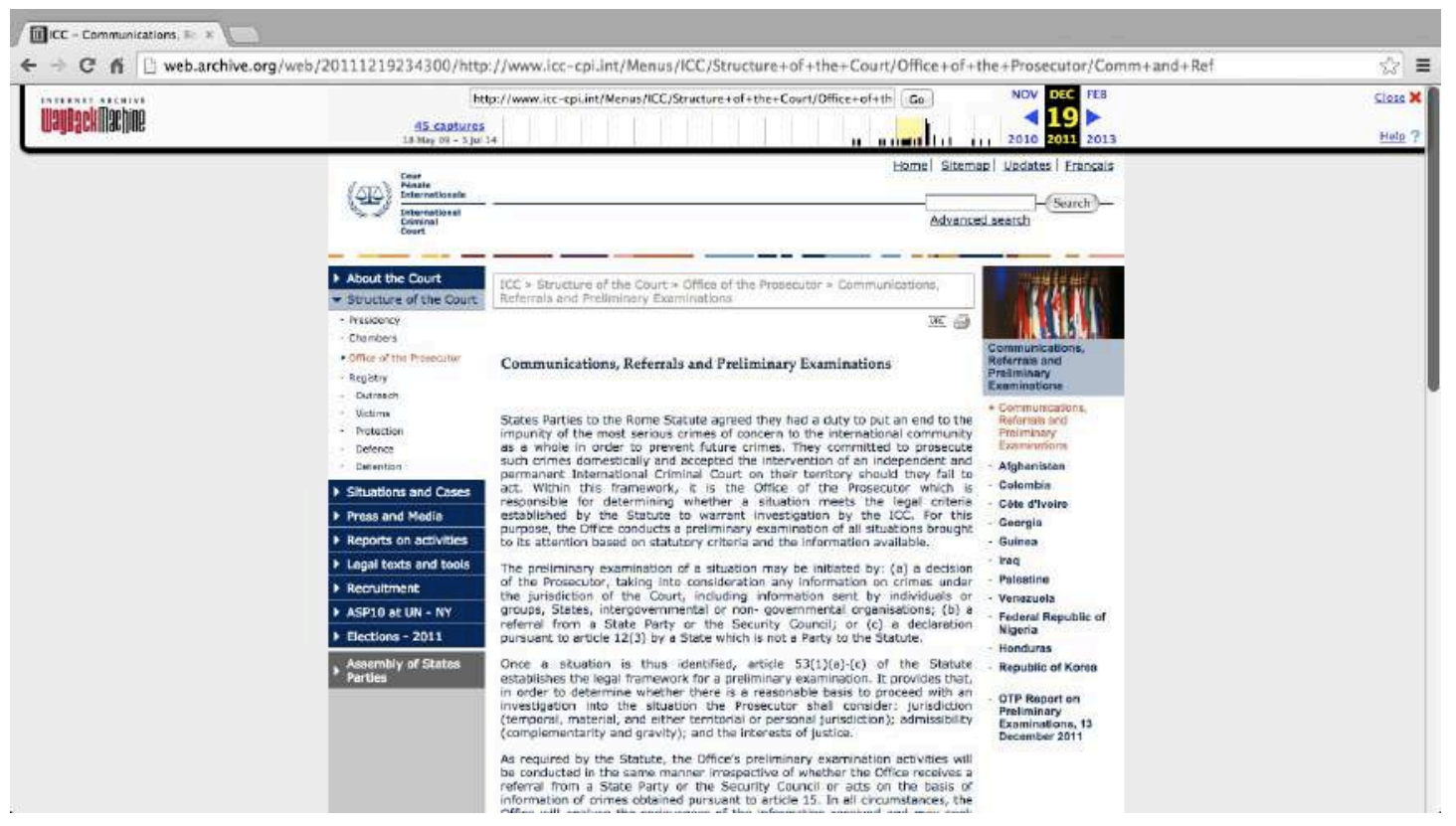

Source: archive.org.

The appointment of prosecutors from the Global South - first an Argentine, Moreno Ocampo, and now a Gambian, Fatou Bensouda - as well as 
the observance of geographical representation in staffing and appointments to elected positions are all testimony to this promise of universality, or at least an assurance of its global nature. On the African question, as early as 2012, Bensouda has already argued that the key to dissipate this notion is to see that the ICC and the OTP are involved in cases beyond the countries where investigations are currently underway, pointing to PEP as an important part of what the Court does (Bensouda, 2012).

When PEP is brought to the forefront, occupying alongside open investigations a space that used to be exclusively the latter's, one can argue that this is an attempt to render the procedures of the OTP and the ICC through it more transparent. In comparing the map in Image 3, which was the one featured in the old website, to that in Image 4, we can also perceive an important difference: while the first one also highlights State Parties, this information is not contained in the second map. The designers of this new homepage for the website decided not to include this information on the lack of actual universality of the Rome Statute in their characterization of the Court's involvement in the world, a piece of information that used to be portrayed in earlier versions, even if not front and center. Information on complementarity was rather hidden under other tabs, as can be seen in Image 2 .

\section{Image 3: Map of ICC involvement globally}

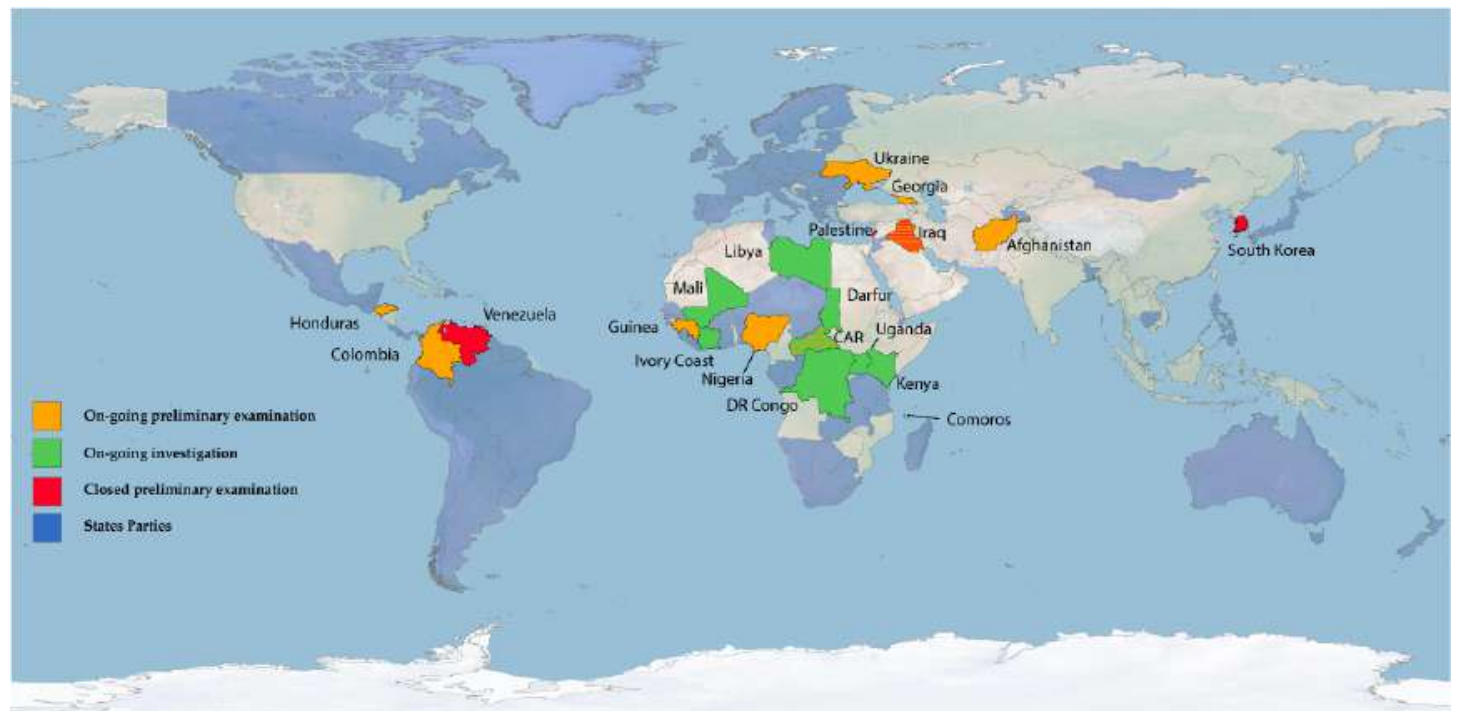

Source: archive.org. 
Thus, one can also perceive a greater incentive to maintain situations under preliminary examination, like the OTP is doing in Colombia, postponing final decisions and adopting alternative strategies for advancing justice, since this would serve to indicate on the map a continuous wider involvement in all regions of the world. International Law and its procedures become, in this manner, a shield for what is being done elsewhere. Preliminary examinations have become not only a matter of actually exercising the OTP's prerogative of keeping itself informed about activities in State Parties to the Rome Statute, but also sees itself turned into a manifestation of the universality of the Court's activities. This dual purpose helps explains the prolongation of preliminary examinations and the development of the positive approach, as well as the continuous non-decision of the OTP in cases under analysis of admissibility.

The maintenance of a shadow in one part of the world is being used as proof of an argument of transparency and universality. The fact that this is displayed on the first page of the ICC's website, where preliminary examinations used to figure in a page inside another directory on the OTP (see Image 2) shows that this was not done without thought.

\section{Image 4: New homepage of ICC website}

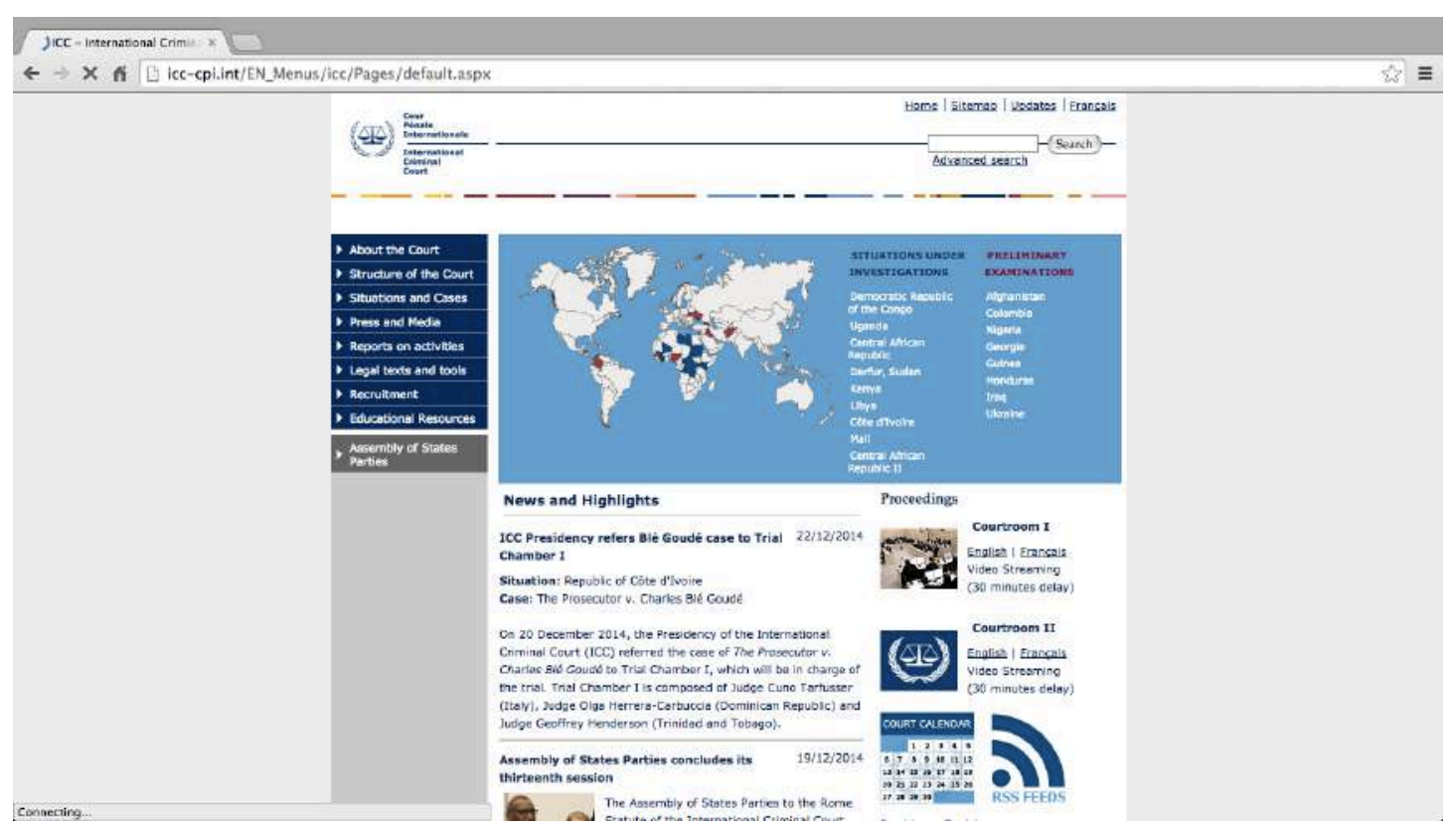

Source: icc-cpi.int/EN 
In this chapter I have tried to advance two main notions. First, that many of the procedures of the ICC are not clear nor were set in stone when the Court was first opened in 2002. Rather, they are developed in the daily workings of the staff and are continuously being changed in minor or major ways. Some are being invented as the court starts maturing and the need for a new procedure is felt. Positive Complementarity was only explained in an OTP policy paper and dismissal letters were only qualified after an intern took the time to write templates. In this sense, it is also possible to see fluctuation in the importance that procedures gain or loose vis à vis other ones inside the OTP and the Court itself. Some procedures can gain higher importance in specific moments, like what happened with the PEP. The placing of such procedure on the ICC website's homepage figures as a material and aesthetic manifestation of these shifting practices within the court.

The use of a map to represent the ICC's worldwide presence, particularly when taken alongside accusations that it is an "African court" appears as a telltale sign of its wish to establish a global/universal presence. In this, it is coherent with what Koskenniemi has proposed as the telos of international law and institutions that enact it. This is my second point for the chapter. In the next chapter, more focused on the ICC's involvement in Colombia, I will try to sketch out how this wish for universality ends up creating shadows. Then I explore traces of how this shadow haunts locally, in its wish to produce universal transparency. The fact that these shadows creep beyond judicial proceedings and thus go under the radar of legal analysis is symptomatic of the reproduction of epistemic violence when one embarks on a counter-disciplinary journey. It becomes important to, in this sense, adopt a more open methodology, in order to be able to pick up the traces of what is kept in the shadows. 


\section{Colombia and the International Criminal Court}

The ICC's involvement in Colombia is, as was explored earlier, encapsulated in the terms of PEP and later characterized by the OTP as consisting in a positive approach to the Rome Statute's principle of complementarity. This would explain the non-decision behind this permanence of the situation under PEP. Attempts to state clearly whatever involvement the OTP has on the ground have been developed now in a group of documents - one Interim Report specifically on Colombia and other reports on all situations under PEP. Despite being active now for more than ten years, the first ICC publications on Colombia were released only in the end of 2012.

\section{Image 5: Occurance of International Criminal Court in newspapers}

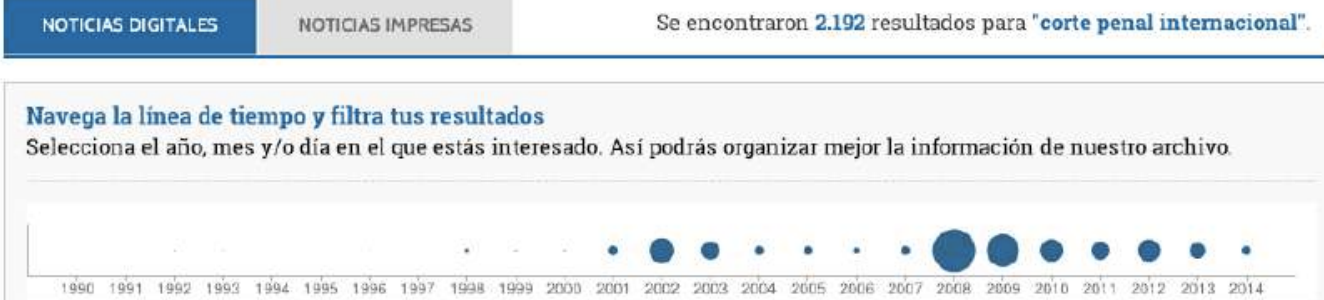

El Tiempo, Colombian newspaper of national scope. Number of times "Corte Penal Internacional," the name of the ICC in Spanish, appears in the past years. The peak is 2008, with 356 occurrences. Source: http://www.eltiempo.com/archivo/buscar?q=\%22corte+penal+internacional $\% 22$

This delay created lots of indeterminacy surrounding what would be done, both inside and outside the OTP. The previous chapter has tried to build on this, showing how fluctuating practices and importance accorded to procedures impact the expectation around preliminary examinations. Since the final decision to present a plea to open an investigation lies beyond the IEU, for example, my superiors at the office were led to believe that an investigation might actually be open, that it was only a matter of time, and I ended up ultimately involved in the picking and choosing of colors for tags of a would-be Colombian situation on a certain afternoon in the middle of 2012. As we can see in image 5, the ICC has not left newspapers in Colombia, with all-time highs being hit in 2008-onwards. 
The non-decision of the OTP impacted others a lot more than it did my own routine. I will explore this in this chapter in three steps.

First, I will analyze documents produced by civil society in both their aesthetic presentation and the language that they use to refer to the court. They will be compared to documents the court itself has issued. Then, I will analyze political cartoons, a popular culture vehicle that can serve as a thermometer for seeing how a certain institution is currently being portrayed in a given setting. These will be interpreted as actual representations of the ICC and the international legal enterprise. Finally, I will explore the possibility of using aesthetics and other media to re-present what has happened in Colombia and how this fares alongside legal attempts to do so.

\subsection{Producing documents}

Courts and tribunals are bureaucratic institutions. Like most bureaucracies, their work centers on the production and circulation of documents. We normally associate them with the image of a piece of paper, but recently electronic documents started being used in larger numbers. As I have stated earlier, the ICC aims to be a paperless court and all documentation, evidence and communications are circulated in electronic systems, using computer filing programs that sort documents according to the metadata staff enters into each file. The complex system of assembling and disassembling files, creating new documents and rearranging orders was part of my daily routine at the court.

The ICC also works on a tight schedule of embargoing information, that is kept secret due to its sensitiveness, and sharing what has been found. The protection of evidence and witnesses is a common practice in law. Yet, all evidence that was used in legal arguments that sustains prosecution has to be presented to the defense and to the judge, in order for the former to be able to defend the individual being accused and the latter to issue a decision. During my time at the Court, the first sentence ever had just been issued, on the Lubanga case, so no procedure on what to do with this material after the proceedings were over was still in place. The plans for moving into the new permanent headquarters in another part of town were also bringing to the fore questions 
about disposing all the material documents perceived as unnecessary - article 15 communications that had lead to no PEP's and other things.

Yet, as an important part of achieving justice, knowing the truth - and having access to these materials interpreted by the OTP as being evidence - is particularly important as a form of providing reparation to victims (HRC, ISC \& ISA, 2012, p. 4). This is directly related to the notion of having the violence that occurred come back to haunt society (Gordon, 2008) - and contributes to the feeling of shadow. That which is known and present, the acknowledged loss does not haunt, for it is not absent. The effects of time suspension no longer take place, the constant fear of the return of a past, which ultimately turns the past into the present, goes away and it is possible to move on with complicated life. Transparency is also a part of the culture of formalism, as proposed by Koskenniemi (2005).

Celerity in making information public is far from being the specialty of the ICC. As already mentioned, it took many years for the first publication on the preliminary examination in Colombia to be publicly released. This adds to the idea of the shadow.

In this vacuum created by the OTP's silence on its examination and handling of so-called evidence, material collected on the ground or turned voluntarily over to the Office, other actors took the fore, for "when an unspeakable or uncertain history, both personal and collective, takes the form of a 'ghost,' it searches for bodies through which to speak" (Cho, 2008, p. 46). So, a lot of production by civil society was published and circulated online, be it in the form of academic papers, reports on events, or Non-Governmental Organization reports leaning towards a more activist side.

When searching Scopus, a big academic database, for publications on Colombia and the ICC, a lot of material is churned up (see Annex 1). Most of these are papers and production spiked somewhere around 2010. Kai Ambos, a scholar that is very enthusiastic about the theme, leads the chart of authors who have most published on the matter.

Ambos published a book specifically on the matter of the ICC and Colombia, and hosted as well a series of events at the ICC and elsewhere on the 
theme. He also took part in the expert conference that resulted in the report "In the Shadow of the ICC" (HRC, ISC, ISA, 2010), to which I will return to later. In his book, "The Colombian Peace Process and the Principle of Complementarity of the International Criminal Court" Ambos analyzes both the application of the LFP in Colombia and the criteria of admissibility of a situation according to the Rome Statute (2010). He finds that while there are many shortcomings in the procedure of the LFP, an end to impunity is still being pursued in Colombia but problems "must be resolved as soon as possible to avoid an intervention of the ICC" (2010, p. 89-90).

\section{Image 6: Kai Ambos}

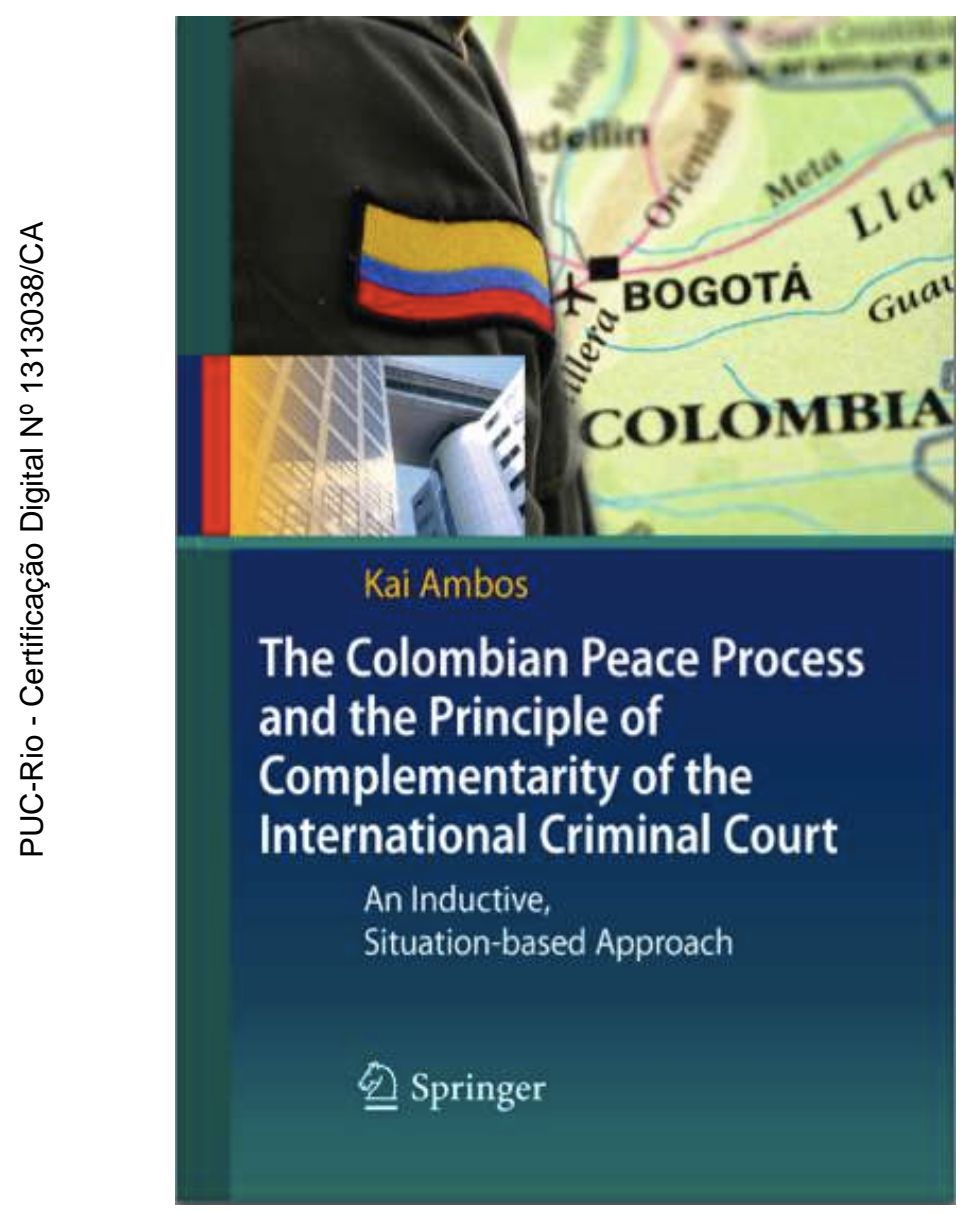

Source: Ambos, 2010.

The book centers mainly on institutional aspects and possibilities involved in the case. This is betrayed not only by the text but also by the cover of the actual book. In conducting his own preliminary examination of the 
implementation of LFP and the possibility of Colombia being admitted as a situation by the OTP, the book brings on its jacket a series of symbols: a map, centered on Colombia's capital city, Bogotá; an military uniform with the patch of the national flag; and a photo of the ICC building in Den Haag. The cover, as a relevant part of the book as a specific kind of document, reveals precisely what will be discussed inside.

When comparing to other documents produced, we see a radical change. The next two reports I will focus on are radically different aesthetically, despite aiming at discussing the same theme and, arguably, impacting the same people. These three documents were not chosen by chance. They were all made available to me during my time at the ICC, be it through tips by colleagues or by way of the well-furnished library. One of the reports, on the false positives, was even formally presented at the ICC. I will analyze this one next.

The report on false positives was launched by FIDH, an international human-rights NGO. It was launched, like Ambos' book, before the official publication of any documents on the preliminary examination in Colombia. Yet, other OTP documents relating to preliminary examinations that were ultimately turned into investigations upon PTC approval were available. When reading the FIDH document, the structure of the text - that argues for an ICC investigation into the false positives scandal, considered a crime against humanity (2010) - is strikingly similar to the structure of OTP legal argumentation, a mimic of sorts. The fact that it was launched at the ICC furthers the point that this report serves not only to inform, but was conceived in such a manner as to also advocate for a cause - the recognition of a crime against humanity and of the necessity of due process at international level.

The report constructs its argument by referring to the case of the false positives. As the argument goes, Colombian national procedures have not led to justice on the matter and impunity abounds - being both the background and the result of the scandalous practice of extrajudicial execution. In this situation, the report then becomes a mediation between what has happened and the goals its authors intend to achieve, precisely because the report takes the individual situations where young men were killed and then accounted for by army-men as rebels and links this to a bigger process, an institution, the ICC, as a particular 
manifestation of the institution of IL. It is parallel to how Gordon understands haunting:

Rather, it is a matter of exploring here the particular mediation that is haunting. As a concept, mediation describes the process that links an institution and an individual, a social structure and a subject, and history and a biography. In haunting, organized forces and systemic structures that appear removed from us make their impact felt in everyday life in a way that confounds our analytic separations and confounds the social separations themselves. Paying attention to the disjuncture between identifying a social structure (or declaring its determinate existence) and its articulation in everyday life and thought, I have hoped that working at understanding these gaps, the kinds of visions they produce, and the afflictions they harbor would enable us not to eradicate the gap - it is inevitable - but to fill in the content differently. Could it be that analyzing hauntings might lead to a more complex understanding of the generative structures and moving parts of historically embedded social formations in a way that avoids the twin pitfalls of subjectivism and positivism? Perhaps. If so, the result will not be a more tidy world, but one that might be less damaging. (Gordon, 2008, p.19)

The FIDH report talks about haunting - the unresolved violent crimes committed against innocents in Colombia. Yet, it does so in a manner completely different from that which is found in Ambos' book (2010). Even though it employs legal structure - an institutional language - it is still very centered on the violence that motivated its conceptions and the people who have suffered and are still suffering from physical violence per se and from the pain of loss.

This becomes clear when one compares the cover of the report to that of the book (see image 7). While the book focuses on institutions and bureaucratic processes and their implementation, the cover of the FIDH report, in overwhelming red - a clear allusion to the blood that is cited in its title - brings a single photo of a protest. When compared to ICC documents as well, it differentiates itself as a document that brings on its cover the very people it aims at impacting - who will benefit from the deliverance of justice. The photo also serves to make a claim, like the protesters it brings on its cover. Yet, there is no portrayal of the actual people who suffered physical violence, only of those who are haunted by their absence. Like other reports of this nature, put together by NGOs, there is also a presentation of FIDH and more information on its activities. This is something that is missing from other documents surveyed here.

This report particularly stands out for it incurs in two instances of the shadow that we are trying to state. In the first place, it is directed at the ICC, in an attempt to attain some sort of positioning from the OTP regarding the situation in Colombia. It, in a sense, tries to dispel the shadow and end the haunt of this 
ethereal legal presence. But it is also the product of a haunt - impunity over the scandal of false positives, whose stories, past and future, as part of the crime, were erased. In this sense, the report itself becomes a ghost story, one on "permissions and prohibitions, presence and absence, about apparitions and hysterical blindness"(Gordon, 2008, p. 17). As Gordon writes:

To write stories concerning exclusions and invisibilities is to write ghost stories. To write ghost stories implies that ghosts are real, that is to say, that they produce material effects. To impute a kind of objectivity to ghosts implies that, from certain stand- points, the dialectics of visibility and invisibility involve a constant negotiation between what can be seen and what is in the shadows. (Gordon, 2008, p. 17)

It can be argued that the report attempts to engage with the critical potential of international legal practice, by presenting these ghost stories to the OTP in hopes that it will take action. The OTP's prolonged non-decision was the only answer.

\section{Image 7: The FIDH's Mock-ICC-document}
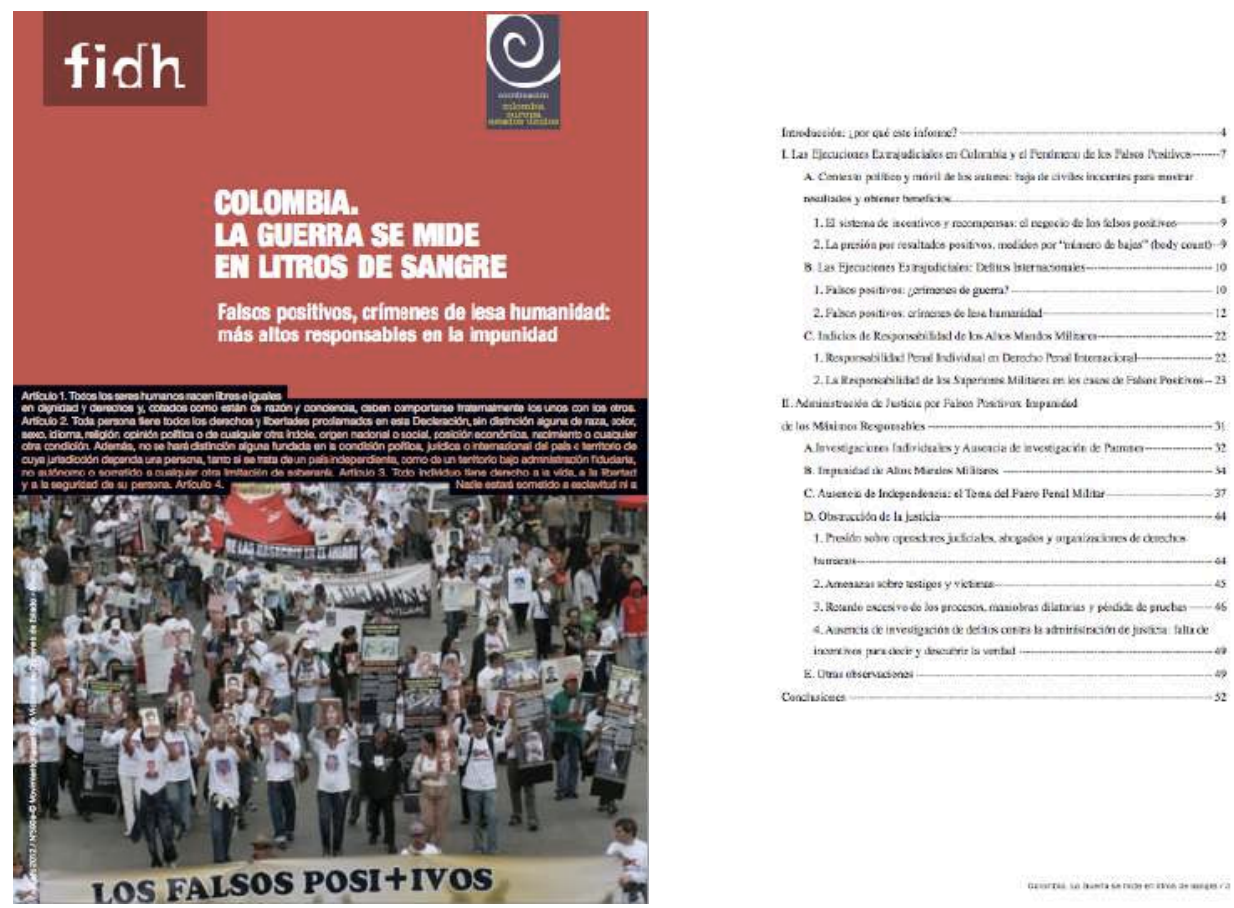

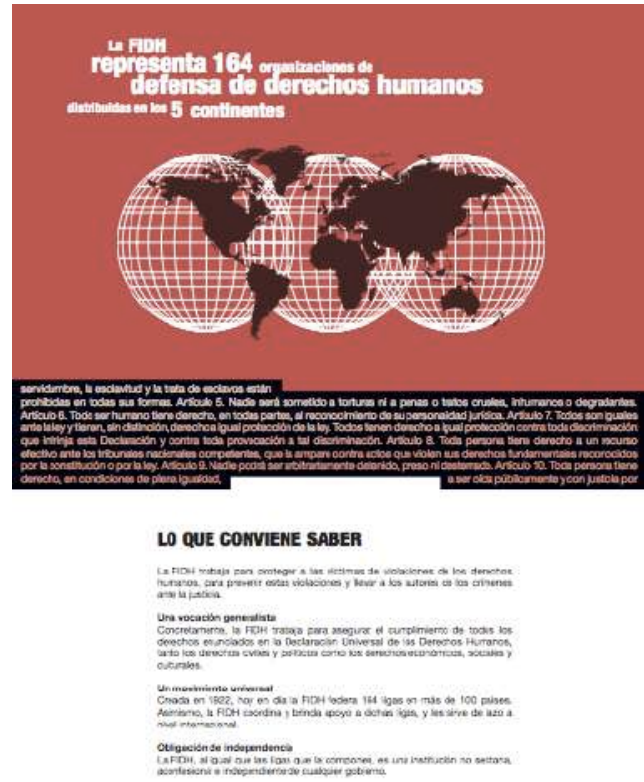

fich
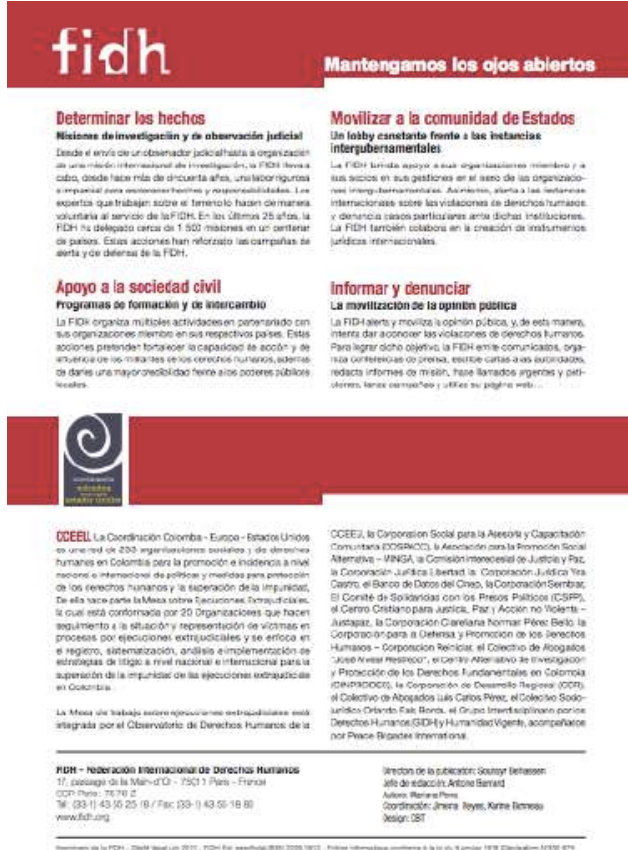

Source: FIDH, 2012.

The last document I wish to explore in this chapter is the one that originally brought the image of the shadow to my attention. In the report about a conference that took place in 2011 at the University of London, we find yet another aesthetics. The report itself is long and brings a series of summaries of the points discussed, as well as recommendations. It is a more academic enterprise, when compared to the FIDH publication (2012). Also, another important difference is the specificity of the public this report aims to impact. While FIDH wanted to be read by OTP personnel and to impact the outcome of PEP on the Colombian case, this report is of a more informative nature. It stands of the notion of reporting facts that occurred at the Conference - and creates, in an analogy to Gordon's assessment of sociological works, a "fiction of the real" (2008, p. 11).

Differing largely from the FIDH report, this one, launched by the HRC, ISC and ISA does not go so much into the material matters of the violence that occurred in Colombia, of the crimes that could possibly come under ICC scrutiny, but focuses on the possible proceedings and the existence of said "shadow" of the Court - the impact it has generated on the ground. In this it is a lot closer to Ambos' proposal than to that of the FIDH. 
Aesthetically, it is also a lot more similar to OTP documents (see image 9) than to book Ambos' book and FIDH's report. The lack of images and pictures on the cover, overly present in the other two documents, differentiates the whole document from other, more public impact-minded ones. The design, with the placing of appropriate logos, is also more in harmony with how the ICC lays out their documents. The ICC documents are also more of an internal nature, despite their posterior release to the wider public. Their similarities are not mere coincidences. There is a lot of blank space in the title pages - as is the case with the cover of this thesis. Different from academic papers, who have no proper cover, except for that of the journal, this report is not "naked," but it is neither dressed to impress. The only people cited in this report are academics and other experts who took part in the conference.

\section{Image 8: The Shadow Conference Report}

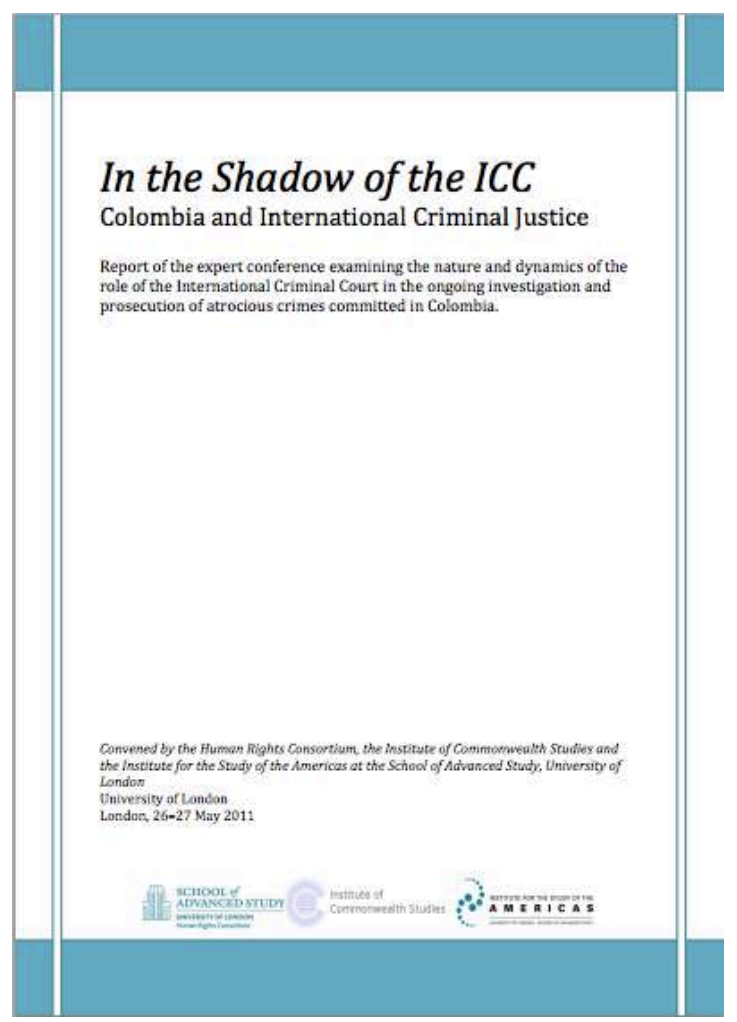

Source: ICS, SAS, ISA, 2012. 
Image 9: ICC Documents

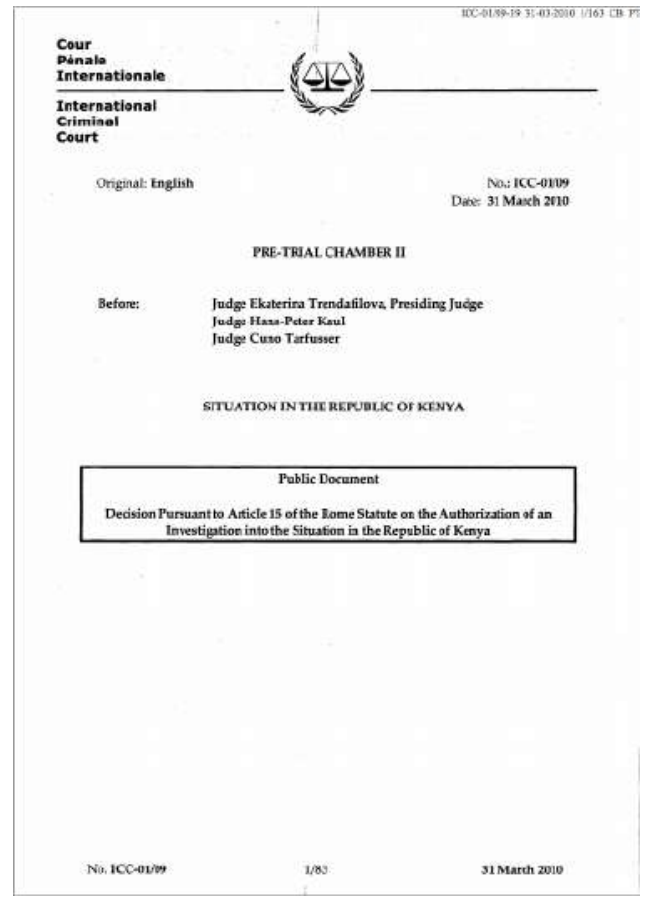

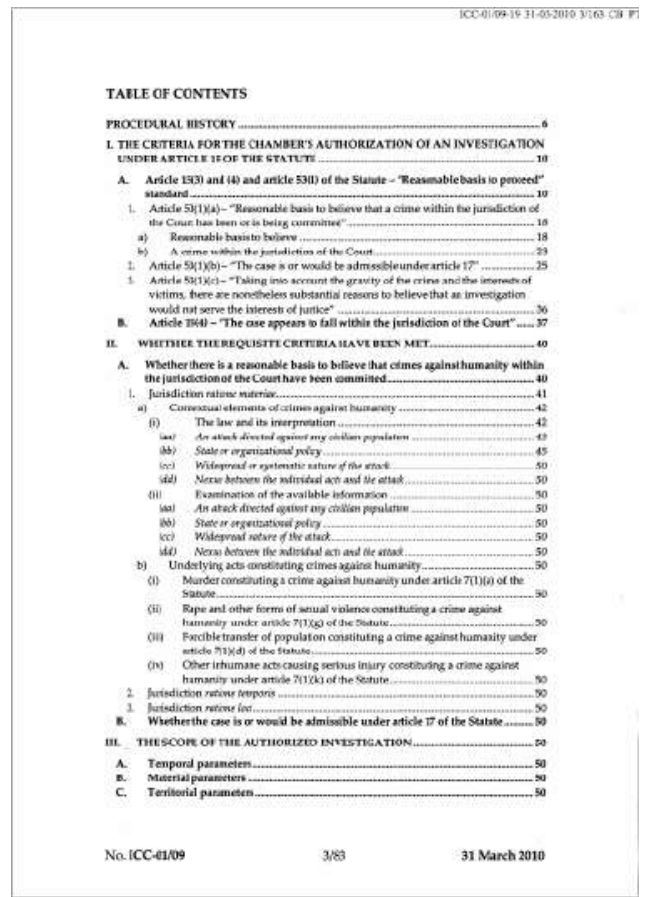

Source: ICC. Pre Trial Chamber II. Decision on sitution of the Situation of Kenya, 2010.

Comparing these three documents, there are more limits than possibilities to advance. They were all drafted before any official position by the OTP regarding its preliminary examination on Colombia came to be documented. They all employ their own particular methods to develop on the theme, with different motivations in mind. But they all have in common this trace: they were prompted into existence - their authors felt the need to author them - because of the shadow of the ICC, the lack of decision regarding the situation in Colombia.

They are all, in the sense, a product of the haunting through which Colombia goes through. This haunting has many facets and traces - some of them are related to the violence crimes committed throughout the country, but others derive from a lack of institutional response and clarity on its actions. A failure to achieve the outcome of accountability and transparency in its legal proceedings for the first years of its involvement has led the ICC to become a shadow, a specter and a haunt itself. I argue that this reproduces violence in epistemic ways - the very way that lawyers and others at the ICC and surrounding it wish to portray events that happened on the ground. The analysis of the cover of documents undergone here is telling. They are clearly portraying the institutional 
purposes for which they were drafted and tell stories in a fashion that suit this purpose, fitting the frame of fiction into the reality they wish to make known to their reader. The person who suffers violence - the subaltern - is not portrayed as a layered human being, complex in his or her existence. He or she fits only into the category of a victim of the crime being described, in a passive position in the whole story being told by others.

In the next section of this chapter I will search for traces of this shadow in political cartoons, aware that the ICC's involvement has created silencing of its own. The last section, on the movie Manos Sucias, offers a counterpoint by exploring a portrayal of haunted existence in Colombia, diving head on into the traces of the physical violence of complicated life in the country. Free from the cage of documents and their obligation to clarity and the storing and transmitting of certain information, the film is freer to pursue this task.

\subsection{Images of the Court and Justice}

Comedy and attempts at entertainment betray a lot of what images populate common sense regarding certain social groups. In a now infamous episode, David Letterman, a famous American television personality, made a joke that almost became an international incident. Commenting on the Miss Universe Competition, he said: "You know what has really gotten impressive? The talent competition. For example, Miss Colombia, she swallowed 50 balloons full of heroin." This was an unsayable, a reference to drug-smuggling, that left the then Miss Colombia Andre Noceti outraged, stating that she didn't "know why we have this stereotype" (Ruiz \& Hutchinson, 2001). After a declaration from the Colombian Consul General, Letterman offered a mea culpa and Noceti was invited for an interview on his show.

This incident shows the power of how images, even when conjured verbally in jokes, can bring up powerful reactions. This is even clearer when the humorous effect is portrayed through drawings, as is the case with political cartoons. In an analysis on the power behind these images - that are often simple but evoke immense emotion - Navasky tries to explore theories behind the 
incendiary quality of this art form (2013). He has three hunches, based respectively on the content, the image and the combined two, which he calls the stimulus (Navasky, 2013). Though not very academic in nature, his book dips into his experience as an editor for widely circulating newspapers and the political cartoons that wreaked havoc when they were released, as controversial as Letterman's joke about Miss Colombia. Here I will take Navasky's third theory - that it is both the content and the image, the synergy of these two - that make this such an unique aesthetic manifestation of political critique.

In the Colombia, there are many artists doing this type of cartooning for many different types of media. Of my research, I have separated five images that were relevant to the themes of justice and the International Criminal Court in Colombian political cartoons. The images they develop are useful for establishing how popular imagination is portraying the deliverance of justice nationally and also how the layman views the ICC. I was unable to date exactly all the cartoons, since this information was not available in their sources but, different than the case of documents, date is not as much of importance. Their availability online was considered a more important criterion.

These images, taken together with the notion that the ICC projects a shadow over the country, offer us traces as to how this shadow materializes itself in the emergence of its ethereal presence. Temporality and spatiality are of utmost importance and serve as keys for analyzing these traces.

The cartoonist Gova published recently two important portrayals of justice in the Colombian newspaper El Espectador. These pieces center on the classical image of justice as a woman, Lady Justice, or the Greek goddess Themis, who holds a sword in her right hand and balance scales in the left. She is furthermore blindfolded, an allusion to the idea that justice should not see on whom it is bestowing its sentence, so that not distinction is made between privileged and unprivileged - or, in direct allusion to the ICC, from which continent the indicted comes from. This representation is widely used in the western world and tends to be celebrated in statutes and images, placed in front or inside palaces of justice and rooms where justice is enacted or invoked as an overarching goal. 


\section{Image 10: Wounded justice}
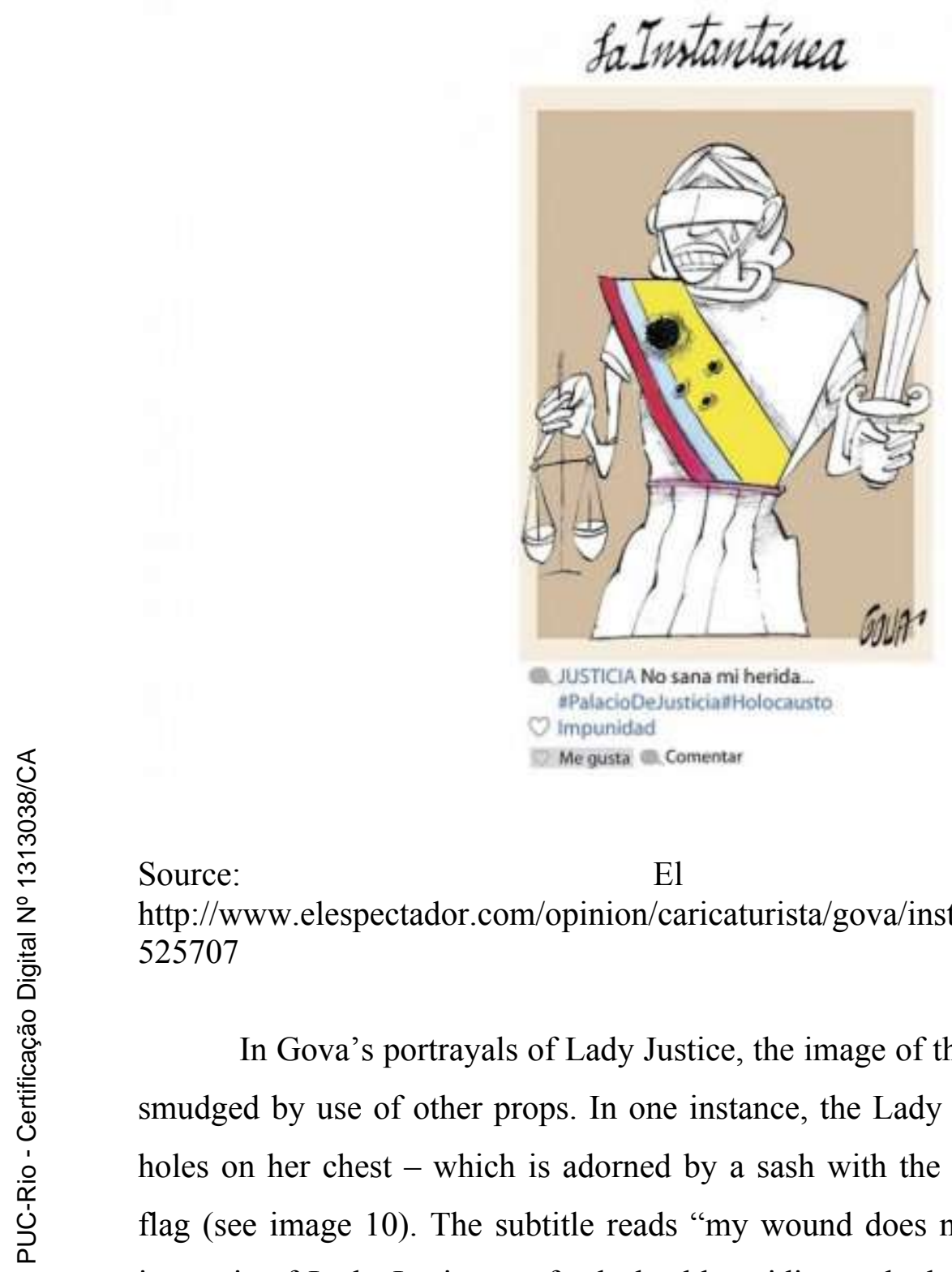

Source:

El

Espectador http://www.elespectador.com/opinion/caricaturista/gova/instantanea-imagen525707

In Gova's portrayals of Lady Justice, the image of the goddess is severely smudged by use of other props. In one instance, the Lady is wounded by bullet holes on her chest - which is adorned by a sash with the colors of Colombia's flag (see image 10). The subtitle reads "my wound does not heal." The second image is of Lady Justice, perfectly healthy, riding a donkey, which has stalled. The subtitle is an exclamation used traditionally in order to get the animal to move forward (see image 11). The donkey is known popularly both for being a slow and dumb animal.

These are for from positive portrayals of justice being delivered nationally. The first image is very clear: judicial proceedings are still being marked by violence. The second one can be interpreted as portraying the delays in delivering justice to those that have been wronged during Colombia's recent history, despite mechanisms such as the LFP being put into place. Another 
important aspect of the images is that they allude to Instagram's ${ }^{38}$ layout. They are both portrayed as photos taken of Lady Justice and posted by herself to her own account. In the first image, an account named Impunity has liked the photograph. In the second one, Delinquency gave a like.

\section{Image 11: Slow justice}

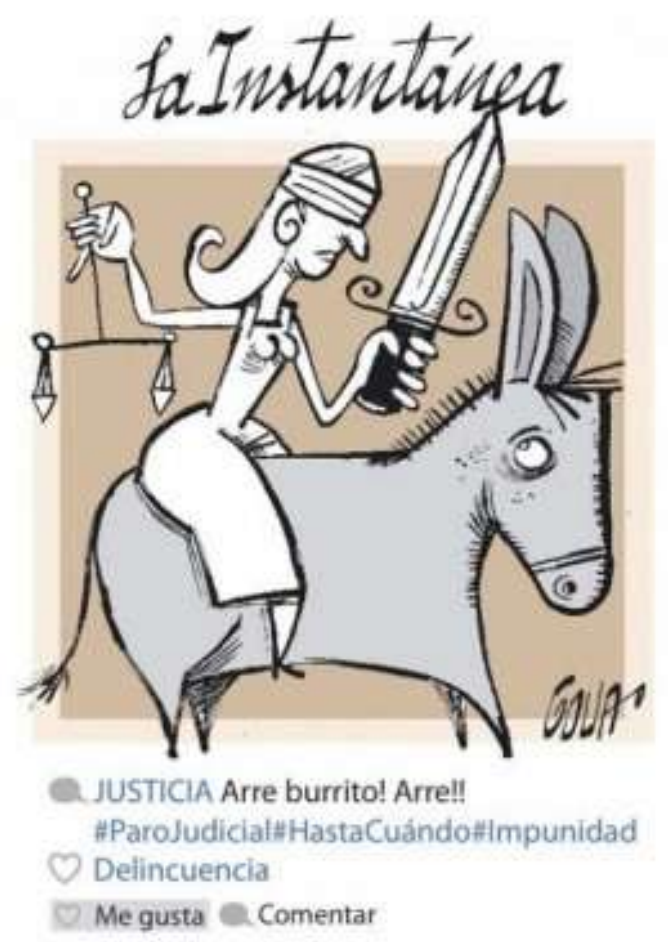

Source: El Espectador http://www.elespectador.com/opinion/caricaturista/gova/instantanea-imagen524224

Portrayals of the ICC do not fare any better. I have found portrayals of the ICC as a cage, as a part of the subtitle and as Moreno Ocampo - the prosecutor during the time when Uribe was in office - himself.

Portraying the ICC as a cage in the first cartoon is not the entire context (see Image 12). Then-president Uribe is seen walking towards the embodiment of the Court, stating that he has a claim to make, probably against other actors in the Colombian civil war. Taped to the side of the ICC-Cage is a poster that reads

\footnotetext{
${ }^{38}$ Popular social media platform used to share photographs and follow other users. The main form of interaction is through liking and commenting on photos.
} 
something along the lines of "It will be our pleasure to be of assistance." A hand slyly holds up the bars that close the entrance to the cage. The ICC figures as a trap, one that will encase the President once he enters.

\section{Image 12: Uribe trapped}

\section{STEIRO MPLONATICO}

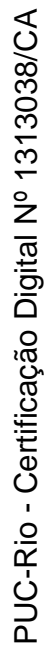

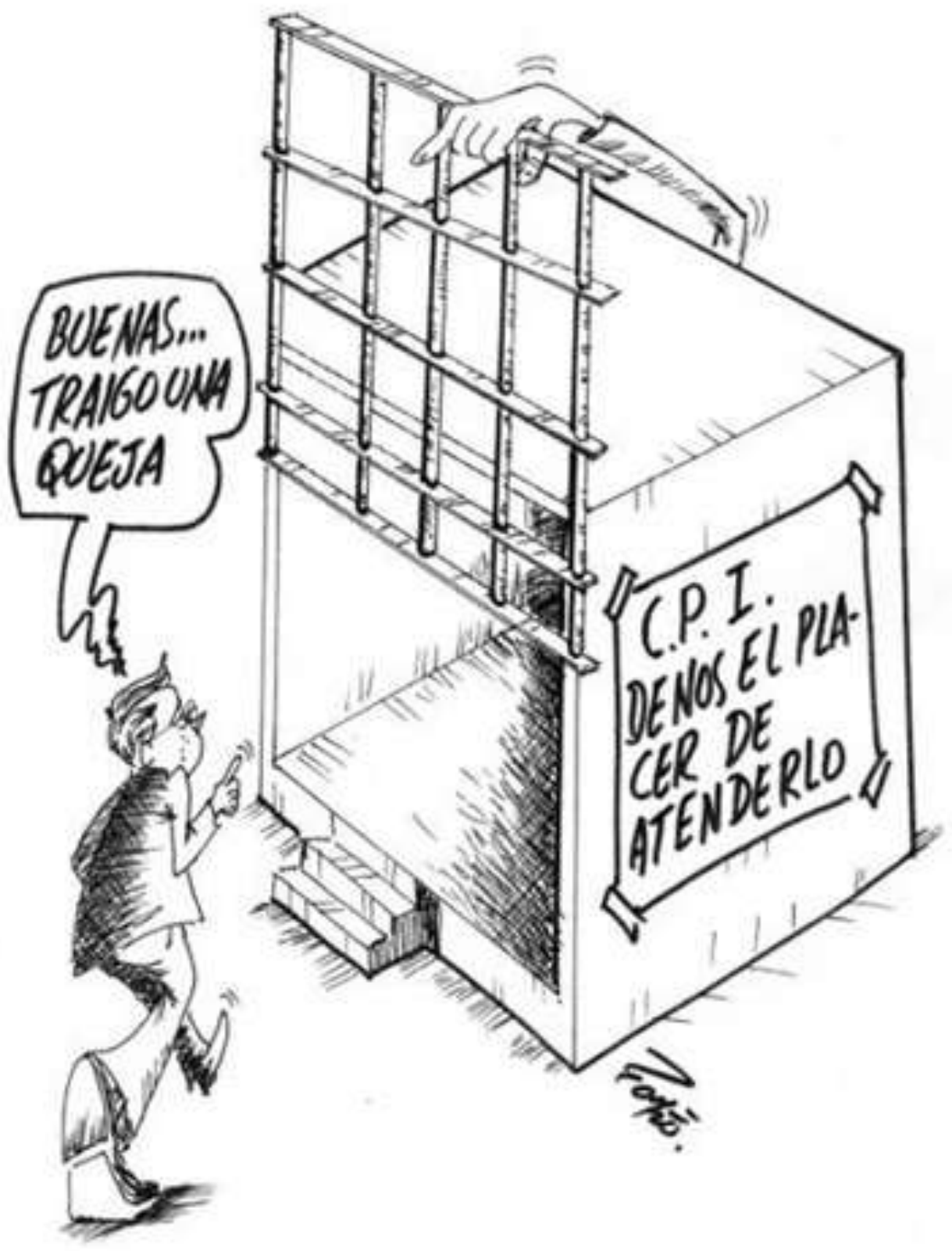

Source: http://www.cronicon.net/paginas/juicioauribe/CPI1.htm 
This image is featured as one of the first in a search conducted on the popular research engine Google for the keywords "Corte Penal Internacional" (ICC in Spanish) and Colombia ${ }^{39}$. The fact that the first entry is listed in a website pro-Uribe's indictment means that Colombians feel that their now expresident can only be punished by trope, the only way he would be caught is if he were somehow tricked into walking by himself into his own captivity. This is what is being portrayed in the cartoon, which is named Diplomatic Suicide another allusion to extradition agreements, which vigor over any sovereign immunity a head of state might allude to in his own country. If Uribe was ever indicted - something that has not still happened - he would not have the right to plea sovereign immunity, since it is not observed in the Rome Statute. Even if Colombia did not turn him in, other State Parties that have signed extradition agreements with the ICC would have to turn him over if he ever entered their national territories. It can also be interpreted as being a risk Uribe always played, flirting with being indicted by the ICC while courting the necessity of its proceedings and the application of jurisdiction over the country.

In another cartoon that also scored highly in the search engine, armed men and women are seen in a bus that reads "Congress" on the side. More armament is on the top of the bus and some of the passengers are wearing armlets with Autodefensas Unidas de Colombia (AUC), a big paramilitary group, written on them. The paramilitary are right-wing militia with well-known ties to congressmen and women in the Colombian political system. They are portrayed as healthy and muscular individuals, maybe also wealthy. They seem happy to be on their way, ecstatic even - one of them has her arms held up in a victory pose, with a pistol in her left hand.

The bus is headed, as portrayed by the arrows on its hood, towards impunity and is rolling over skulls, not on pavement. The subtitles ask for the end to impunity and that Uribe be tried by the ICC. This has never happened. This is also the only instance where the victims of violence are portrayed, as skulls. They are also playing a passive role in this image, being rolled over by the bus.

\footnotetext{
${ }^{39}$ This search was conducted on an "incognito" tab in a Chrome browser, in order to not influence the outcome with previous searching history, which is taken into account in the search engine's algorithms.
} 
Image 13: The road to impunity

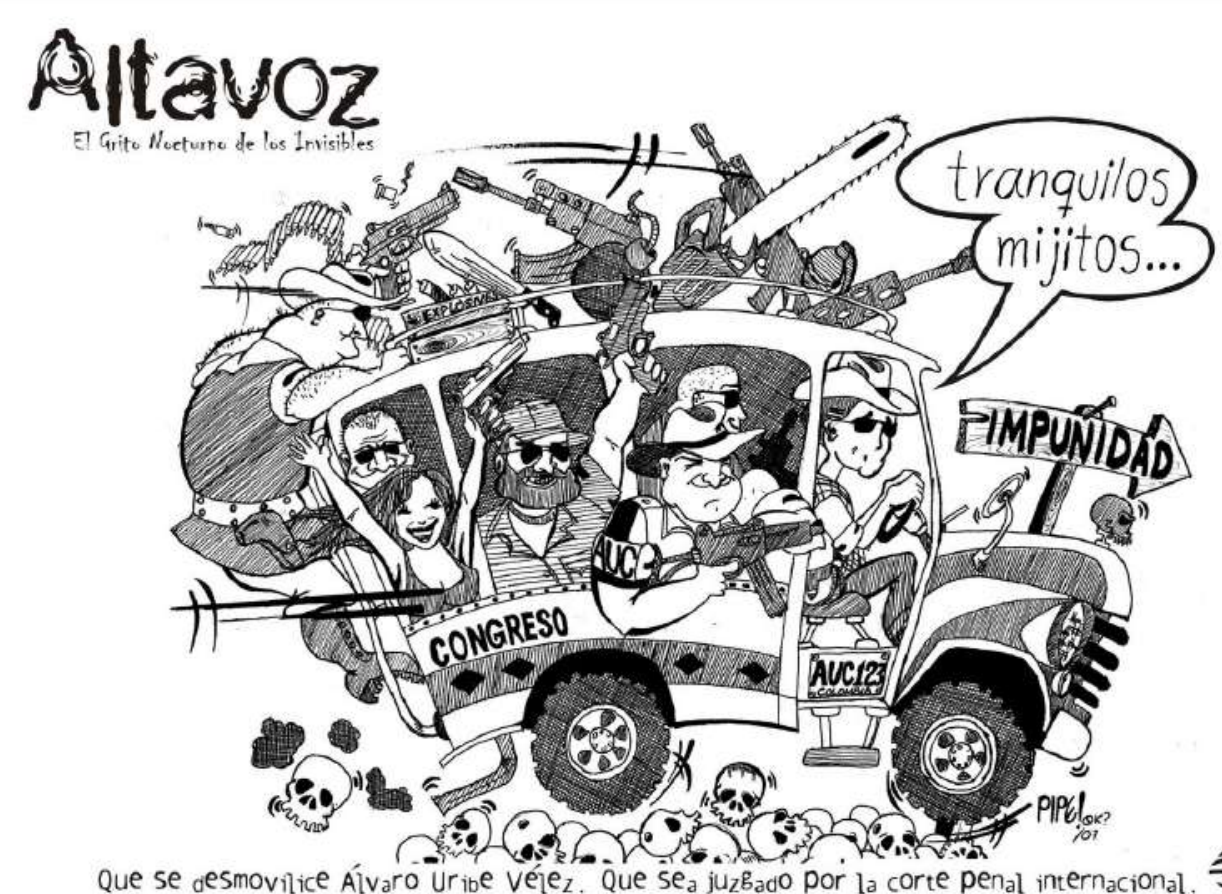

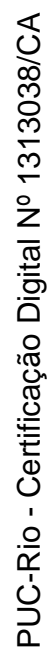

Source: http://elsalmonurbano.blogspot.com.br/2011/01/colombia-la-justiciatransicional-y-la.html

Image 14: Uribe and Lady Justice

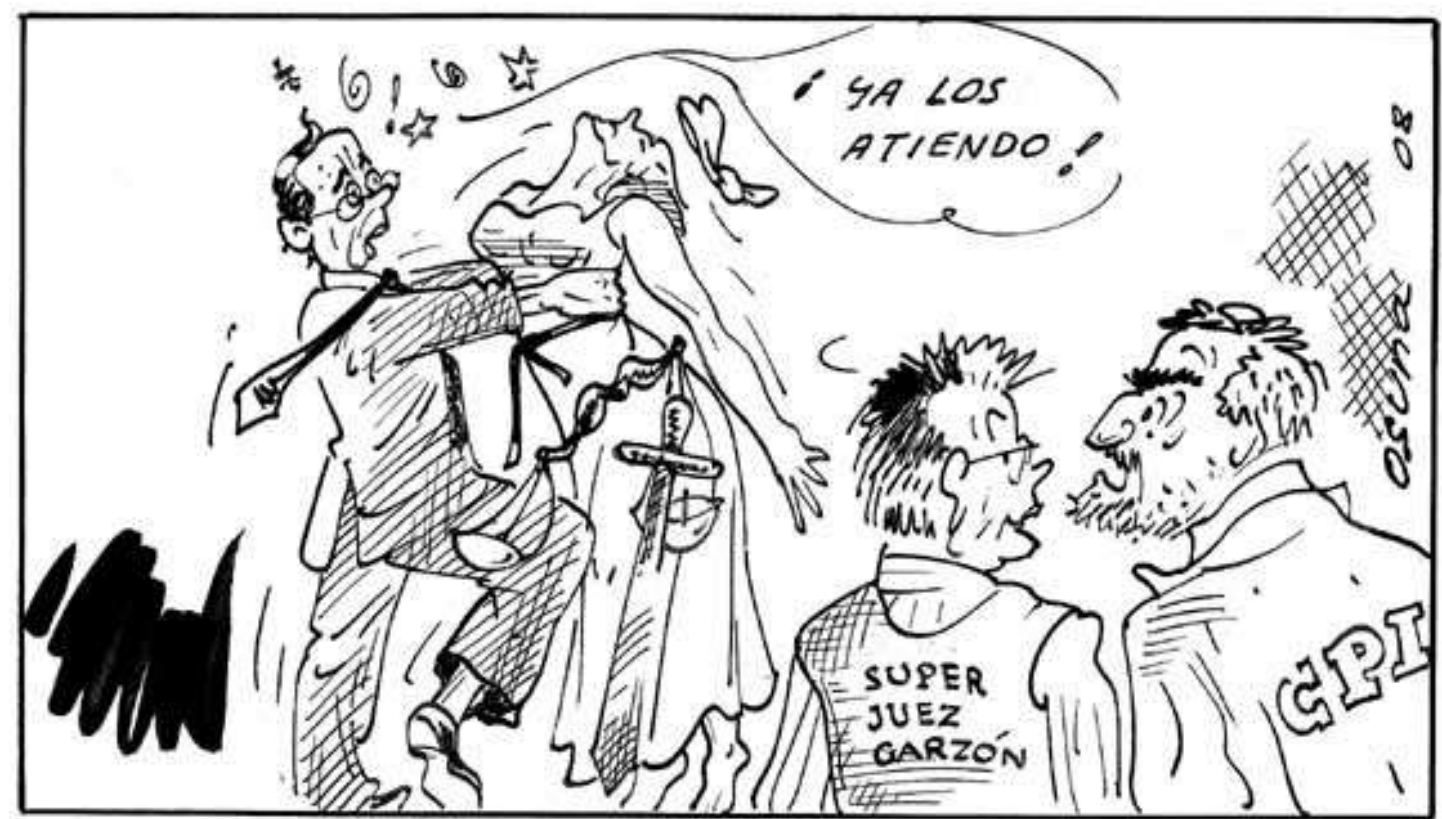

Source: http://www.anarkismo.net/article/9731?condense_comments=true 
The last cartoon, from 2008, portrays both national justice and international judicial proceedings. In it, a visibly distressed Álvaro Uribe is seen holding an unconscious Lady Justice in his arms. It is not clear if she is alive or not, but her blindfold has fallen and she holds neither the sword not balanced plates, which seem to be falling down. Both Baltazar Garzón, a Spanish Jurist who worked for the Audiéncia Nacional of Colombia during Uribe's term, and Moreno Ocampo - who wears a jacket written ICC written on the back - are portrayed in the right corner, looking at each other with puzzled expressions. Uribe, with his tie over his shoulder, asks them to wait a minute, that he'll meet with both men soon.

All these cartoons portray, each in their own way, the limits of justice and the inability of delivering it in the Colombian case. Lady Justice is always being abused of, wounded, or unable to fulfill her duties. The ICC can never actually grasp Uribe or the AUC and other armed groups that have committed crimes under the Rome Statute. Both international and national institutions appear to be duped by political proceedings and to be always on the sidelines.

It can be said, then, that these portrayals are symptomatic this latent presence of the ICC on the ground. They are very effective in portraying the way in which the ICC always kept its distance, but made its presence felt. The ICC is always waiting, not being active in any portrayal. Even the trap is passive. When considered alongside the documents reviewed in the first section of this chapter that plea for ICC involvement, the cartoons betray a sense of dissatisfaction with both national and international instances. Talk of impunity, a negative word, is constant.

Despite not being portrayed as illegitimate in any of these cartoons, it can be said that the ICC is being portrayed as inefficient in its activities. The shadow of the Court was, due to its murky involvement in the situation at hand, not developed in a conscious manner. One needs to keep in mind that the ICC, mainly through the activities of Moreno Ocampo, then Prosecutor, was still developing its modus operandi - it had not released any position papers on the development of the concept of "positive complementarity" yet - still setting the ground for how it wanted to be perceived internationally and designing its reputation worldwide, as I have stated in the previous chapter. This betrays a 
certain lack of structure in the proceedings of the legal institution - a fault in its culture of formalism that is symptomatic of the impact of its shadow. The life of the ICC is also complicated.

While the ICC imagines itself as a respectable legal institution, that works with set procedures, has international credibility and aims at a universal scope, actors on the ground in Colombia have been portraying it for years as inefficient at best - having to really on deception in place of real procedures, or being puzzled by the situation at hand - and uninvolved at worse. They wished for its involvement and, when it did not come, were left with a feeling that their situation was too complex to be meddled with and that impunity was the only possible future and physical destination. This goes well beyond the self image the ICC paints for itself, or even the image that is painted by those that engage with it through the production of documents.

That life is complicated is a theoretical statement made by Gordon (2008) that I have already explored earlier. I will return to it in the next section, where I will explore the possibility of using cinema and not law to talk about the violence in Colombia.

\subsection{Dirty hands}

Manos Sucias is a co-production by Colombia and the US that breaths complexity into Colombian landscape and social reality (2014). It follows the unglamorous life of two men, Delio and Jacobo - who we discover to be brothers only after a certain point in the movie - that are involved in trafficking a small fortune worth of cocaine for the paramilitaries up the Colombian pacific coast. I will not be able to cover the whole plot of the movie nor its aesthetics, but will highlight that which stands out for the particular purposes of this thesis.

The movie opens with the drugs being loaded into a torpedo, which is immersed into waters and tied to a boat the two will maneuver on their journey. They are accompanying another man, part of the paramilitary, who has the coordinates of where they should drop their cargo off. The whole movie was actually filmed in war-torn parts of the country, but more than this, it explores how war has torn people apart. 
Delio and Jacobo, the brothers, used to live in the countryside near a city called Buena Ventura. Delio went to the city in search for better education and Jacobo stayed on their property, but was soon taken out of their house, which the paramilitary occupied as a stronghold in the region. Jacobo moved into the poor suburbs of Buenaventura and started running small errands for the men that took him away from home in order to make enough money to leave for Bogotá. He is a visibly sour man and we soon learn that he has lost a son.

Delio was not faring much better. Younger then Jacobo, he still entertains dreams of becoming a rapper and wishes to fall into good graces with a certain big shot of the slum where he lives - who also happens to meddle with drug trafficking. He wants to leave construction work, that does not pay well, in order to provide a better future for his newborn son and girlfriend and immediately accepts when his contact offers him a chance to win some easy cash - "it's just like paid vacation," they laugh between themselves, upon explaining the task they need him to perform.

But reality is far from this promised ease. Both estranged brothers find themselves on the same boat. They had not kept in touch and there is clear tension between them. They are both in it for the money and thus keep quiet, obeying their superior's orders. At night, in a more relaxed scene, while they discuss football, another tension arises between them and the paramilitary, who considers himself to be white and the other too poor and black. The racial theme comes back up again when they are discussing leaving Buenaventura and heading to Bogotá - a city where there are no blacks, as everyone in the movie puts it.

The story reaches a first high point in the next chain of events, when both brothers go retrieve the drug-filled torpedo they had hidden for the night. They find it with a group of kids, who are playing in the forest. The paramilitary, visibly irritated when they do not obey his commands to back off, kills one of them with his gun and then tries to suffocate Delio, who had been wrestling him. Jacobo, enraged, kills the man. They keep on going in their journey, leaving both bodies behind. 


\section{Image 15: Manos Sucias Movie Poster}

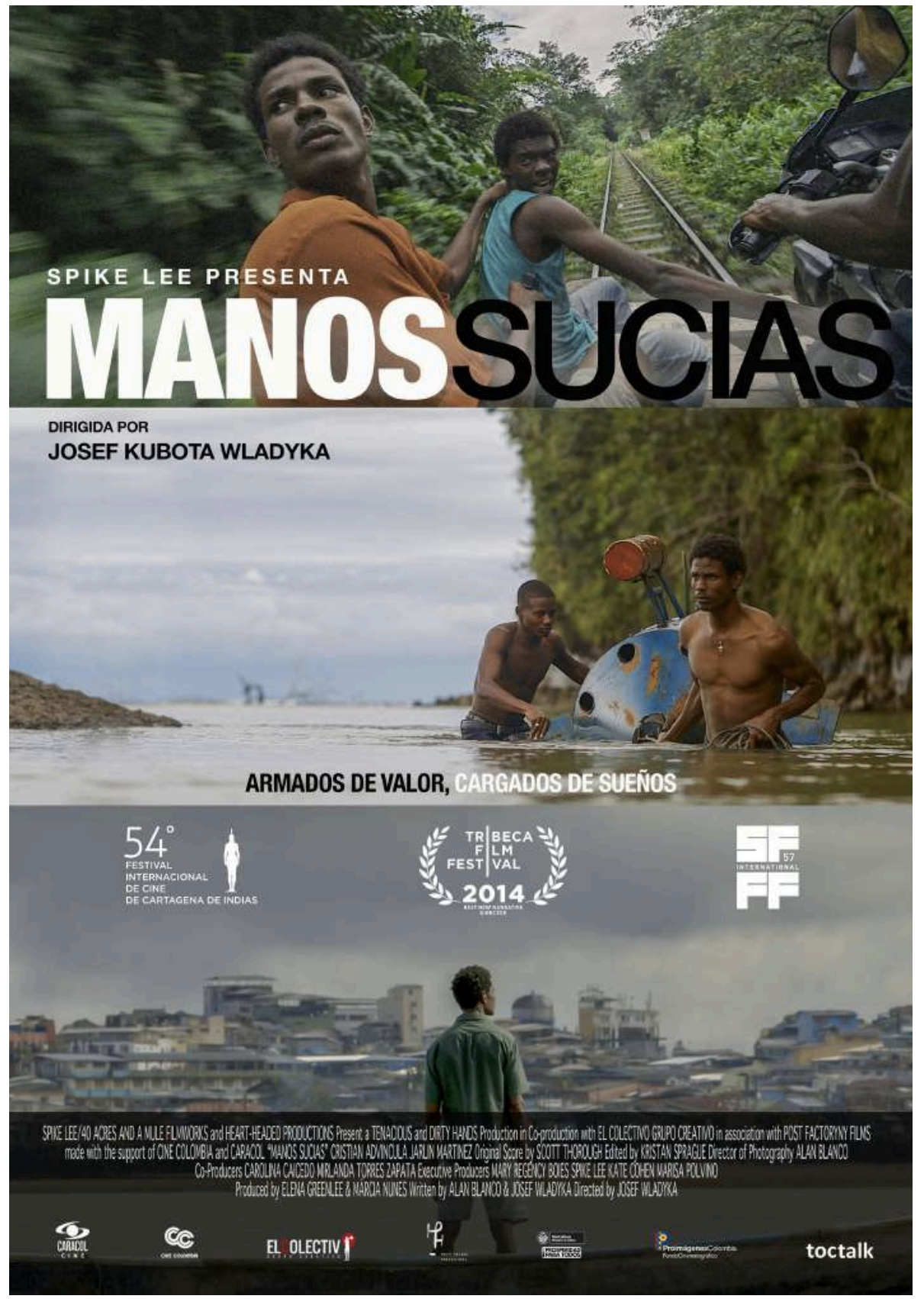

Source:

http://confidencialcolombia.com/es/1/808/14126/\%E2\%80\%9CLuchando-porsobrevivir-en-medio-del-narcotr $\% \mathrm{C} 3 \% \mathrm{~A} 1$ fico $\% \mathrm{E} 2 \% 80 \% 9 \mathrm{D}-J a r l i n-$ Mart $\%$ C3\%ADnez-Manos-sucias-pel\%C3\%ADcula-colombiana-Buenaventurasupervivencia-narcotr $\% \mathrm{C} 3 \% \mathrm{~A} 1$ fico-Pac $\% \mathrm{C} 3 \% \mathrm{ADfico} . \mathrm{htm}$

We later learn, when both of them are talking, that Jacobo has lost his son in a similar fashion - a paramilitary killed him during a raid in a neighboring soccer field. His son did not obey some order that was given and was shot pointblank. In another chain of events - their torpedo gets stolen by a youth when they 
are almost reaching their destination and both brothers go on a frenzied drive to retrieve it - it is Delio's turn to kill someone, by drowning the youth who had started to shout for help to armed forces he knew were lurking around the waterfront.

In the end of the movie, both brothers survive with minor injuries and receive the promised amount of money for their task. The film closes with them counting dollars. They may have made enough to actually entertain their dreams of leading a better life, but the price they had to pay was murder, they both got their hands dirty.

The symmetry in the murders, the losses and threats they themselves have suffered is not by chance. Jacobo kills the paramilitary after witnessing a murder similar to the one who took his son away from him. Delio suffocates and drowns a youth while having been suffocated earlier by the paramilitary. The fact that they kill always out of necessity, in what can be interpreted as self-defense, shows that violence in the system seems to be inevitable in its many echelons, where complex relations between war-torn society, poverty and drug-trafficking criss-cross over the life stories of these people.

It is impossible to talk about these brothers as victims - but they cannot either be fully held responsible for the situation. The film makes it clear that there is bigger complexity behind the notion that someone is to blame and another person is a victim. This goes directly in the direction of what Gordon identifies as the second consequence of taking "life is complicated" as a serious theoretical statement (2008, p. 3-4). The movie poster even reads "armed with values/valuables, carrying dreams" (see image 15). This word-play makes clear reference to this complicated feature of life, how not all things are clear-cut - but in reality are far from it. That values are juxtaposed to the verb 'armed,' a reference to a weapon is overbalanced by the juxtaposition of drugs and dreams. The verb in Spanish that I have translated for "carrying" here is the same one used to describe a loaded gun.

The opening and closing scenes in the movie are also very significant. As stated, the movie opens with a close-up of the colorful torpedo entering the water - the drugs inside. It is the material that is being ferried up and interferes with all these people's lives, bringing them together, ending some; representing an 
opportunity to others. The closing scene is Delio looking at the money he received as payment for the whole debacle, another material object. The labor relation, in a Marxist analysis, becomes clear in only in this closing scene, where the director's decision to cut with the dollar bills is counter-intuitive to most viewers, uncomfortable even, for we do not get to know what happens to both brother from then on.

They have both sold their labor in return for cash - but they have been explored for more than their labor alone. This is not clear, mainly to Delio, when he first agrees on taking the trip. Jacobo, who has had more experience in dealing with these odd jobs and with harsh realities of involvement with the paramilitary, seems more aware of the possibility of incurring in complications. This is the first consequence of seeing life as complicated, that "power relations that characterize any historically embedded society are never as transparently clear as the names we give to them imply" (Gordon, 2008, p. 3). The brothers do not only sell their labor, nor to they only deliver merchandise. They work as pegs in a greater engine that feeds one of a myriad of armed groups that have been active in Colombia at least throughout the past 50 years - and they all meddle with right and wrong and get involved with violence, recurrently.

In Delio's and Jacobo's world, justice is not an option. The movie does not even talk about impunity of the possibility of being taken to court. The absence of legal consequences of their murders is trace of an absence - one that haunts all aspects of their lives. The fact that they will be haunted by this experience will be only one of the many other hardships both brothers have already endured in their lives: social inequality, bad housing, violence, lack of public policy support, racism.

\subsection{Uncovering violent stories}

These are all manifestations of violence and exclusion that bring two instances of the stories explored here together. In a sense, what separates the story of the men in the case of the false positives I explored earlier when analyzing civil society documents and that of Jacobo and Delio is only their 
outcome and media through which they were told. Their background is mostly the same, as well as the violence they suffer in daily life. Yet, the media is radically different.

While the falsos positivos are portrayed in documents that wish to build a case for an investigation by the ICC in Colombia, the movie Manos Sucias does not build any case. It is a work of fiction, but that strives to explore the complicated nature of the life stories of many Colombians and the violence that has touched them in recent years - or not so recently. While one hopes for justice for those who have been violently killed, the other creates a biographical account, staged in the actual settings of violence in the countryside, a feature that cannot be dutifully portrayed in the former. Manos Sucias forgoes legal justice in order to do justice to the story it is telling. The richness of this is lost when conforming to the structured argument of the legal practice - one that is never even enacted in the Colombian case.

I argue here that the ICC, albeit projecting a shadow in Colombia and having, as stated in the Report that gave rise to this inquiry (HRC, ISC \& ISA, 2011), given rise to demobilizations and actions beyond the realm of pure judicial proceedings, is seriously limited in its capacity to bring justice and an end to impunity. I cannot affirm that a decision to actually investigate the situation would have solved this overall impression in Colombian society that serious crimes will not be punished - and neither will smaller ones - but it is clear that the shadow of the ICC has not managed to produce the desired effect of nudging justice forward. Seated on a donkey, Lady Justice continues to be a bit behind on matters. The OTP's non-decision has contributed to this greater feeling of being lost - and of overall loss that is irreparable. On loss, Butler writes that it is paradoxical: "the past is irrecoverable and [it] is not past; the past is the resource for the future [which] is the redemption of the past; loss must be marked and it cannot be represented; loss fractures representation itself and loss precipitates its own modes of expression" (2003, p. 467).

While even proper justice can never repair this original loss, it still seeks to remediate it. Yet, in this remediation, one can seek political possibilities beyond the realm of the legal. The temporality of loss, haunting and of healing is not easily translated into legal documents, but cannot be simply erased from 
political reality, as something “one cannot 'get over,' one cannot 'work through,' which is the deliberate act of violence against a collectivity, humans who have been rendered anonymous for violence and whose death recapitulates an anonymity for memory" (Butler, 2003, p. 468).

That "such violence cannot be 'thought,' constitutes an assault on thinking, negates thinking in the mode of recollection and recovery" (Butler, 2003 , p. 468) precludes the possibility of it being adequately brought to the political sphere only on the shared grounds of the legal practice. Other, aesthetic practices, like that of movies and literature, works of fiction in general, may serve to better document and offer grounds on which to uncover and talk about violence and losses, particularly when no legal proceedings are in sight.

This serves not to propose aesthetic enterprises such as movies or even cartoons as a replacement for legal proceedings, but as a way for keeping each tool in the right box. The latter must not be preferred over the other, nor must the former ones be undervalued and not taken seriously, their cathartic or denunciatory properties relegated.

One must then acknowledge that the legal practice has its limits - limits which the ICC needs to be aware of when engaging with situations on the ground and trying to deliver justice and bring an end to impunity. While it may be a way to lay the conditions of possibility for politics, it is not the only one available, nor is it the best, comparatively. There are other ways in which to portray stories and to make realities become known - truthtelling being an important feature of achieving justice and settling haunted stories. 


\section{Concluding Remarks}

This thesis has embarked on a double project, one particular to the analysis of the case of the ICC's involvement in Colombia; and another more ambitious one, regarding the relationship between IR and IL. During the last two chapters, I have expanded mostly on the former. It is time to address the latter.

First, it is necessary to sum up the argument that closes this academic effort. When I set out with my two questions, namely "What is the impact/shadow of the OTP's non-decision (pursuant to the opening of an investigation) in Colombia? How does it come to be?" I had not yet delved into the actual shadow. My answer is very straightforward: the shadow of the OTP's non-decision is the sense that now pervades Colombia that justice is unattainable, for it is injured, deceived, the victims run over by a bus that speeds away. This is how the actors on the ground portray it aesthetically. And basically, I have found, it has come into being through the drafting of documents whose purpose is to dialogue specifically with the ICC or keep the ICC in mind in a certain way - as well as policy maneuvers, such as demobilizations that were enacted to keep the Court at bay.

Clearly, there is a price to pay when one keeps this international institution in mind when acting under its shadow: the complexity of the lives who the very justice one wants to achieve is supposed to touch is lost. People become just victims, pegs. They have no voice and cannot speak in these proceedings. Even if they are not legal per se, their logic is one that wants to dialogue with the legal sphere. This shows us that the legal really does have consequences beyond the courtroom - but this also means that legal actors need to understand how these impacts play out and become responsible for the dimensions that they touch. To reduce the political to the conditions of possibility produced by the legal sphere is to leave this simplification of complex personhoods unchallenged. To only look at the legal is to loose sight of the richness of that which is beyond things that are also deeply impacted by legal proceedings.

The issue of competence comes back to us - only those competent in the legal practice can inhabit the legal courtroom and maneuver it expertly. Yet, as Gordon has stated in her work (2008), life is complicated and cannot be 
completely translated into legal documents - they are a fiction of the real, in a sense, that they construct a narrative. Thus, international lawyers are drafting stories - with a clear purpose in mind - and, in doing so, they make simplifications. Their wish to become transparent betrays them.

Complexity finds ways to express itself through other means, means that are equally political and valid, even if not legally competent to give rise to proceedings. To aesthetically explore symbols and word-plays breaths life back into the stories that are portrayed as "true" in legal documents. Justice becomes a complicated matter and the legal decision seems impossible - not because of legal indeterminacy, but because of the social reality beyond the courtroom.

Thus, one must qualify international law and international legal proceedings. While extremely formalistic at face value, we can perceive that international law itself is not exactly strictly set, but responds to outside critique and stimuli in its practice - thus the changes in the ICC website. Also, as an institution, it transforms itself and sets new standards - as the delayed release of policy papers by the OTP reveals. But this means that it is not always as transparent as the project would initially wish itself to be. It is neither as universal, nor can it promise to be as much - omitting relevant geopolitical information from maps that feature on the ICC's homepage. There are shortcomings in international law and not all can be portrayed through its practice, not all problems related to justice can be solved.

Furthermore, other forms of engaging with the political - of promising to engage with universal audiences from a particular point-of-view - is possible through other practices. Cartoons and movies are a different language, albeit very effective ones, to do just that. They engage with their audience and have space to portray complex personhoods in a manner that judicial proceedings, due to their constraints never will. The critique here is about how open international law really is and how celebrated it must be. The ICC is not transparent in these images $-i$ is personificated.

When one notices the limits of international law and dutifully qualifies it, the international lawyer ceases to occupy this transparent space of representation and comes back into the picture. Ocampo becomes a man who is duped by Uribe. Justice is Lady Justice, passed out in the president's arms. We can once again 
notice that what is being stated in court is a fiction of the real and one in many attempts to construct a narrative. The same is true for movie-watchers. The director chooses the angle of the camera, how to portray a scene, the screenwriter chooses who says what - it is all a more delicate construction, a mediation which the viewer is more aware of when inside the theatre. The person who reads the paper also knows that the political cartoon in question portrays the opinion or the provocation of its author, that he or she is not seeing this ipsis literis. It is amazing how, when liberated from the obligation of being completely truthful, these different media can actually portray the truth in even greater fidelity. Life is complicated in this sense also.

International Relations, as International Law, is also guilty of wishing to make science in such a way as to render the researcher invisible. This is why I have taken up the use of the first person in this project that was also built on a personal experience I had while I was at the International Criminal Court. It is not shameful to become aware of and to admit to our limitations in IR as researchers, nor does it mean we need to abandon our trade. Rather, this means that we need to be aware of the outcomes we can produce - and being aware that even when we are careful, we may cast shadows, just like the one that was cast (un)intentionally in the case I studied these past couple of years.

Set into place and with a well-rounded mandate, both IL and IR become, as practices, conditions of possibility for the political, together with the other modes of production explored here. IR must, as IL, be understood as a practice too, where knowledge is a means to achieve other ends - be it the production of truth, which may lead to achieving justice. Aware of this possibility, the researcher that embarks on this journey is then free to read into other realms and analyze other ways of mediating stories - without loosing her own grounding. Transdisciplinarity becomes possible. To read other practices under the lens of IR becomes just that - not declaring one way of understanding superior to the other.

This sums up my argument: IL is not the only shared surface on which to construct on, as Koskenniemi has advanced it (2011, p. 266) and cannot wish itself transparent. The culture of formalism is not as open as other mediations or forms of representation can be and this lack of openness comes at a price. The 
complicated nature of life demands to be known, in a way, and seeks voices through which it can be manifested - these are rarely through international law, not easily accessible to those on the ground. Awareness of these limitations is crucial.

Yet, revisiting the project of the culture of formalism as Orford puts it (2006), one cannot help but also see it in positive eyes. Like IR, when practicing IL consciously - keeping in mind that none of these practices should render our places either as researchers or as lawyers transparent - there is space for the promise of achieve greater goals, like justice or the possibility that violence outbreak be transformed into political engagement.

Events now in Colombia perhaps are proof of just that. The currently ongoing peace talks - the most promising attempts in the last two decades to end this overlapping series of violent times in the country - are widely supported by international and national actors. The FARC - that were shunned by international community as terrorists and thus as "impossible to negotiate with" - are now seated in Havana with government and other actors of Colombian politics. That they have a place at the table is symptomatic of a recognition of the complexity of the situation at hand and that political definitions that enact legal consequences - lists of terrorists, for example - are not always the best way to solve things. It is necessary to recognize the political in all practices, even in the violence the FARC have employed. To talk about shared ground and the practice that constructs it is always to delve into the complexity of the people whose lives will be touched by decisions made at the table. To keep these considerations in mind is to be aware of how life is complicated. To focus only on simplifying reality will not be a successful endeavor - it will only produce haunts and shadows.

What I proposed in the preceding paragraphs is more a provocation into the practice of IR and IL - a shout-out so that we keep in mind the complexity of the political when taking about our professional lives as researchers or international lawyers. The ability to listen to specters and to explore shadows, I propose, should not be shunned, but further explored in these disciplines. Only when we become fully aware of our shortcomings and the multiplicity of practices that surrounds us - engaging with them - will we be able to practice a real critique of our own trade. 


\section{Bibliography}

ABBOT, K. W. International Regimes Theory, International Law, and the Regime Governing Atrocities in Internal Conflicts. The American Journal of International Law, v. 93, 1999, p. 361-379.

AFROSVENSKARNA. Africa in the Shadow of the ICC. No date. Available at: http://www.afrosvenskarna.se/index.php?option=com_content\&view=article\&id $=261$ :africa-in-the-shadow-of-the-icc \&catid $=44$ : senaste-nytt\&Itemid $=88$

AMBOS, K. HUBER, F. The Colombian Peace Process and the Principle of Complementarity of the International criminal Court: Is there sufficient willingness and ability on the part of the Colombian authorities or should the Prosecutor open an investigation now? Extended version of the Statement in the “Thematic session: Colombia”, ICC OTP - NGO roundtable, 19-20 Oct. 2010, The Hague.

AMBOS, K. The Colombian Peace Process and the Principle of Complementarity of the International Criminal Court: an Inductive, Situationbased Approach. London: Springer, 2010.

. Procedimineto de la Ley de Justicia y Paz (Ley 975 de 2005) y Derecho Penal Internacional. In: Estudio sobre la facultad de intervención complementaria de la Corte Penal Internacional a la luz del denominado processo de “justicia y paz” en Colombia. Bogotá: Editorial Temis, 2010.

Bensouda, F. The International Criminal Court: a new approach to international relations. Council of Foreign Relations' David Rockerfeller Lecture Series, 12 set. 2012. Disponível em $<$ http://www.cfr.org/international-criminal-courts-andtribunals/international-criminal-court-new-approach-internationalrelations/p29067>. Acesso em: 20 set. 2012.

Bensouda, F. The 'Shadow' of the ICC. Statement at The Stanly Foundation, 19 Jan. 2012. Fora TV. Available at:

http://www.dailymotion.com/video/xvl8jr_fatou-bensouda-the-shadow-of-theicc_news 
Brenneis, D. Reforming Promise. In: Riles, A (Ed). Documents: artifacts of modern knowledge. Minneapolis: University of Michigan Press, p. 41-70, 2006.

Butler, J. Afterword: After loss, what then? In: Eng, D. L. Kazanjian, D. Loss: The Politics of Mourning. Los Angeles: University of California Press, p. 467473, 2003.

Cho, G. M. Haunting the Korean diaspora: shame, secrecy, and the forgotten war Minneapolis: University of Minnesota Press, 2008.

Dudley, S. Walking Ghosts: Murder and Guerrilla Politics in Colombia. New York: Routeledge, 2004.

Gitelman, L. Paper Knowledge: Toward a Media History of Documents. Durham: Duke University Press, 2014.

Goldberg, M. L. "ICC Prosecutor on the "Shadow of the Court". UN Dispatch. 5 Feb. 2010. Available at: http://www.undispatch.com/icc-prosecutor-on-theshadow-of-the-court/

Goldstone, Richard J. Smith, Adam M. International judicial institutions: the architecture of international justice at home and abroad. Londres: Routeledge, 2009.

Gordon, A (2nd Ed). Ghostly matters: haunting and the sociological imagination. Minneapolis: University of Minnesota Press, 2008.

Heimer, C. A. Conceiving Children: How Documents Support Case versus Biographical Analysis. In: Riles, A (Ed). Documents: Artifacts of Modern Knowledge. Minneapolis: University of Michegan Press, p. 95-126, 2006. Human Rights Consortium (HRC), Institute of Commonwealth Studies (ICS), Institute for the Study on the Americas (ISA). In the Shadow of the ICC: Colombia and International Criminal Justice. 2011. Available at: https://www.academia.edu/1383204/In_the_Shadow_of_the_ICC_Colombia_and _International_Criminal_Justice International Federation for Human Rights (FIDH). Colombia. The War is Measured in Litres of Blood: False Positives, Crimes Against Humanity: those most responsible enjoy impunity. 2012. 
Koskenniemi, M. From Apology to Utopia: the Structure of International Legal Argument (Ed. 2). Cambridge: Cambridge University Press, 2005.

. On Law, Teleology and International Relations. International Relations, v. 26, n. 1, 2011a. . The Gentle Civilizer of Nations: the Rise and Fall of International Law 1870-1960. Cambridge: Cambridge University Press, 2001. . The Politics of International Law. Oxford: Hart Publishing, 2011b.

Krasner, S. 1982. Structural Causes and Regime Consequences: Regimes as Intervening Variables. International Organization v. 36, n. 2, p. 185-205, Spring.1982.

LaRosa, M. J. Mejía, G. R. Colombia: A Concise Contemporary History. New York: Rowman \& Littlefield Publishers, Inc. 2012.

Navasky, V. S. The Art of Controversy: Political Cartoons and their Enduring Power. New York: Alfreda A. Knopf, 2013.

Office of the Prosecutor (OTP) Interim Report: Situation in Colombia. Nov. 2012. Available at: http://www.icc-cpi.int/NR/rdonlyres/3D3055BD-16E2-4C83BA85-

35BCFD2A7922/285102/OTPCOLOMBIAPublicInterimReportNovember2012. pdf . Policy Paper on Preliminary Examinations. Nov. 2013a. Available at: http://www.icccpi.int/en_menus/icc/press\%20and\%20media/press\%20releases/Documents/OTP \%20Preliminary\%20Examinations/OTP\%20\%20Policy\%20Paper\%20Preliminary\%20Examinations\%20\%202013.pdf . Report on Preliminary Examination Activities 2013. Nov. 2013b. Available at: http://www.icccpi.int/en_menus/icc/press\%20and\%20media/press\%20releases/Documents/OTP $\% 20$ Preliminary\%20Examinations/OTP\%20\%20Report\%20\%20Preliminary\%20Examination\%20Activities\%202013.PDF 
Orford, A. A Journal of the Voyage from Apology to Utopia. German Law Journal, v. 7, n. 12, 2006. p.993-1010.

Rome Statute, 1998. Available at: http://www.icc-cpi.int/nr/rdonlyres/ea9aeff75752-4f84-be94-0a655eb30e16/0/rome_statute_english.pdf

Riles, A. Introduction: In Response. In: Riles, A (Ed). Documents: Artifacts of Modern Knowledge. Minneapolis: University of Michigan Press, p. 1-40, 2006. Riles, A. [Deadlines]: Removing the Brackets on Politics. In: Riles, A (Ed). Documents: Artifacts of Modern Knowledge. Minneapolis: University of Michigan Press, p. 71-94, 2006.

Riles, A. The Anti-Network: Private Global Governance, Legal Knowledge and the Legitimacy of the State. Cornell Law Faculty Publications. Paper 36, 2008.

Riles, A. The Network Inside Out. Ann Arbor: The University of Michigan Press, 2001.

Roach, S. C. (Ed) Governance, Order and the International Criminal Court: Between Realpolitik and a Cosmopolitan Court. Oxford: Oxford University Press, 2009.

Roach, S. C. Politicizing the International Criminal Court: the Convergence of Politics, Ethics and Law. New York: Rowman \& Littlefield Publishers, 2006.

Ruiz, A. Hutchinson, B. Letterman Swallows Remark About Miss Colombia. New York Daily News, May 17, 2001. Available at:

http://articles.philly.com/2001-05-17/entertainment/25300211_1_lettermanswallows-miss-colombia. Acess on October 20, 2014.

Shapiro, M. J. Studies in Trans-disciplinary Method: after the aesthetic turn. New York: Routeledge, 2013.

Shaw, M. N. International Law $\left(6^{\text {th }}\right.$ Ed). Cambridge: Cambridge University Press, 2008.

Spivak, G. Can the Subaltern Speak? In: Nelson, C. Grossberg, L. (Eds) Marxism and the Interpretation of Culture. Chicago: University of Illinois Press, 66-111, 1988. 
Stegmiller, Ignaz. The pre-investigation stage of the ICC: criteria for situation selection. Berlin: Duncker \& Humnblot GmbH, 2011.

Steiner, S. Tribunal Penal Internacional: aspectos relevantes, progressos alcançados e desafios por enfrentar. X Curso de Inverno de Direito Internacional. Centro de Direito Internacional (CEDIN). Belo Horizonte, Brazil. 14-25, July, 2014.

United Nations General Assembly (UNGA). Resolution 44/23. Available at: $<$ http://www.un.org/documents/ga/res/44/a44r023.htm>. 


\section{Glossary}

Article 15 Communications - information submitted by any person or organization via email or letter to the Office of The Prosecutor. Any information that contains a clear claim is logged onto the appropriate court system and analyzed by OTP personnel.

Complementarity - Complementarity is one of the listed elements of the admissibility of situations under the Rome Statute. It states that the ICC's jurisdiction only complements that of State-parties. Thus, it will only open an investigation when the State is unwilling of incapable of doing so itself. It is spelled out in Article 17 of the Rome Statute.

Situation - "Situation" relates to the investigation on the overall crime being investigated and is normally referred to by the name of the State where the crime occurred, i.e. "the situation in Mali".

Investigation / Opening an investigation - In the International criminal Court's jargon, an investigation relates to the overall official procedure that is undertaken by the OTP after approval by the Pre-Trial Chamber (PTC). The opening of an investigation is only possible after the Office of the Prosecutor achieves a certain threshold of certainty that crimes under the Rome Statute took place and can be lawfully investigated and tried in court.

Case - "Case" refers to the investigation of specific people identified and accused as those most responsible for those crimes, i.e. "the Lubanga case". It also appears in jurisprudence under the more formal name "Prosecutor v. Lubanga".

Falsos Positivos - Allegations that state actors, mainly members of Colombian army, have deliberately killed thousands of civilians to bolster success rates in the context of the internal armed conflict and to obtain monetary profit from the State's funds. 
Preliminary examination / Examination - Before a formal investigation is open, the Office undertakes what it calls an "examination", under the Preliminary Examination Procedure.

Positive complementarity - a specific approach to the ICC's jurisdiction where the OTP decides to keep itself informed of national proceedings, fostering national initiatives rather than opening international ones. The OTP can then decide to cooperate with national legal actors and conduct visits and other activities. 


\section{Annex 1}

Graph results of Scopus search.

\begin{tabular}{|c|c|c|}
\hline Year & Source & Author \\
\hline Year 7 & Documents & \\
\hline 2014 & 529 & \\
\hline 2013 & 874 & \\
\hline 2012 & $B 68$ & \\
\hline 2011 & 862 & \\
\hline 2010 & 756 & \\
\hline 2009 & 605 & \\
\hline 2008 & 600 & \\
\hline 2007 & 397 & \\
\hline 2006 & 394 & \\
\hline 2006 & 280 & \\
\hline 2004 & 149 & \\
\hline 2003 & 97 & \\
\hline 2002 & 110 & \\
\hline 2001 & 907 & \\
\hline 2000 & 80 & \\
\hline 1999 & 70 & \\
\hline
\end{tabular}

986 to $2014 \rightarrow$ Analyze \begin{tabular}{l|l|l|l|} 
Affiliation & Country & Document type & Subject area
\end{tabular}

Documents by year

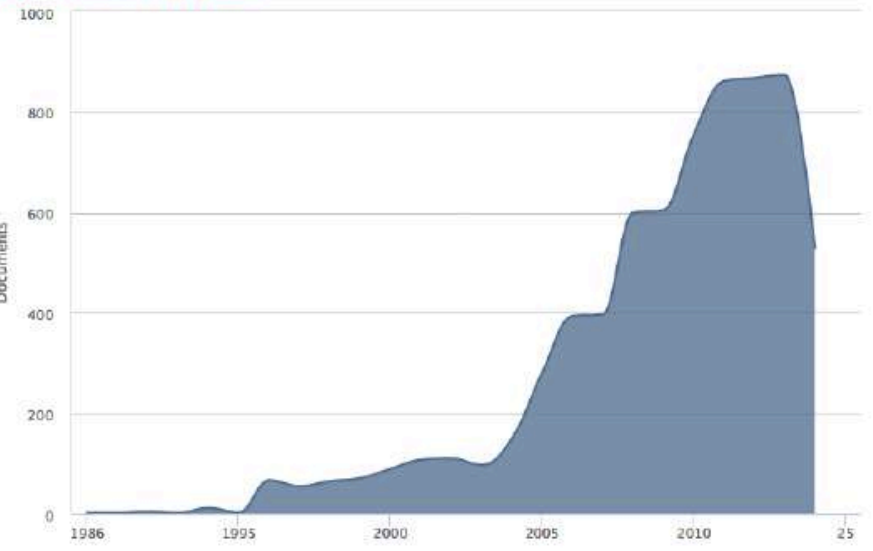

6991 document results Choose date range to analyze: 1986 - to 2014 - Anclyze

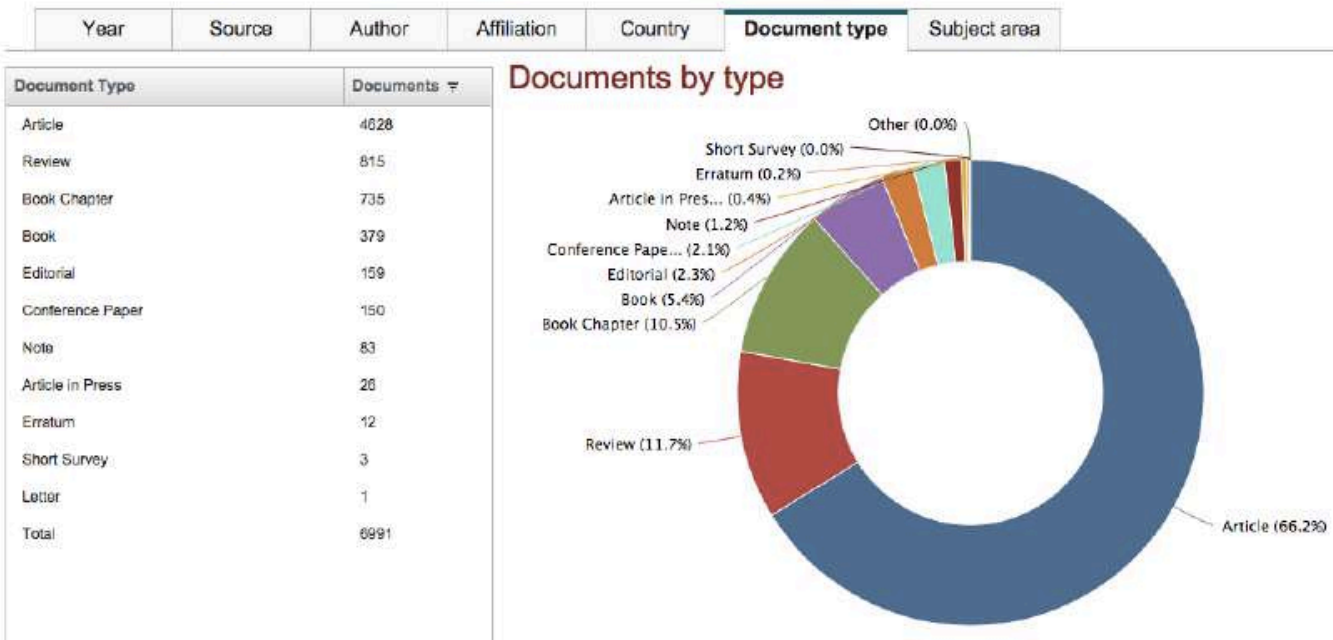




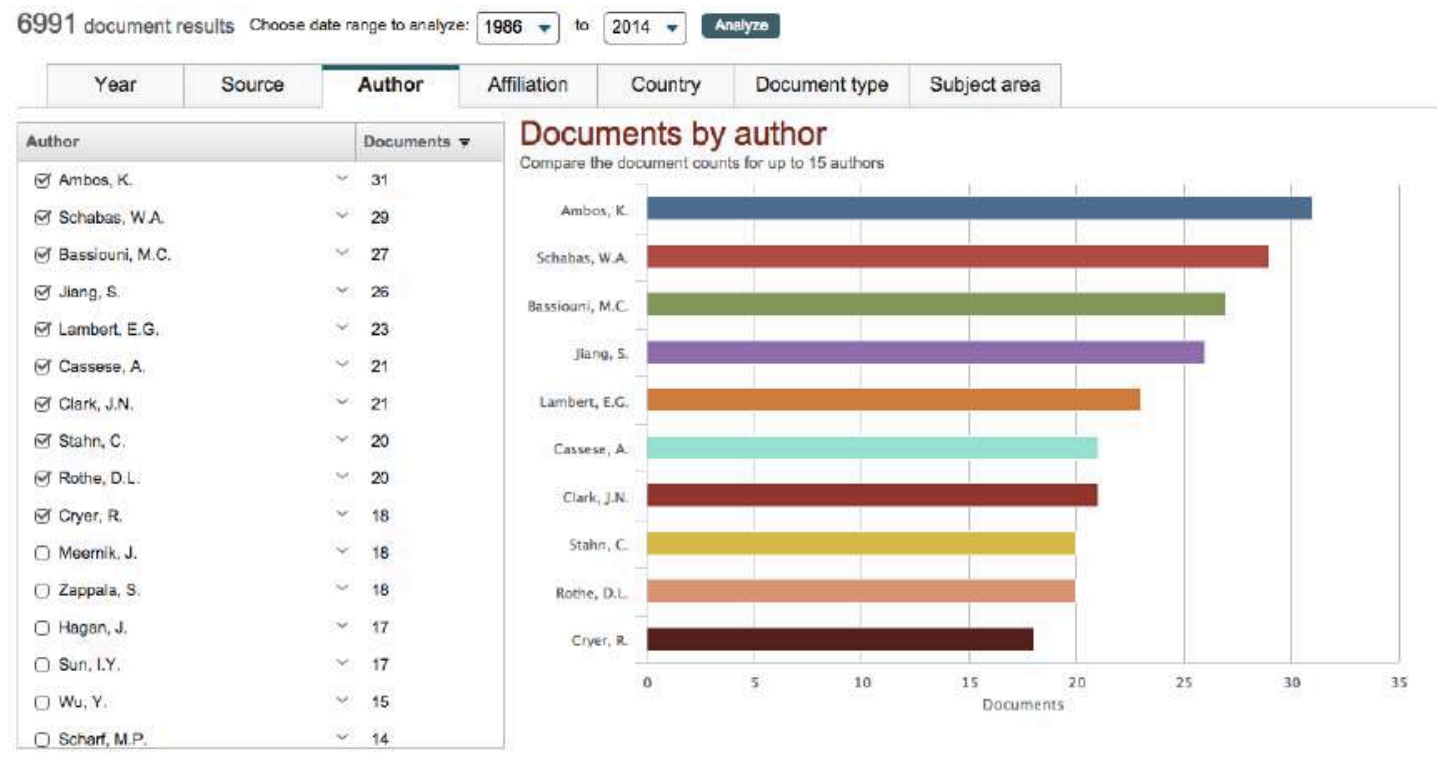

Source:

http://www.scopus.com/term/analyzer.url?sid=2BAF9F9D64957B4D05E6F2060 C8A8E8A.y7ESLndDIsN8cE7qwvy6w $\% 3 a 580 \&$ origin $=$ resultslist\& $s r c=s \& s=\% 2$ 8ALL\%28\%22International+Criminal+Court\%22\%29+OR+ALL\%28\%22Intern ational+Criminal + Law $\% 22 \% 29+\mathrm{OR}+\mathrm{ALL} \% 28 \% 22$ International+Criminal $\% 22$ $\% 29+\mathrm{OR}+\mathrm{ALL} \% 28 \% 22$ International+Tribunal $\% 22 \% 29 \% 29+\mathrm{AND}+\mathrm{SUBJARE}$ $\mathrm{A} \% 28 \mathrm{MULT}+\mathrm{OR}+\mathrm{ARTS}+\mathrm{OR}+\mathrm{BUSI}+\mathrm{OR}+\mathrm{DECI}+\mathrm{OR}+\mathrm{ECON}+\mathrm{OR}+\mathrm{PSYC}+\mathrm{OR}$ + SOCI $\% 29 \&$ sort $=$ plf-

$\mathrm{f} \& \mathrm{sdt}=\mathrm{b} \& \mathrm{sot}=\mathrm{b} \& \mathrm{sl}=207 \&$ count $=6991 \&$ analyzeResults $=$ Analyze + results $\&$ txGid =2BAF9F9D64957B4D05E6F2060C8A8E8A.y7ESLndDIsN8cE7qwvy6w\%3a6 4 